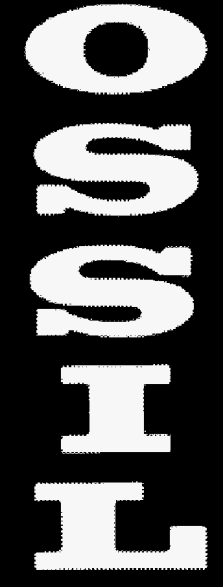

INCREASED OIL RECOVERY FROM MATURE OIL FIELDS USING GELLED POLYMER TREATMENTS

Annual Report

June 16, 2000 - June 15, 2001

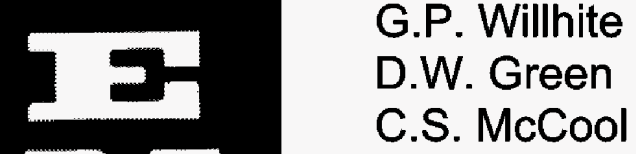

$I_{1}$

C.S. McCool

Date Published: May 2002

Work Performed Under Contract No. DE-AC26-99BC15209

The University of Kansas Center for Research, Inc.

Lawrence, Kansas

National Energy Technology Laboratory National Petroleum Technology Office U.S. DEPARTMENT OF ENERGY Tulsa, Oklahoma 


\section{DISCLAIMER}

This report was prepared as an account of work sponsored by an agency of the United States Government. Neither the United States Government nor any agency thereof, nor any of their employees, makes any warranty, expressed or implied, or assumes any legal liability or responsibility for the accuracy, completeness, or usefulness of any information, apparatus, product, or process disclosed, or represents that its use would not infringe privately owned rights. Reference herein to any specific commercial product, process, or service by trade name, trademark, manufacturer, or otherwise does not necessarily constitute or imply its endorsement, recommendation, or favoring by the United States Government or any agency thereof. The views and opinions of authors expressed herein do not necessarily state or reflect those of the United States Government.

This report has been reproduced directly from the best available copy. 


\title{
Increased Oil Recovery from Mature Oil Fields Using Gelled Polymer Treatments
}

\author{
By \\ G.P. Willhite \\ D.W. Green \\ C.S. McCool
}

May 2002

Work Performed Under DE-AC26-99BC15209

\author{
Prepared for \\ U.S. Department of Energy \\ Assistant Secretary for Fossil Energy \\ Jerry Casteel, Project Manager \\ National Petroleum Technology Office \\ P.O. Box 3628 \\ Tulsa, OK 74101
}

Prepared by

The University of Kansas Center for Research, Inc.

Tertiary Oil Recovery Project

1530 W. $15^{\text {th }}$ Street

Lawrence, Kansas 66045-7609 


\section{Table of Contents}

Page No.

List of Figures

$\mathrm{v}$

List of Tables $\quad$ ix

$\begin{array}{ll}\text { Abstract } & \text { xi }\end{array}$

Chapter $1 \quad$ Introduction $\quad 1-1$

Chapter 2 Determination of Molar Mass and Size of Aggregates during the Gelation of a Polyacrylamide-Chromium-Acetate Gel System

Chapter 3 Effect of Added Acetate on the In Situ Gelation of the PolyacrylamideChromium(III) Acetate System

Chapter 4 Study of Water and Oil Flow in Gel-Treated Berea Sandstone 4-1

Chapter 5 Technology Transfer

$5-1$ 



\section{List of Figures}

Fig. No. Title

Page No.

2.1 Schematic of equipment used for light scattering measurements.

2.2 Viscosity of gelants as a function of time and chromium concentration.

2.3 Molar mass as a function of time for gelant containing $100 \mathrm{ppm}$ chromium.

2.4 RMS radius as a function of time for gelant containing $100 \mathrm{ppm}$ chromium.

2.5 Relative change from initial values of viscosity, molar mass and rms radius during gelation for gelant containing $100 \mathrm{ppm}$ chromium.

2.6 Relative change from initial values of viscosity, molar mass and rms radius during gelation for gelant containing $20 \mathrm{ppm}$ chromium.

3.1 Flow resistance profiles after different amounts of polymer solution were injected through the 40-foot long sandpack; PVI [=] pore volumes of solution injected.

3.2 Schematic diagram of equipment for flow experiments.

3.3 Bulk gel time as a function of the acetate-to-chromium ratio.

3.4 Differential pressure across sections of sandpacks during the injection of gelant with an acetate-to-chromium ratio of 103 .

3.5 Differential pressure across sections of sandpacks during the injection of gelant with an acetate-to-chromium ratio of 44 .

3.6 Insitu gel time as a function of the acetate-to-chromium ration in the gelant.

3.7 Relationship of the insitu gel time and the bulk gel time.

4.1 Schematic description of the slabs and flow directions.

4.2 Schematic description of equipment used for microwave scanning of slabs.

4.3 Injection pressures and average saturations during post-treatment oil and brine floods in Slab 1. 
4.4 Volumes of oil and brine displaced during post-treatment floods in Slab 1 as a function of time.

4.5 Volumes of oil and brine displaced during post-treatment floods in Slab 1 as a function of volume injected.

4.6 Permeability of oil and brine at the end of the post-treatment floods in Slab 1. 4-10

4.7 Permeability of oil and brine at the end of the post-treatment floods in Section 1 of Slab 1.

4.8 Permeability of oil and brine at the end of the post-treatment floods in Section 2 of Slab 1.

4.9 Permeability of oil and brine at the end of the post-treatment floods in Section 3 of Slab 1.

4.10 Change in brine saturation during pre-treatment brine flood 2 in Slab 1.

4.11 Change in brine saturation during injection of gelant in Slab 1.

4.12 Change in brine saturation during the first post-treatment oil flood in Slab 1.

4.13 Change in brine saturation during post-treatment brine flood in Slab 1.

4.14 Change in brine saturation during the second post-treatment oil flood in Slab 1.

4.15 Change in brine saturation during the first post-treatment oil flood and the post-treatment brine flood in Slab 1.

4.16 Change in brine saturation during the post-treatment brine flood and the second post-treatment oil flood in Slab 1.

4.17 Flow resistance in Slab 2 during injection of gelant.

4.18 Injection pressures and average saturations during post-treatment oil and brine floods in Slab 2.

4.19 Response of oil-phase tracers conducted at end of oil floods. 4-24

4.A1 Brine saturation after pre-treatment oil flood in Slab1. 
Fig. No. Title

Page No.

4.A2 Brine saturation after pre-treatment brine flood in Slab1. 4-28

4.A3 Brine saturation after gelant injection in Slab1.

4-29

4.A4 Brine saturation after first post-treatment oil flood in Slab1.

4-30

4.A5 Brine saturation after post-treatment brine flood in Slab1.

4-31

4.A6 Brine saturation after second post-treatment oil flood in Slab1.

4.32 



\section{List of Tables and Exhibits}

Table No. Title

$\underline{\text { Page No. }}$

2.1 Molar mass and rms radius determined by light scattering fo the 5.55million polyacrylamide standard.

2.2 Effect of filtration procedures on the results of light scattering measurements.

2.3 Molar mass and rms radius for non-dried Alcoflood 935 (Lot 7158V) using a $5.0 \mu \mathrm{m}$ screen-type filter to clarify the polymer stock sample.

2.4 Molar mass and rms radius for dried Alcoflood 935 (Lot 7158V) using a $5.0 \mu \mathrm{m}$ screen-type filter to clarify the polymer stock sample.

2.5 Molar mass and the rms radius of Alcoflood 935 (Lot 7158V) after shearing in an Osterizer blender at high stir speed for 15 minutes.

3.1 Summary of gel times for flow experiments.

4.1 Sequence of floods.

4.2 Average water saturations and permeabilities of Slab 1.

4.3 Residual resistance factors (RRFs) for sections and for the total length of Slab 1.

4.4 Residual resistance factors (RRFs) for sections and for the total length of Slab 2.

4.5 Average water saturations and permeabilities of Slab 2.

\section{Exhibit No.}

2.1 Standard Procedure for Measurement of the Weight-Average Molar Mass and RMS Radius of Polyacrylamide Samples 



\begin{abstract}
Gelled polymer treatments are applied to oil reservoirs to increase oil production and to reduce water production by altering the fluid movement within the reservoir. This report describes the progress of the second year of a three-year research program. This program is aimed at reducing barriers to the widespread use of gelled polymer treatments by (1) developing methods to predict gel behavior during placement in matrix rock and fractures, (2) determining the persistence of permeability reduction after gel placement, and (3) developing methods to design production well treatments to control water production. The work described in this report focuses on the gel system composed of polyacrylamide and chromium acetate. Light scattering measurements of dilute polymer/aggregate solutions were conducted to determine the weight-average molar mass and the rms radius (size) of polyacrylamide molecules and gel aggregates that form during the gelation process. The average molar mass approximately doubled in value and the rms radius increased on the order of $10 \%$ at the onset of gelation. The in situ performance of these "added acetate" systems was investigated to determine the applicability of this system for in-depth treatments. Increased acetate concentrations delayed the development of increased flow resistance during gelant injection in short sandpacks. The development of increased flow resistance (in situ gelation) was extended from 2 to 34 days by increasing the acetate-tochromium ratio from 38 to 153 . Insitu gelation occurred at a time that was approximately $22 \%$ of the bulk gelation time. An investigation of the flow characteristics of oil and brine in Berea sandstone slabs after a gel treatment using the polyacrylamide-chromium acetate system is described. The treatments did not reduce the permeability to brine by a greater factor than the permeability to oil was reduced. The factors by which the permeabilities to oil and brine were reduced decreased along the slabs from the end where gelant was injected. Oil saturation was also a function of the length of the slabs as measured by a microwave attenuation apparatus. The experimental results are interpreted using the concepts of gel dehydration and the formation of a new pore space. Presentations and technical papers that present results from this work and work conducted in a previous DOE contract are listed.
\end{abstract}





\section{Chapter 1}

\section{Introduction}

Gelled polymer systems are applied to injection wells in mature oil fields for the purpose of in situ permeability modification to improve volumetric sweep efficiency in displacement processes such as waterflooding. Gelled polymers are also used to treat production wells to reduce water production and operating costs, prolonging the economic life of the wells. While the technology has been applied successfully, there are barriers to widespread utilization. These barriers generally involve a need to develop gel systems that can be used for in-depth treatment of matrix rock and a need for improved understanding of performance in matrix rock and fractures. This research program seeks to diminish these barriers through fundamental studies to predict gel behavior and placement in matrix rock and fractures and to develop a new approach to the control of water production in production wells.

A focus of studies for in-depth treatment in injection wells is the role of pre-gel aggregates which form during the gelation process. Aggregates affect gel placement and performance and information about their formation and growth can aid in the design of treatments so that the treatments can be made more reliable. A second focus is on gel systems that have long gel times due to the addition of ligands that slow the overall reaction rate. The added ligand systems have the potential to be placed deep in reservoirs, but their performance under flow conditions in porous media needs to be investigated.

The approach to water control in production wells is based on two-phase flow characteristics of gelled polymer systems that are dehydrated in the reservoir rock after placement. Development of successful treatment strategies will provide the means for oil operators to reduce costs, since water production commonly represents a significant portion of oilfield operational expenses.

This report presents most of the work that was accomplished during the second year of a threeyear program. Graduate students and post-doctorial persons performed the laboratory work. Contributions of students are acknowledged at the beginning of each chapter.

The work described in this report focuses on the polyacrylamide-chromium acetate gel system. Chromium(III) ions form a complex ion group that reacts with carboxyl groups on the polyacrylamide molecule. A crosslink is formed when two polymer molecules join the complex ion. A gel is formed as a result of the crosslinking process.

A study to develop procedures and to measure the weight-average molar mass and the rms radius (size) of polyacrylamide molecules and gel aggregates that form during gelation is described in Chapter 2. Light scattering measurement of dilute polymer/aggregate solutions is the principal step of the procedure. Measurements on a polyacrylamide-chromium acetate gelant showed moderate increases in the molar mass and rms radius up to the time when the viscosity of the gelant increases rapidly, or the gel point. The molar mass approximately doubled in size and the rms radius increased on the order of $10 \%$. 
Supplying additional acetate ions to the polyacrylamide-chromium acetate system extends the bulk gel time of the system as determined in bottle tests. Bulk gel times in the range from one day to three months were achieved be varying the acetate-to-chromium ratio from 7:1 to 153:1 for a typical gelant composition. The in situ performance of these "added acetate" systems was investigated to determine the applicability of this system for in-depth treatments. Increased acetate-to-chromium ratios delayed the development of increased flow resistance during gelant injection in short sandpacks. The development of increased flow resistance (in situ gelation) was extended from 2 to 34 days by increasing the acetate-to-chromium ratio from 38 to 153 . In situ gelation occurred at a time that was approximately $22 \%$ of the bulk gelation time. This study is described in Chapter 3.

An investigation of the flow characteristics of oil and brine in Berea sandstone slabs after a gel treatment using the polyacrylamide-chromium acetate system is described in Chapter 4 . The treatments did not reduce the permeability to brine by a greater factor than the permeability to oil was reduced. The factors by which the permeabilities to oil and brine were reduced decreased down the slabs from the end where gelant was injected. Oil saturation was also a function of the length of the slabs as measured by a microwave attenuation apparatus. The experimental results are interpreted using the concepts of gel dehydration and the formation of a new pore space.

A listing of presentations and technical papers that present results from this work and work conducted in our previous DOE contract is given in Chapter 5 . 


\title{
Chapter 2
}

\section{Determination of Molar Mass and Size of Aggregates during the Gelation of a Polyacrylamide-Chromium-Acetate Gel System}

\author{
Graduate Research Assistant: Tong Wang
}

\section{Introduction}

The polyacrylamide-chromium(III) gel system is used for gel treatments to control fluid movement in oil reservoirs by reducing the permeability of selected zones of the oil reservoirs. Control of the gel placement in the reservoir requires an understanding of the physical properties of the system during the gelation process. Gelation occurs by the crosslinking of polymer molecules by the chromium(III) ion. The crosslinking reaction forms pre-gel aggregates that grow in size to eventually form a gel. The aggregates filter from the solution during flow through the reservoir rock. The retained aggregates develop significant flow resistance in the reservoir during gelant injection, retarding the depth of placement. Knowledge of how the aggregates develop and grow is required to understand the gel placement process.

The objective of this study is to determine the molar masses and the root-mean-square (rms) radii of the pre-gel aggregates as a function of reaction time. Measurements of molar mass and size were conducted using a multi-angle laser light scattering (MALLS) instrument. Preliminary work using the MALLS detector was also conducted with a polyacrylamide standard and Alcoflood 935 to develop standard procedures for measuring polymers and reacting gel systems.

\section{Experimental Equipment, Procedures and Materials}

Equipment. Light scattering measurements were conducted with a Dawn EOS Light Scattering Instrument (Wyatt Technology Corp., Santa Barbara, CA) that was configured in microbatch mode as shown in Figure 2.1. Solvent was continuously pumped through the instrument at a flow rate of $0.5 \mathrm{~mL} / \mathrm{min}$. Samples of polymer prepared at several known concentrations are inserted into the flow stream using an injection valve fitted with a $0.91-\mathrm{mL}$ sample loop. The computer program ASTRA (Wyatt Tech. Corp.) was used to collect and process the light-scattering data.

Runs were also conducted using the same flow system described in Figure 2.1 but using the Optilab DSP interferometric refractometer instrument and DNDC software (Wyatt Tech.Corp.). These measurements are used to determine the specific refractive index increment, $\mathrm{dn} / \mathrm{dc}$, which is the change of refractive index with the concentration of polymer. Densities of the polymer solutions and the refractive index of the solvent were also measured. These measured values are required for the determination of molar mass and size parameters from the light scattering data. All of the instruments were calibrated according to manufacture's procedures.

Procedures. A general procedure was developed to determine the weight-averaged molar mass and rms radius of polyacrylamide samples with molar masses on the order of 5 million Daltons. This procedure is outlined in the following Exhibit 2.1. 


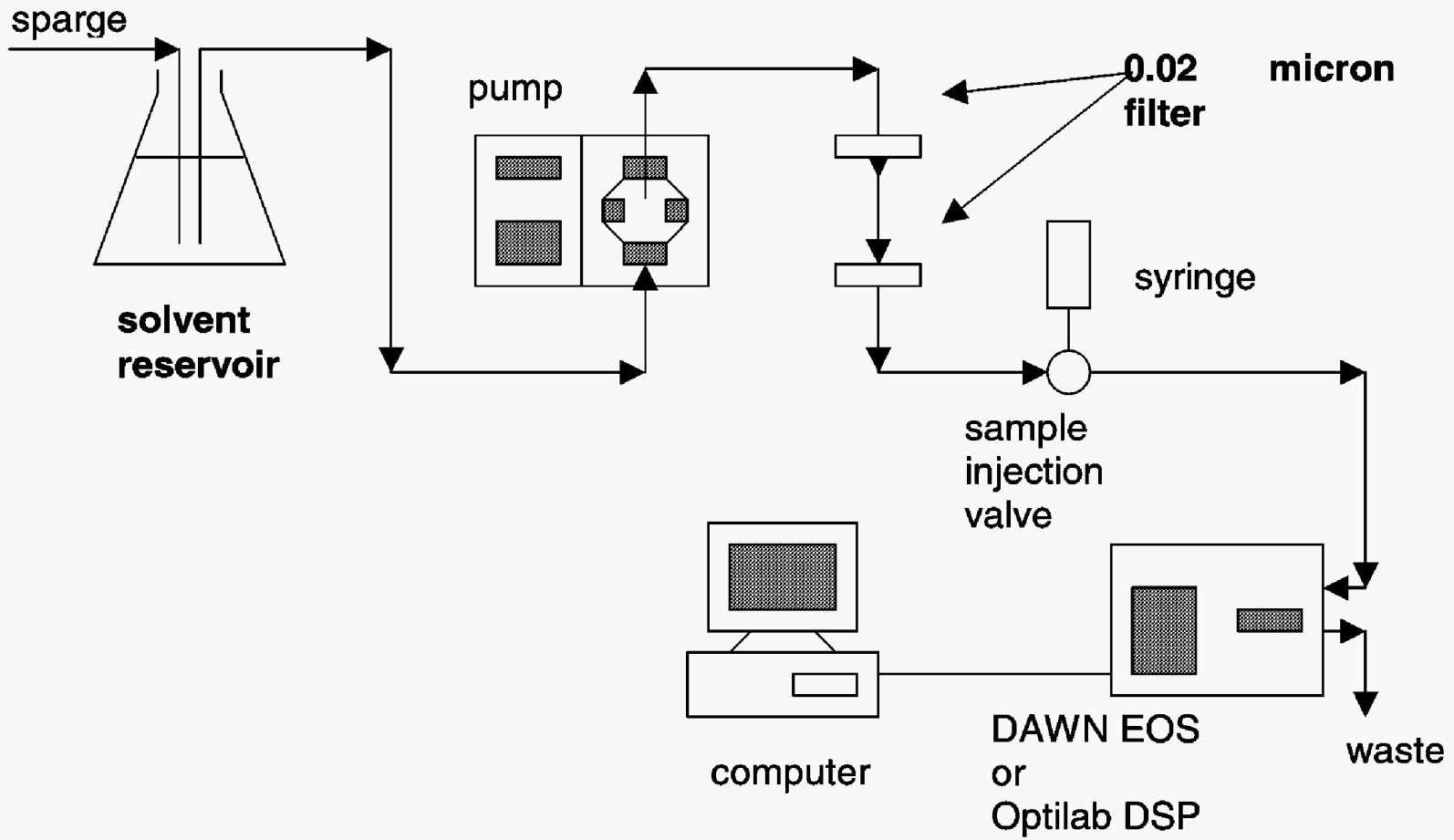

Figure 2.1 - Schematic of equipment used for light scattering measurements.

\section{Exhibit 2.1}

\section{Standard Procedure for Measurement of the Weight-Average Molar Mass and RMS Radius of Polyacrylamide Samples}

These procedures were developed for measuring the weight-average molar mass and rms radius of polyacrylamide samples that have molar masses on the order of 5 million Dalton. The light scattering measurements were conducted with a Dawn EOS multi-angle light scattering detector that is configured to run in the batch mode.

\section{Drying of polyacrylamide sample}

- Dry polyacrylamide sample in a vacuum oven at $100^{\circ} \mathrm{C}$ and -17.5 inches of mercury until the weight of the polymer remains constant. Typically, this process will take 24 hours to two weeks.

- Store the dried polymer sample at $50^{\circ} \mathrm{C}$ and -17.5 inch vacuum mercury until use.

- Non-dried samples can be used if the active amount of polymer in the sample is known.

\section{Glassware cleaning}

- Wash glassware with water using detergent.

- Rinse glassware thoroughly with water followed by distilled water.

- Air-dry glassware upside down on lint free tissues. 


\section{Solvent preparation}

- Dissolve $\mathrm{KCl}$ and sodium azide in laboratory -grade water to obtain a solution with $1 \% \mathrm{KCl}$ and $100 \mathrm{ppm}$ sodium azide.

- Filter the solution through a $0.02 \mu \mathrm{m}$ filter membrane.

\section{Refractive index of solvent}

- Measure the refractive index of solvent using a refractometer.

\section{Stock solution preparation}

Stock solutions are usually prepared with polyacrylamide concentrations of $500 \mathrm{ppm}$.

- Weigh polyacrylamide sample on an analytical balance.

- Weigh the appropriate amount of solvent in a beaker or jar.

- Stir the solvent with a magnetic stirrer to produce a deep vortex.

- Add the polyacrylamide sample onto the shoulder of the vortex to wet each granule/bead of polyacrylamide.

- Stir the stock solution for $\mathbf{2 4}$ hours to ensure complete dissolution. Take steps to eliminate evaporation.

\section{Filtration}

- Filter polyacrylamide stock solution twice using a screen-type filter membrane. A 5.0 $\mu \mathrm{m}$ filter was used for Alcoflood 935 . The size of the filter was determined by measuring the molar mass of a series of stock samples that were filtered by a range of filter sizes. The smallest filter size that did not reduce the molar mass was selected.

\section{Diluted solution preparation}

- Prepare six samples at polymer concentrations between 20 and 100 ppm by diluting the stock solution.

- Shake the vials to ensure uniform concentrations.

- Measure the density of each diluted samples, and convert the concentration to $\mathrm{g} / \mathrm{mL}$.

\section{dn/dc measurements}

This procedure is conducted once for each type of polymer sample and solvent pair. For example, Alcoflood 935 , Lot $7158 \mathrm{v}$ in the $1.0 \% \mathrm{KCl}, 100 \mathrm{ppm}$ sodium azide solvent represents a pair. A measurement is required for a change in the polymer lot number or when the solvent is changed, for example, to $0.5 \% \mathrm{KCl}$ brine.

- Prepare six samples at polymer concentrations between 100 and 1000 ppm.

- Measure the $\mathrm{dn} / \mathrm{dc}$ value using the Optilab DSP differential refractometer.

\section{Molar mass and RMS radius measurement}

- Measure the light scattering data with DAWN EOS.

- Repeat the measurements several times to ensure reproducibility.

\section{Data processing}

The measured data are the amount of light scattered as functions of the angle to which it is scattered and the polymer concentration. These data are fitted to polynomials and extrapolated to zero concentration and zero angle in order to determine the weight-average molar mass and the RMS radius. Several methods are used to perform the extrapolations. These methods produce different results for the relatively large polymer molecules of this study. We are currently analyzing these methods to determine the best method for our samples. Even though we have not determined the best method for data processing, results from different samples can be compared if the data are processed by the same procedure. 
Determination of the active amount of polymer in a sample and the filtration of the stock sample solution are key elements of the experimental procedure described in Exhibit 2.1. The active amount of polymer was assumed to be $100 \%$ after drying the sample to constant weight. Approximately $10 \%$ of an original polymer sample was removed during the drying process. The filtration procedure was developed to remove dust and extraneous material without affecting the measured molar mass and rms radius. The filtration method selected was the filtration of only the stock polymer solution using a screen-type filter membrane (Nuclepore $®$ Polycarbonate TrackEtch Membranes). A $5.0 \mu \mathrm{m}$ pore size was suitable for Alcoflood 935, the commercial polymer used in this work. Some data are presented in the Results and Discussion Section that were collected using different filtration techniques that were tested during the development of the standard procedure.

The last step of the procedure is the processing of the light-scattering data. There are various methods to process the data and currently these different methods are being evaluated to determine the appropriate one for our samples. Even though a 'best" method has not been determined at present, results from different samples can be compared if the data are processed using the same method. Unless otherwise mentioned, all of the molar mass and size data were obtained by the Debye method using a linear fit in concentration and a third-order polynomial fit for the angles.

\section{Materials.}

Solvent. The aqueous solvent contained $1 \%$ by wt. potassium chloride and $100 \mathrm{ppm}$ sodium azide (bactericide). The solvent was filtered through a $0.02 \mu \mathrm{m}$ membrane filter before use.

Polyacrylamide Standard. A polyacrylamide standard (Polymer Standards Service) with a weight-average molar mass of $5.55 \times 10^{6}$ Daltons was tested. The cited molar mass value was determined by a gel permeation chromatography method.

Alcoflood 935 Polyacrylamide. Alcoflood 935 polyacrylamide (Lot 7158v) is a commercial polymer that is used in the field for gelled polymer treatments.

Alcoflood 935 Polyacrylamide-Chromium Acetate Gelant. The gel system selected for study contained Alcoflood 935 polyacrylamide (Ciba Chemical Co., Lot 7158v) and chromium acetate. (McGean and Rhoco, Inc.). A stock polymer solution containing $6667 \mathrm{ppm}$ Alcoflood 935 polyacrylamide and $1.33 \% \mathrm{KCl}$ was prepared and filtered twice through a $5.0 \mu \mathrm{m}$ screen filter membrane. The chromium acetate was dissolved in distilled water to obtain a solution that had a chromium(III) concentration four times as high as the desired chromium(III) concentration in the gel. The chromium acetate solution was filtered through a $0.02 \mu \mathrm{m}$ membrane. The gelling reaction was initiated by adding the freshly prepared chromium acetate solution into the filtered polymer solution at a ratio of 1-to-3 such that the gel solution contained $5000 \mathrm{ppm}$ polymer and $1.0 \% \mathrm{KCl}$. Chromium(III) concentrations in the gelants were $10 \mathrm{ppm}, 20 \mathrm{ppm}, 40 \mathrm{ppm}, 60 \mathrm{ppm}$, $80 \mathrm{ppm}$, and $100 \mathrm{ppm}$. The reaction was conducted at $25^{\circ} \mathrm{C}$ by keeping the glass bottles that contained the reacting mixture in a temperature-controlled water bath. The viscosity of the reacting gelant was measured periodically using a cone-and-plate microviscometer. 
The molar mass and rms radii of the gel aggregates in the reacting Alcoflood 935 polyacrylamide-chromium gels were measured as a function of time for gels containing $100 \mathrm{ppm}$ and $20 \mathrm{ppm}$ chromium(III). At selected reaction times, an aliquot of the gelant was removed from the sample bottle to a $40 \mathrm{~mL}$ vial and then diluted to desired concentration by adding solvent. Light scattering measurements were conducted immediately after the dilution to prevent further reaction.

\section{Results and Discussion}

Polyacrylamide Standard. Polymer content and the $\mathrm{dn} / \mathrm{dc}$ value for 5.55 million Dalton polyacrylamide standard was determined to be $81 \%$ and $0.178 \mathrm{~mL} / \mathrm{g}$, respectively. A $5.0 \mu \mathrm{m}$ screen filter was used to clarify the polymer stock sample. Results of the light-scattering measurements on nine samples of the 5.55 million polyacrylamide standard are shown in Table 2.1. The average molar mass was $5.06 \times 10^{6}$ daltons and the average rms radius was $146 \mathrm{~nm}$. These data are representative of the repeatability of light-scattering measurements.

Table 2.1. Molar mass and rms radius determined by light scattering for the 5.55-million polyacrylamide standard.

$\begin{array}{cccccccccc}\text { Run } & 1 & 2 & 3 & 4 & 5 & 6 & 7 & 8 & 9 \\ \begin{array}{c}\text { Molar mass } \\ \left(10^{6} \text { daltons }\right)\end{array} & 5.19 & 5.26 & 4.60 & 4.73 & 4.73 & 5.15 & 5.40 & 5.10 & 5.33 \\ \begin{array}{c}\text { RMS radius } \\ (\mathrm{nm})\end{array} & 147 & 156 & 142 & 140 & 139 & 146 & 146 & 146 & 149\end{array}$

Alcoflood 935 Polyacrylamide. The polymer content ranged from $90 \%$ to $92 \%$ for the Alcoflood 935 polyacrylamide samples. The average refractive index increment $(\mathrm{dn} / \mathrm{dc})$ was determined as $0.182 \mathrm{~mL} / \mathrm{g}$ at $25^{\circ} \mathrm{C}$ in the $1 \% \mathrm{KCl}$ aqueous solvent.

During the development of the standard procedure, light-scattering measurements were conducted on samples that were filtered with different sizes and types of membranes in addition to filtering the stock solution or the diluted solutions as they were injected into the sample valve of the flow system. Examples of the type of results that were obtained are given in Table 2.2 for a series of samples that were filtered through membranes that were rated with pore sizes ranging from 0.8 to $20 \mu \mathrm{m}$. Three to sixteen runs at each pore size were conducted and the averaged values of the molar mass and rms radius are given in Table 2.2. Inconsistent results were obtained for samples that were filtered through screen-type membranes with pore sizes of 20 and $10 \mu \mathrm{m}$ which indicated that the samples still contained extraneous dust after filtration. Reliable results were obtained using depth-type, syringe membranes with pore ratings from 5.0 to $0.8 \mu \mathrm{m}$. Little change in the light scattering results were observed by increasing the pore size from 1.0 to 
$5.0 \mu \mathrm{m}$ which indicated that extraneous dust was removed while not removing the larger polymer molecules. Filtration of the stock solution through a $5.0 \mu \mathrm{m}$ pore size, screen-type filter was the selected procedure for Alcoflood 935.

Table 2.2 - Effect of filtration procedures on the results of light scattering measurements.

$\begin{array}{ccccccc}\begin{array}{c}\text { Pore size of } \\ \text { filter membrane } \\ (\mu \mathrm{m})\end{array} & 20 & 10 & 5.0 & 5.0 & 1.0 & 0.8 \\ \begin{array}{c}\text { Filter type } \\ \text { Solution filtered }\end{array} & \text { Screen } & \text { screen } & \text { screen } & \text { depth } & \text { depth } & \text { depth } \\ \begin{array}{c}\text { Molar mass } \\ \left(10^{6} \text { Daltons }\right)\end{array} & ? ? & \text { stock } & \text { stock } & \text { diluted } & \text { diluted } & \text { diluted } \\ \begin{array}{c}\text { RMS radius } \\ (\mu \mathrm{m})\end{array} & ? ? & ? ? & 4.70 & 4.31 & 4.23 & 3.7 \\ & & & 147 & 148 & 148 & 134\end{array}$

Polyacrylamide samples as obtained in dry form contain a significant amount of water or volatiles. The samples are dried in a vacuum oven to remove the water/volatiles in order to determine the amount of active polymer. Light scattering data for Alcoflood 935 were obtained for samples that were dried and for samples that were not dried to determine if the drying process affected the measurements. The amount of polymer in non-dried samples was determined using the assay determined from the drying process. The molar masses and rms radii for the non-dried and dried samples are given in Tables 2.3 and 2.4, respectively. There was no significant difference between the results of the non-dried and the dried Alcoflood 935 samples as shown in the tables. The average molar mass for Alcoflood 935 (Lot 7158v) was $4.70 \times 10^{6}$ Daltons and the average rms-radius was $148 \mathrm{~nm}$. Individual molar mass measurements were within $6 \%$ of the average and the RMS values were within $4 \%$ of the average. A $5.0 \mu \mathrm{m}$ pore size, screen-type filter was used to filter the stock solutions.

A test was conducted to determine if the application of a high shear stress would reduce the molar mass and rms radius of an Alcoflood 935 sample. A $2000 \mathrm{ppm}$ Alcoflood 935 stock sample that had been filtered through a $5.0 \mu \mathrm{m}$ membrane was stirred at high speed for 15 minutes in a Osterizer blender. The sheared sample was then diluted and the light scattering measurements were conducted six times. The molar mass and the rms radius of the degraded sample are presented in Table 2.5. The average molar mass of the sheared Alcoflood 935 sample was $1.96 \times 10^{6}$ Daltons and the average rms radius was $95 \mathrm{~nm}$. Shearing in the blender reduced the weight-averaged molar mass by $58 \%$ and reduced the rms radius by about $36 \%$. 
Table 2.3 - Molar mass and rms radius for non-dried Alcoflood 935 (Lot 7158V) using a $5.0 \mu \mathrm{m}$ screen-type filter to clarify the polymer stock sample.

\begin{tabular}{ccccccc} 
Run & 1 & 2 & 3 & 4 & 5 & 6 \\
$\begin{array}{c}\text { Molar mass } \\
\left(10^{6} \text { daltons }\right)\end{array}$ & 4.33 & 4.688 & 4.90 & 4.80 & 4.58 & 4.81 \\
$\begin{array}{c}\text { RMS radius } \\
(\mathrm{nm})\end{array}$ & 143 & 148 & 152 & 146 & 146 & 149 \\
\hline Run & 7 & 8 & 9 & 10 & 11 & 12 \\
$\begin{array}{c}\text { Molar mass } \\
\left(10^{6} \text { daltons }\right)\end{array}$ & 4.47 & 4.70 & 4.43 & 4.88 & 4.90 & 4.91 \\
$\begin{array}{c}\text { RMS radius } \\
(\mathrm{nm})\end{array}$ & 146 & 150 & 151 & 150 & 148 & 147
\end{tabular}

Table 2.4 - Molar mass and rms radius for dried Alcoflood 935 (Lot 7158V) using a $5.0 \mu \mathrm{m}$ screen-type filter to clarify the polymer stock sample.

\begin{tabular}{ccccccccc} 
Run & 1 & 2 & 3 & 4 & 4 & 6 & 7 & 8 \\
$\begin{array}{c}\text { Molar mass } \\
\left(10^{6} \text { daltons }\right)\end{array}$ & 4.70 & 4.79 & 4.64 & 4.78 & 4.55 & 4.73 & 4.79 & 4.50 \\
$\begin{array}{c}\text { RMS radius } \\
\text { (nm) }\end{array}$ & 146 & 150 & 144 & 146 & 146 & 149 & 145 & 150 \\
\hline Run & 9 & 10 & 11 & 12 & 13 & 14 & 15 & 16 \\
$\begin{array}{c}\text { Molar mass } \\
\left(10^{6} \text { daltons }\right)\end{array}$ & 4.77 & 4.65 & 4.59 & 4.44 & 4.57 & 4.91 & 4.81 & 4.95 \\
$\begin{array}{c}\text { RMS radius } \\
\text { (nm) }\end{array}$ & 153 & 150 & 146 & 142 & 145 & 148 & 150 & 145
\end{tabular}


Table 2.5 - Molar mass and the rms radius of Alcoflood 935 (Lot 7158v) after shearing in an Osterizer blender at high stir speed for 15 minutes

$\begin{array}{ccccccc}\text { Run } & 1 & 2 & 3 & 4 & 5 & 6 \\ \begin{array}{c}\text { Molar mass } \\ \left(10^{6} \text { daltons }\right)\end{array} & 1.96 & 1.95 & 1.96 & 1.98 & 1.95 & 1.97 \\ \begin{array}{c}\text { RMS radius } \\ (\mathrm{nm})\end{array} & 98 & 92 & 94 & 96 & 95 & 95\end{array}$

Alcoflood 935 Polyacrylamide - Chromium Acetate Gelant. The viscosity behavior was determined for a series of gelants that were prepared at selected chromium concentrations. The gelants contained $5000 \mathrm{ppm}$ polyacrylamide and $1.0 \% \mathrm{KCl}$. Viscosity was measured as a function of time and is shown in Figure 2.2. The measurements were conducted at a shear rate of $11.25 / \mathrm{sec}$ for viscosity values less than $200 \mathrm{cp}$ and at a shear rate of $4.5 / \mathrm{sec}$ for viscosity values greater than $205 \mathrm{cp}$. The viscosity of the reacting gelants increased gradually initially as the crosslinking reaction proceeded, followed by abrupt increases over a short time period. The gel time was defined as the time at which the viscosity of the gelant increased to a value greater than $200 \mathrm{cp}$. Gel time decreased with increasing chromium concentration. The physical nature of the gelant changes considerably during the time period of the abrupt viscosity change which represents approximately $5 \%$ of the measured gel time. During this period, the gelant becomes much more elastic and "stringy" which makes it difficult to separate an aliquot from the gelant for analytical measurements. The sample continues to develop stronger gel characteristics after the defined gel time.

Gelants containing 100 and $20 \mathrm{ppm}$ chromium were selected for study using the light scattering equipment. The gel times were about 38 hours for the gelant containing $100 \mathrm{ppm}$ chromium(III) and 175 hours for the $20 \mathrm{ppm}$ chromium(III) gel. The weight average molar masses and the rms radii of the polymer/aggregates as a function of time for the $100 \mathrm{ppm}$ chromium(III) gel are shown in Figures 2.3 and 2.4. These data show that as the gelling reaction proceeds, the molar mass and rms radius of the polymer/aggregates increased moderately up to the time when the viscosity of the gelant increased abruptly ( 38 hours). This is more clearly shown in Figure 2.5 where the viscosity, molar mass and the rms radius are divided by their initial values and are plotted as a function of reaction time. The relative increase of the molar mass and rms radius are much less than the relative increase in the viscosity value. Similar data for the gelant containing 20 ppm are shown in Figure 2.6.

The procedures used to process the light-scattering data are still being investigated. The different procedures give somewhat different molar masses and rms size results. However, the trends that are observed in Figures 2.5 and 2.6 hold for all processing methods. That is, the size of the aggregates does not increase significantly prior to the time that the viscosity of the gelant increases abruptly. It is unclear how the gelant forms a gel so quickly after this time with such little increase in size. To address this question, an attempt is being made to develop a method to collect and measure samples of the gelant at reaction times that are significantly past the time of the abrupt increase in viscosity. 


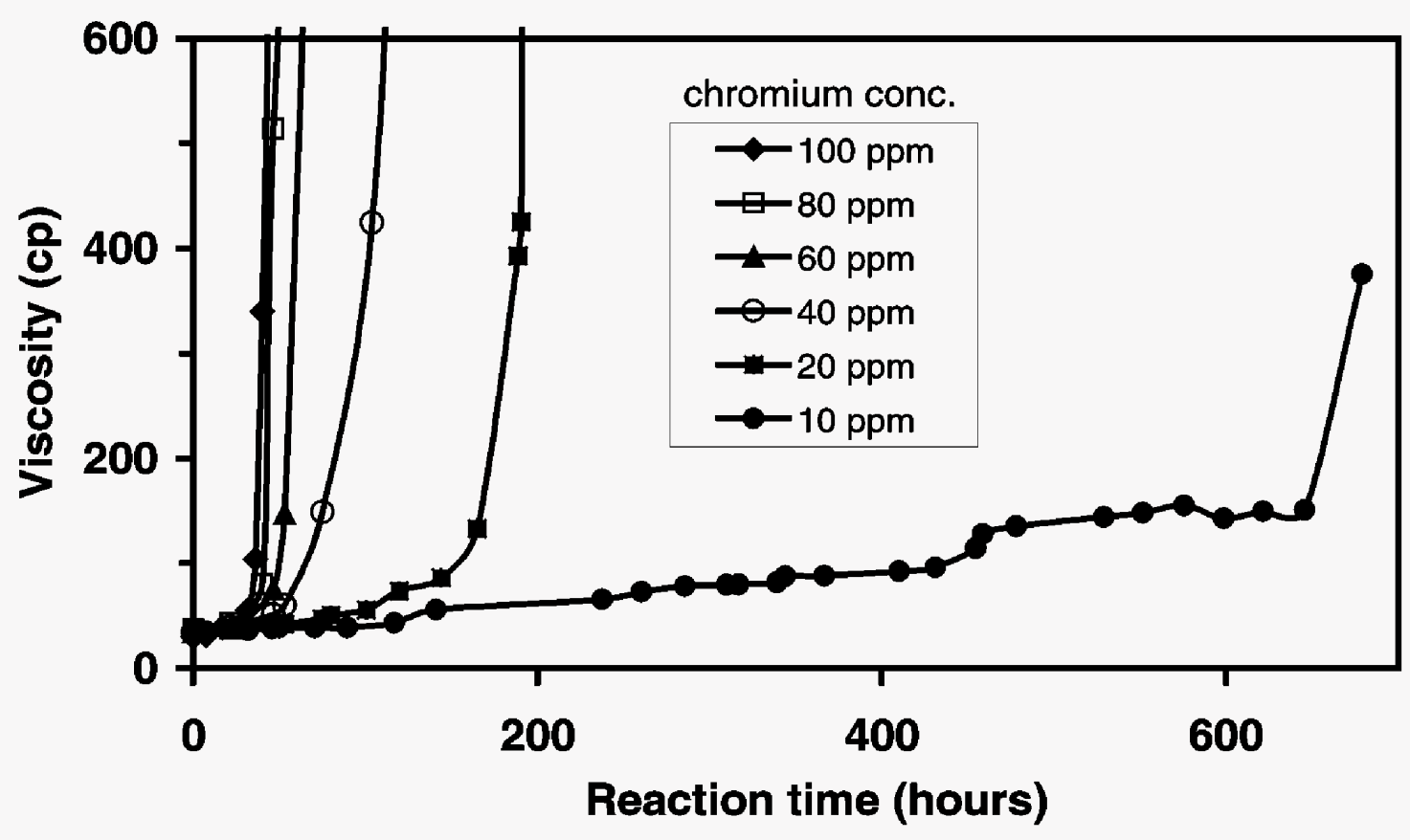

Figure 2.2 - Viscosity of gelants as a function of time and chromium concentration.

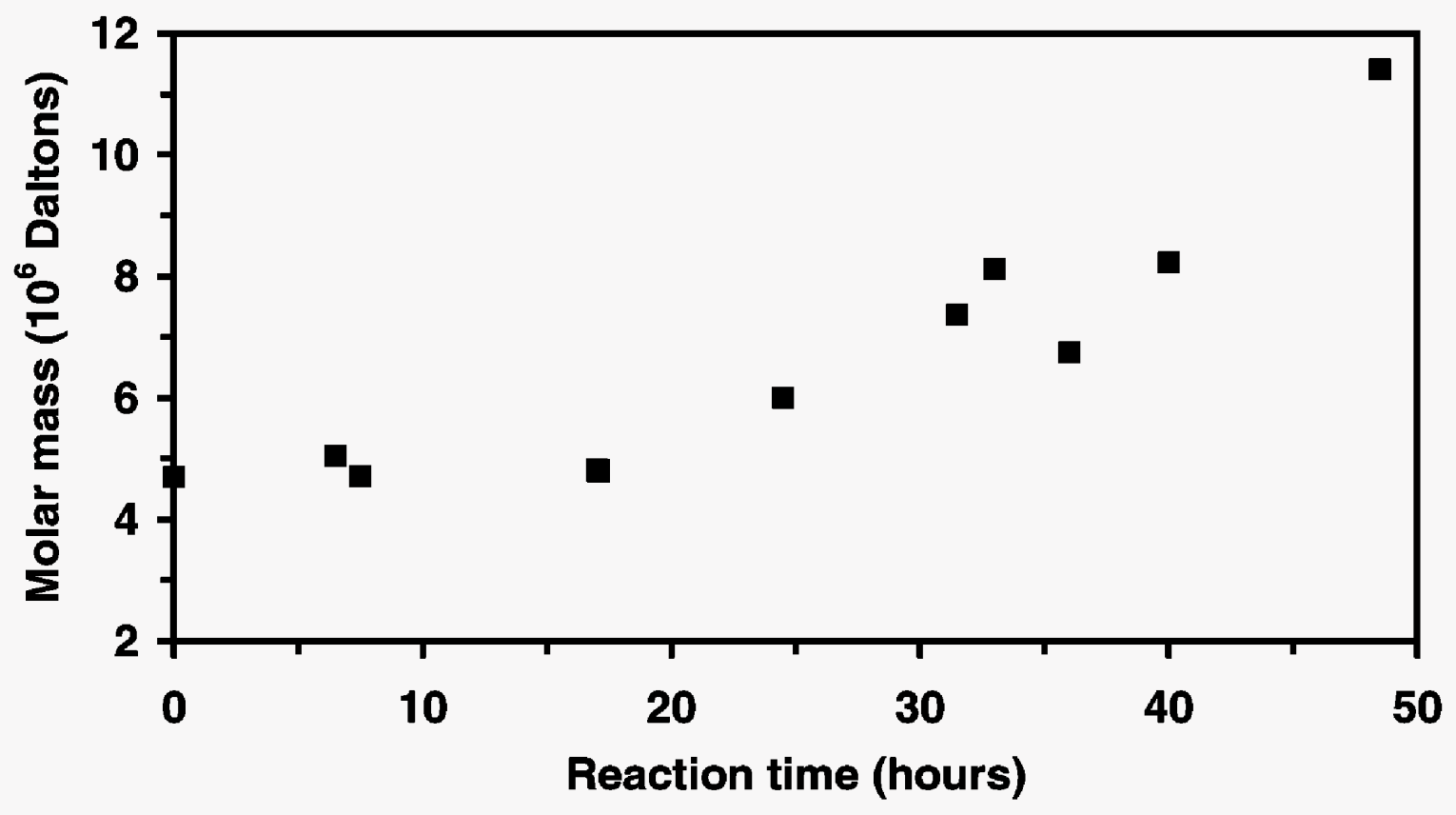

Figure 2.3 - Molar mass as a function of time for gelant containing $100 \mathrm{ppm}$ chromium. 

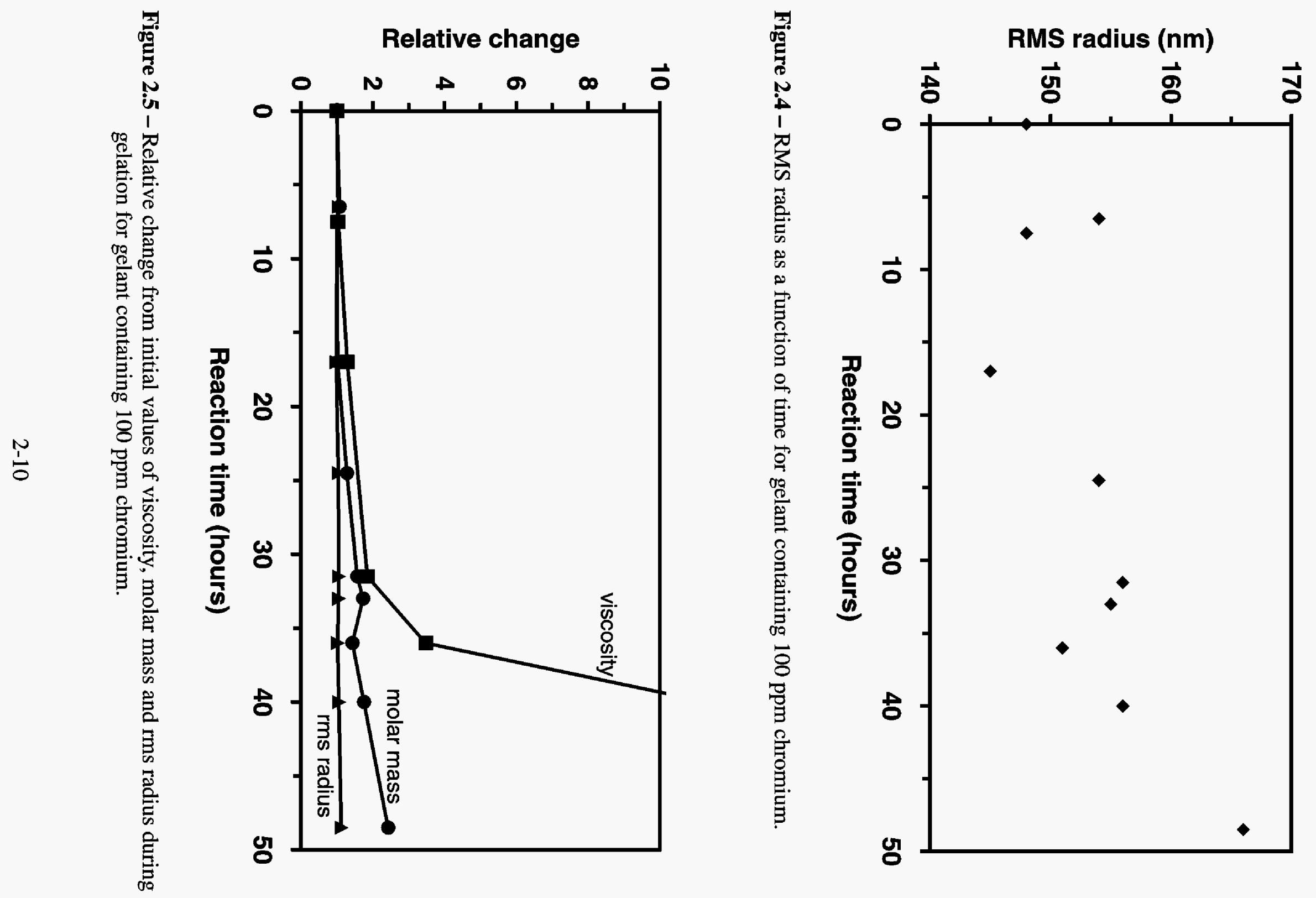


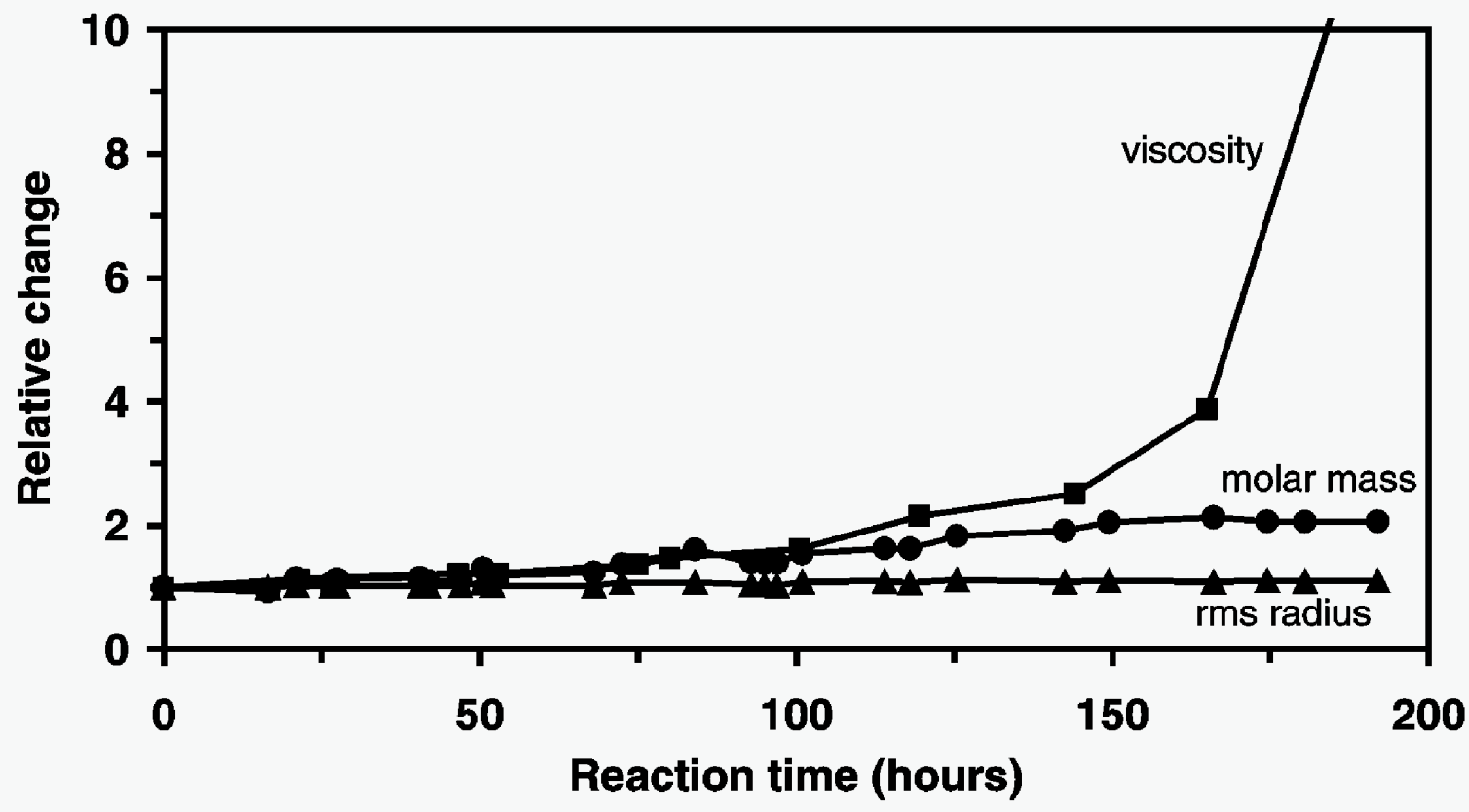

Figure 2.6 - Relative change from initial values of viscosity, molar mass and rms radius during gelation for gelant containing $20 \mathrm{ppm}$ chromium.

\section{Summary}

A standard procedure was developed for the determination of the weight-average molar mass and the rms radius of polyacrylamide samples that are used in oilfield operations. Light scattering measurement of dilute polymer solutions is the principal step of the procedure. Development of the procedure was more difficult than anticipated due to challenges in sample preparation. Measurements of weight-average molar mass and rms radius are repeatable to within $\pm 8 \%$ of the average value. Better precision in the measurements appears difficult to attain.

Light scattering measurements on a polyacrylamide-chromium acetate gelant showed moderate increases in the molar mass and rms radius up to the time when the viscosity of the gelant increases rapidly. The molar mass approximately doubled in size and the rms radius increased on the order of $10 \%$. The magnitudes of the increases of the molar mass and the rms radius do not change significantly when using alternate methods to process the light scattering data. We plan to investigate how the viscosity of the solution can increase so significantly with such small changes in the weight-average molar mass or the rms radius. 



\title{
Chapter 3
}

\section{Effect of Added Acetate on the In Situ Gelation of the Polyacrylamide-Chromium(III) Acetate System}

\author{
Graduate Research Assistant: Lingyun DU
}

\section{Introduction}

Chromium acetate-polyacrylamide systems have been used primarily to treat fracture systems, casing leaks and near wellbore regions in matrix rock where short gel times are acceptable. The relatively rapid chromium acetate-polyacrylamide reaction limits the application of this technology to near-wellbore treatment of matrix rock. Pre-gel aggregates form during the gelation reaction and some of these aggregates are filtered from the solution, thus building up high flow resistance and limiting the depth of penetration into the porous matrix. Our intent is to understand and modify gel systems in order to treat in-depth matrix rock.

Syndansk [1990;1997], Syndansk and Argabright [1987] describe a family of chromium(III)polyacrylamide gels ranging from highly flowing to rigid rubbery gels with a wide range of gel times. Burrafato and Lockhart [1989] and Burrafato et al. [1990] proposed that the chromium uptake from chromium-carboxylate complexes is a ligand exchange reaction in which a carboxyl group on the polyacrylamide displaces ligands (i.e. acetate). Crosslinking occurs when a second polyacrylamide molecule reacts with the attached chromium. The reaction chemistry between $\mathrm{Cr}$ (III) and polyacrylamide is complex as the structure of chromium and the attached ligands vary with $\mathrm{pH}$ and temperature. The chromium uptake and crosslinking reactions are described in Eq.3.1 and Eq.3.2 where the form of chromium acetate is represented by the cyclic trimer [Tackett, 1989]. The symbol OAc ${ }^{-}$indicates an acetate ion and the symbol $\mathrm{P}-\mathrm{CO}_{2}{ }^{-}$indicates a reactive carboxyl group on a polymer molecule. The acetate ion is a product of the reactions which suggests that addition of acetate to the gel solution would limit or reduce the rate of chromium uptake and crosslinking.

Uptake Reaction

$$
\mathrm{Cr}_{3} \mathrm{O}(\mathrm{OAc})_{6}^{+1}+\mathrm{P}_{-} \mathrm{CO}_{2}^{-1} \Leftrightarrow \mathrm{Cr}_{3} \mathrm{O}(\mathrm{OAc})_{5}\left(\mathrm{PCO}_{2}\right)^{+1}+\mathrm{OAc}^{-1} \text { Eq. } 3.1
$$

Crosslinking Reaction

$$
\mathrm{Cr}_{3} \mathrm{O}(\mathrm{OAc})_{5}\left(\mathrm{PCO}_{2}\right)^{+1}+\mathrm{P}-\mathrm{CO}_{2}^{-1} \Leftrightarrow \mathrm{Cr}_{3} \mathrm{O}(\mathrm{OAc})_{4}\left(\mathrm{PCO}_{2}\right)_{2}{ }^{+1}+\mathrm{OAc}^{-1} \mathrm{Eq} .3 .2
$$

Green et al. [1993] studied the effect of various ligands like acetate, nitrate, chloride etc. and their concentrations as free ligands in solution on the gel times of the polyacrylamide chromium (III) system. These studies showed that the use of chromium acetate and the presence of free acetate in solution could delay gelation significantly at $25^{\circ} \mathrm{C}$. Albonico et al. [1993] studied the effect of type and concentration of several organic ligands on delaying the gelation of polyacrylamide and co-polymers of polyacrylamide. 
Bottle tests and displacement experiments were conducted by Natarajan et al. [1998] to determine the effect of added acetate on performance of a polyacrylamide-chromium(III) gel system. Increased concentrations of sodium acetate were shown to delay gelation. Displacement experiments in sandpacks ( 1 to $6 \mathrm{ft}$ long) showed that increased acetate concentrations delayed the development of flow resistance during gelant injection in porous media. Development of flow resistance in the sandpacks was significantly faster than the bulk gel times observed in bottle tests.

The performance of a polyacrylamide-chromium acetate system was tested in a 40 -foot long sandpack [Willhite et. al, 2000]. The concentration of added acetate in the gel system was initially selected to give a bulk gel time of approximately 3 months, much longer than the time for placement of gelant in the sandpack. 1.2 pore volumes of gelant were displaced through the sandpack over a time period of 6.8 days. Buildup of increased flow resistance did not occur during placement. Unfortunately, the gelant was prepared with a new lot of polymer that did not gel as readily as the original lot and bulk gelation of the injected gelant was not observed within two years.

The sandpack was shut-in for 18 months and it was suspected that insitu gelation did not occur since the bulk samples had not gelled. Polymer solution was then injected to displace the 18month old gelant from the sandpack. Pressure data taken during the injection of polymer solution are presented in Figure 3.1 in terms of apparent viscosity as a function of sandpack length. Apparent viscosity is calculated from Darcy's law using the permeability of the sand before gelant injection. Development of increased flow resistance was observed in the third section of the pack that was located between 20 and 27 feet from the entrance. Injection was stopped after 0.39 pore volumes were injected due to high injection pressure. Subsequent work showed that the increased flow resistance was caused by an approximate 1-inch long segment of a gelled sand structure that was located at the front end of the third section $(20 \mathrm{ft}$ from the inlet of the 40 -foot long pack). Pre-gel aggregates apparently filtered from the flowing solution at this position during the displacement. It is unclear why this occurred.

Selection and concentration of various ligands can delay the gelation of bulk gels and delay the in-situ gelation of systems as they are flowed through porous rocks and sandpacks. It is not known how the extension of the bulk gel time translates to the time/distance that a gel can be injected into a porous medium before high flow resistance develops.

The objective of this work is to determine a correlation/relationship between the gel time of bulk samples with the time that insitu gelation occurs in a porous medium. The time/distance that a gel system can be injected into a porous medium requires the porous medium be sufficiently long to contain the injected gelant up to the time in situ gelation occurs. For long gel times, the length of the media can be many meters long and significant amount of time is required for preparing and running a flow experiment. In order to reduce the number of experiments in long media, we propose to conducted a series of flow experiments in which gelant was mixed in bulk and then continuously injected through short (six inch long) sandpacks. These runs are conducted with a series of gelants that contain selected concentrations of acetate that give a wide range of bulk gel times. As the aggregates become of sufficient size and/or reactivity, they are retained in the 


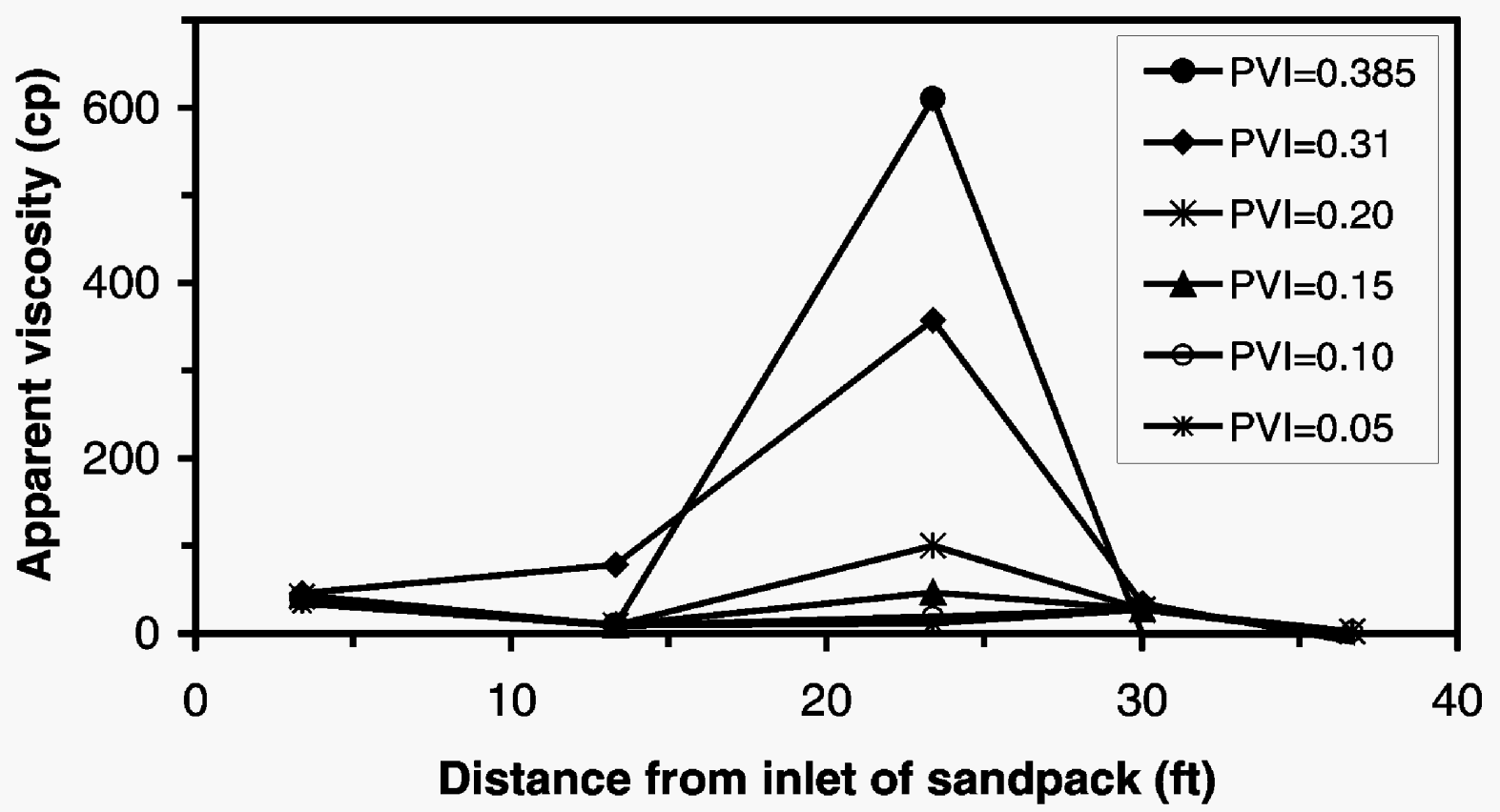

Figure 3.1 - Flow resistance profiles after different amounts of polymer solution were injected through the 40-foot long sandpack; PVI [=] pore volumes of solution injected.

short sandpacks and develop a significant increase in flow resistance (insitu gelation). Flow tests are then conducted where the gelant is mixed inline and injected through long sandpacks. The insitu gel time in the long packs are correlated with the bulk gel time and the insitu gel time in the short packs. We hypothesize that the gel time in the shorter packs are a fraction of the bulk gel time and that the insitu gel times in the long and short sandpacks are closely related. If successful, flow tests in short sandpacks will provide an efficient method for determining the insitu gel time of a particular gelant formulation. A polyacrylamide-chromimum(III) acetate gel system using acetate as the added ligand for delaying gelation was selected for study.

\section{Experimental Details}

Gelant preparation. Four stock solutions were prepared: a polyacrylamide stock containing 8333 ppm Alcoflood 935, Lot 8033 VVR (Ciba Specialty Chemicals); a chromium acetate stock solution containing approximately $1000 \mathrm{ppm}$ chromium (McGeane-Rohco, Inc., 50\% chromium acetate solution); sodium acetate stock containing $10.96 \mathrm{wt} . \% \mathrm{NaOAc}$; and an acetic acid stock containing $4.56 \mathrm{wt} . \%$ HOAc. Appropriate amounts of the stock solutions and lab-grade water were mixed to prepare gelants with mole ratios of acetate-to-chromium that ranged from 7 to 153. All gelants contained $5000 \mathrm{ppm}$ polyacrylamide and had initial $\mathrm{pH}$ value of $5.0( \pm 0.05)$. Gelants were prepared with concentrations of chromium of $110( \pm 1) \mathrm{ppm}$ and $125( \pm 6) \mathrm{ppm}$.

Bottle tests. Bottle tests were conducted to study the effect of added acetate ions on the bulk gel times. These data provide the basis for the design of flow experiments. Gelant samples were 
prepared and placed in a $30^{\circ} \mathrm{C}$ water bath. Portions of the samples were drawn at periodic time intervals and the viscosity was measured in a Brookfield cone-and-plate viscometer. The gel time was defined as the time the viscosity increased beyond the range of the viscometer, which was $1028 \mathrm{cP}$ at a shear rate of $2.25 \mathrm{~s}^{-1}$.

Flow experiments in 6-inch long sandpacks. Flow experiments were conducted by injecting bulk-mixed gelants through 6-inch-long packs. The objective of these runs was to obtain relationships between the in situ gelation time in the short packs with the bulk gelation times.

The sandpack holders were made from schedule 80, 1.5 inch ID, transparent PVC tubes of 6 inches in length with two pressure ports at 2.0 and 4.0 inches from the inlet end. The sandpack holders were packed with acid-washed F-110 Ottawa sand. 37-mesh screens were placed at both ends of the pack. A 1-cm length of coarse sand was placed between the screens and the F-110 Ottawa sand. Porosities of the packs ranged from $36 \%$ to $37 \%$. Tracer tests with $1 \%$ potassium nitrate were conducted on the packs to verify the homogeneity of the packs. Permeabilities of the packs were from 5.2 to 5.7 Darcies.

A schematic of the setup for flow experiments is presented in Figure 3.2. Gelants were mixed in bulk and placed in a transfer cylinder. Gelant was injected through the sandpacks by pumping mineral oil into the transfer cylinder. The injection rate was constant at $0.08 \mathrm{~mL} / \mathrm{min}$ which corresponded to an interstitial velocity of $0.91 \mathrm{ft} / \mathrm{D}$. The transfer cylinder and the sandpack were controlled at $30^{\circ} \mathrm{C}$ by a water bath. Pressure differentials across the pack during gel injection were collected by a computer-based data acquisition system via the transducer setup. A flow experiment was terminated when the pressure differential across any section of the pack exceeded 25 psi.

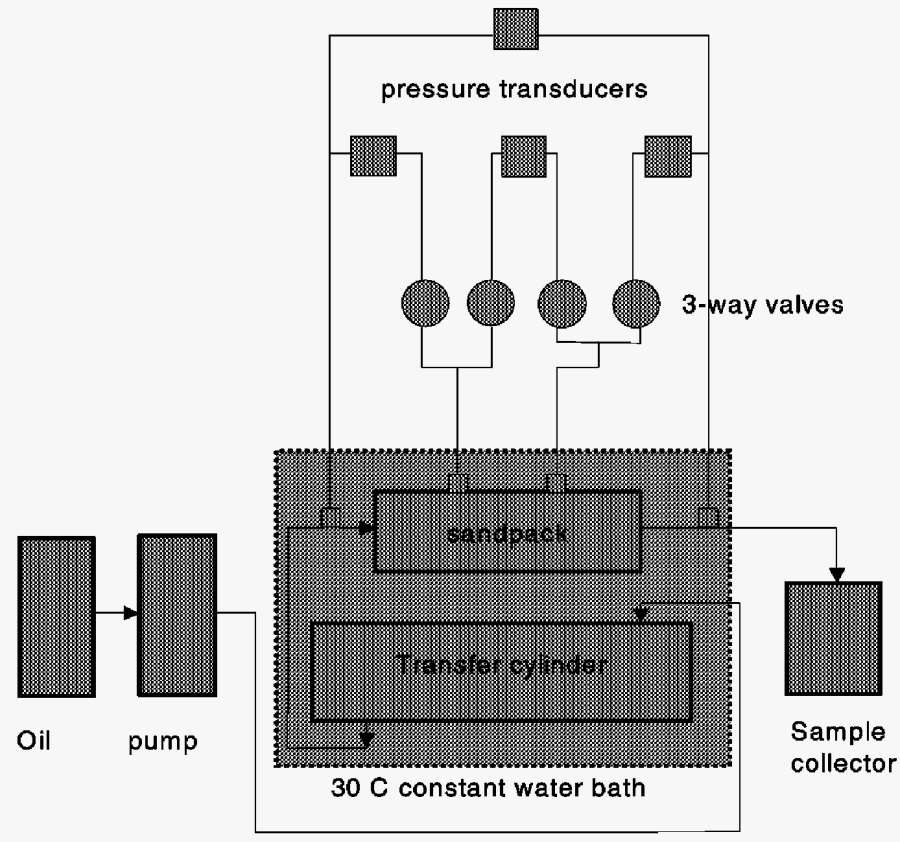

Figure 3.2 - Schematic diagram of equipment for flow experiments. 


\section{Results and Discussion}

Bottle tests. The results of bottle tests are presented in Figure 3.3 where the bulk gel times for gelants containing 110 and $125 \mathrm{ppm}$ chromium are plotted as a function of the acetate-tochromium ratio. Increased acetate concentration delayed the gel time. Acetate ions in sufficient concentrations can effectively delay gelation by competing with the polymer for the chromium ion. The change in chromium concentration from 110 to $125 \mathrm{ppm}$ had little effect on the gel times.

Flow experiments on 6-inch packs.

A summary of the flow experiments is given in Table 3.1. Eight runs were conducted at six acetate-to-chromium ratios. Three runs at an acetate-to-chromium ratio of 103 were conducted to verify the reproducibility of the results. Differential pressure profiles across sections of the packs during gelant injection for the three runs with acetate-to-chromium ratios of 103 are shown in Figure 3.4. Pressure differentials for gelant flow before insitu gelation through the 2-inch long sections was about $0.1 \mathrm{psi}$ which corresponded to a apparent viscosity of about $50 \mathrm{cp}$. Increased flow resistance, as measured by the pressure differential, occurred in only one section of the pack. Flow was stopped when the differential pressure in a section was increasing rapidly and reached a value of $25 \mathrm{psi}$. At that time, the flow resistance in the section had increased by a factor of 250 over that for gelant flow before insitu gelation. Flow resistances in the other sections increased moderately. Insitu gelation, as defined by the 25-psi pressure differential, occurred at 240,280 and 285 hours for the gelant containing an acetate-to-chromium ratio of 103. This range of times was considered reasonable for reproducibility of in situ gel times.

Table 3.1 - Summary of gel times for flow experiments.

\begin{tabular}{cccc}
$\begin{array}{c}\text { Acetate-to- } \\
\text { chromium ratio }\end{array}$ & $\begin{array}{c}\text { Chromium conc., } \\
\text { (ppm) }\end{array}$ & Bulk gel time, (days) & $\begin{array}{c}\text { Insitu gelation time, } \\
\text { (hours) }\end{array}$ \\
\hline 38 & 110 & 9 & 40 \\
44 & 125 & 12 & 12 \\
56 & 110 & 17 & 120 \\
90 & 110 & 30 & 200 \\
$103-A$ & 125 & 52 & 280 \\
$103-B$ & 110 & 55 & 285 \\
$103-C$ & 110 & Not gelled yet & 240 \\
153 & 110 & 163 & 780
\end{tabular}

Similar pressure data were obtained for runs with gelants containing acetate-to-chromium ratios of 56 and higher. That is, the differential pressure across one section rapidly increased to the 25 psi value. The differential pressures for the flow experiments with gelants having lower acetateto-chromium ratios, 38 and 44, exhibited different behavior. The differential pressures increased in all three sections of the pack as shown in Figure 3.5 for an acetate-to-chromium ratio of 44. The pressure data indicates a relationship between the gel time and the resident time for flow in the pack. For gels with relatively short bulk gelation times, the formation of pre-gel aggregates 


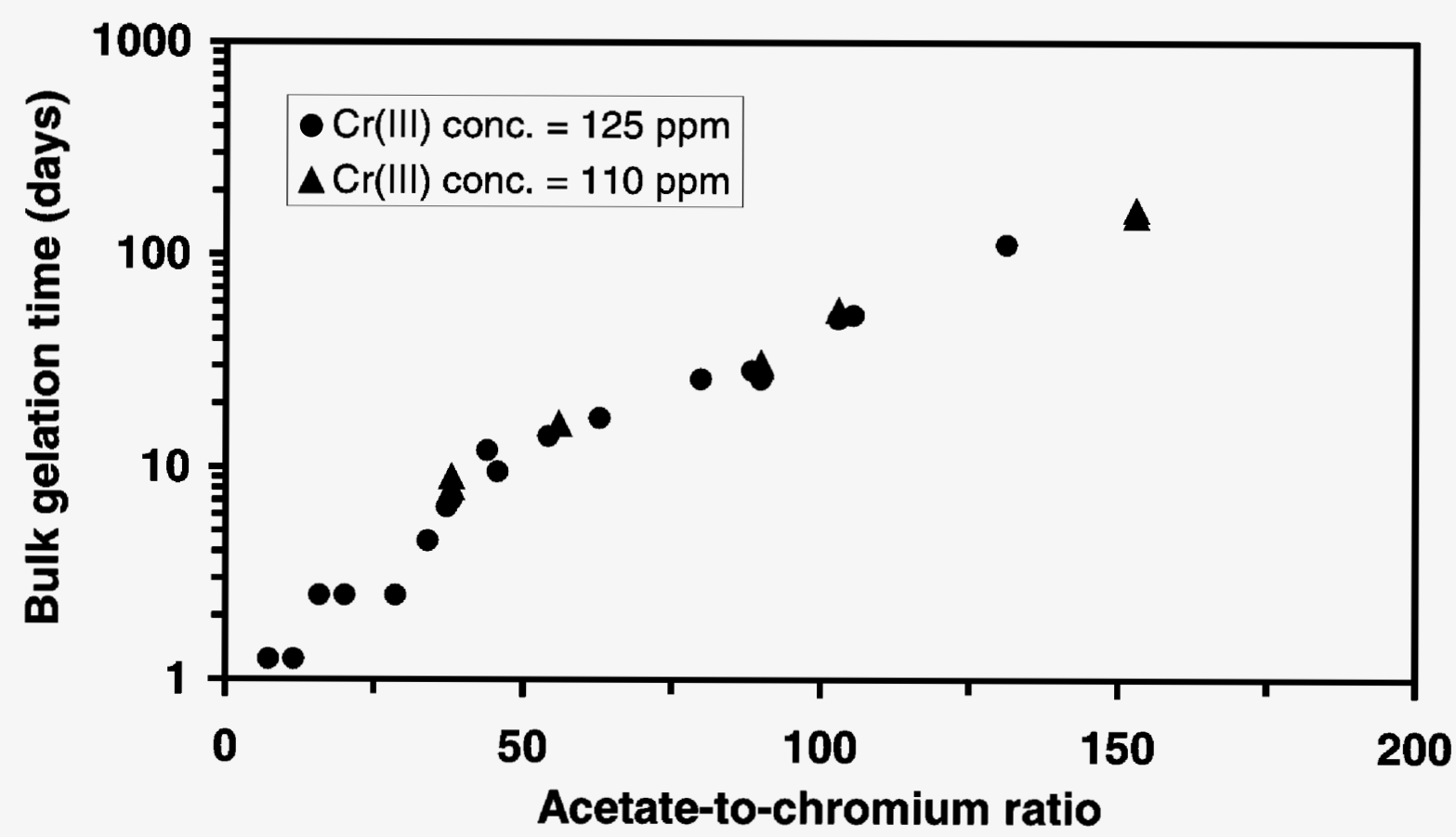

Figure 3.3 - Bulk gel time as a function of the acetate-to-chromium ratio.

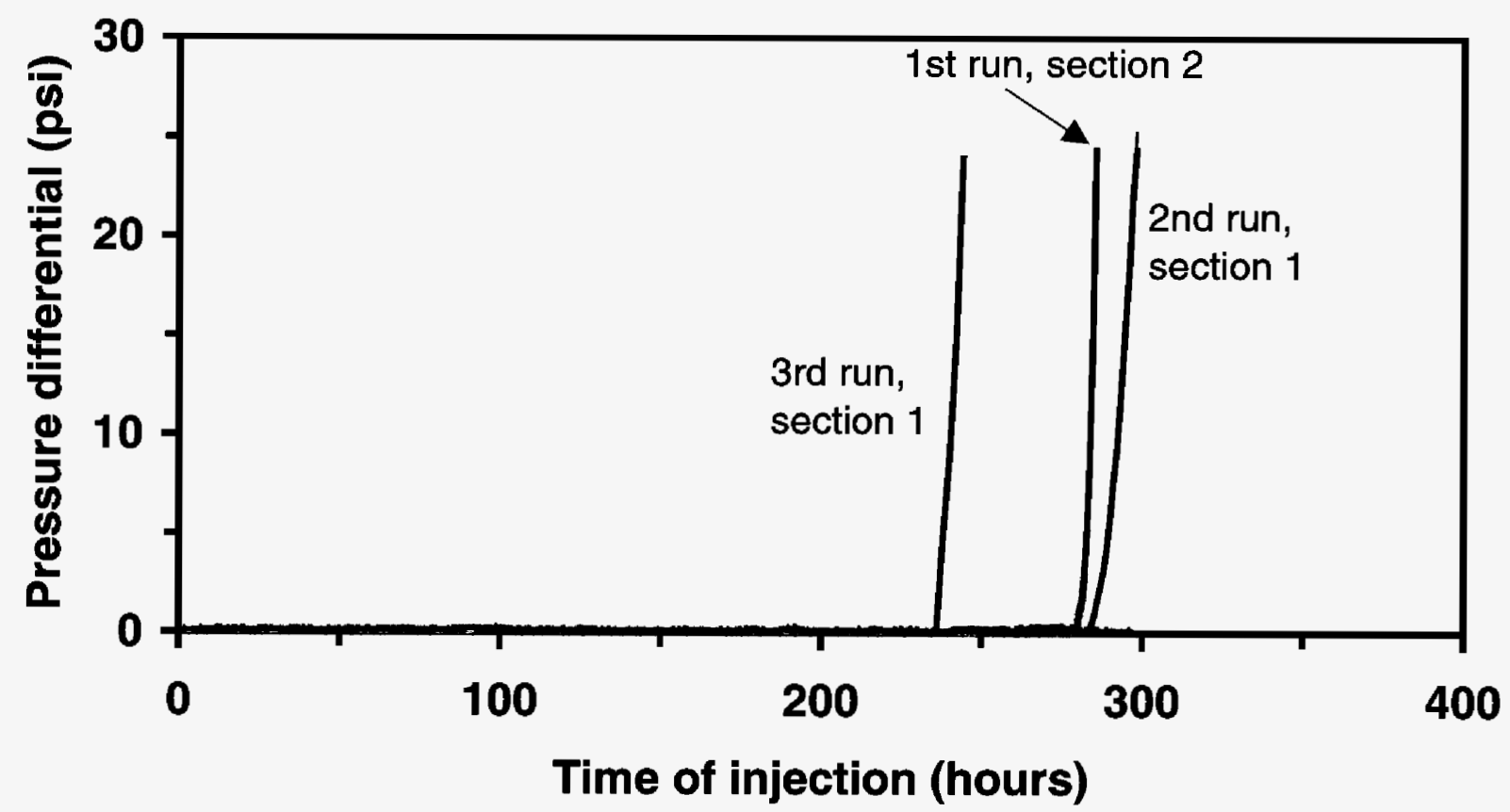

Figure 3.4 - Differential pressure across sections of sandpacks during the injection of gelant with an acetate-to-chromium ratio of 103. 


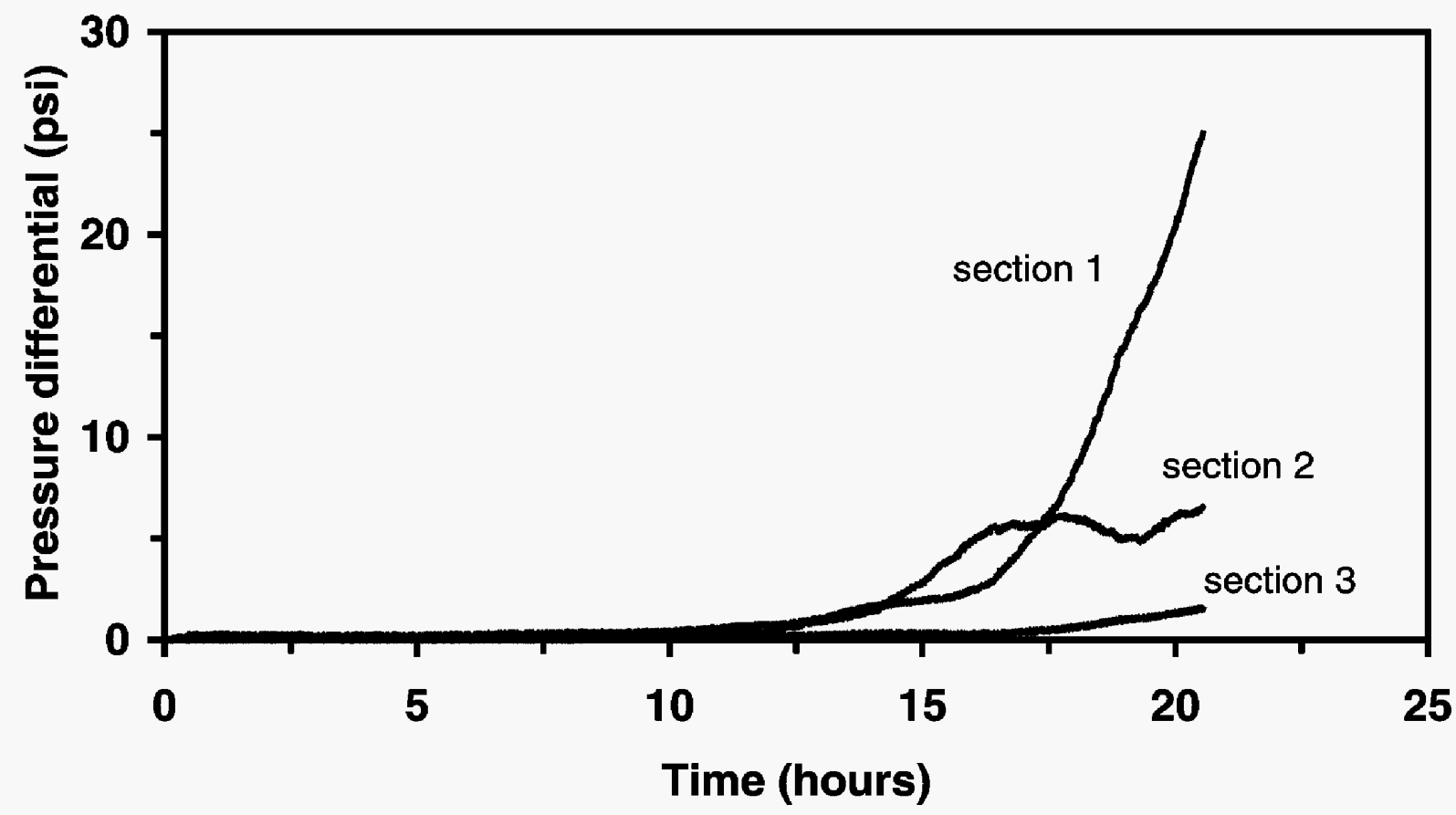

Figure 3.5 - Differential pressures across sections of the sandpack during injection of gelant with an acetate-to-chromium ratio of 44 .

was rapid with respect to the residence time of the gelant in the pack (11 hours) and allowed for a more uniform insitu gelation. In contrast, for gels with relatively long bulk gelation times, the formation of pre-gel aggregates was slower, which allowed for the gradual accumulation of gel aggregates in one part of the pack leading to the formation of a "zone" of high flow resistance. This zone of high flow resistance "stripped" the entering gel solution of some of the polymer content thus making it less likely to gel in the adjacent sections.

Insitu gelation times that were determined by the flow experiments are plotted as a function of the acetate-to-chromium ratio in the gelant in Figure 3.6. Increased acetate-to-chromium ratios increase the insitu gel time as expected. The relationship between insitu gelation time and the bulk gelation time is shown in Figure 3.7. The insitu gelation time was approximately $22 \%$ of the bulk gel time.

\section{Summary}

Gel times of the polyacrylamide-chromium acetate gel system can be increased by adding acetate to the system. Bulk gel times in the range of one day to three months were achieved by varying the acetate-to-chromium ratio from 7:1 to 153:1 for the gelant system which contained $5000 \mathrm{ppm}$ polymer and 110 to $128 \mathrm{ppm}$ chromium. Increased acetate-to-chromium ratios also delayed the development of flow resistance during gelant injection in unconsolidated sandpacks. The development of increased flow resistance in sandpacks was extended from 2 to 34 days by increasing the acetate-to-chromium ratio from 38 to 153 . Insitu gelation occurred at a time that was approximately $22 \%$ of the bulk gelation time. 


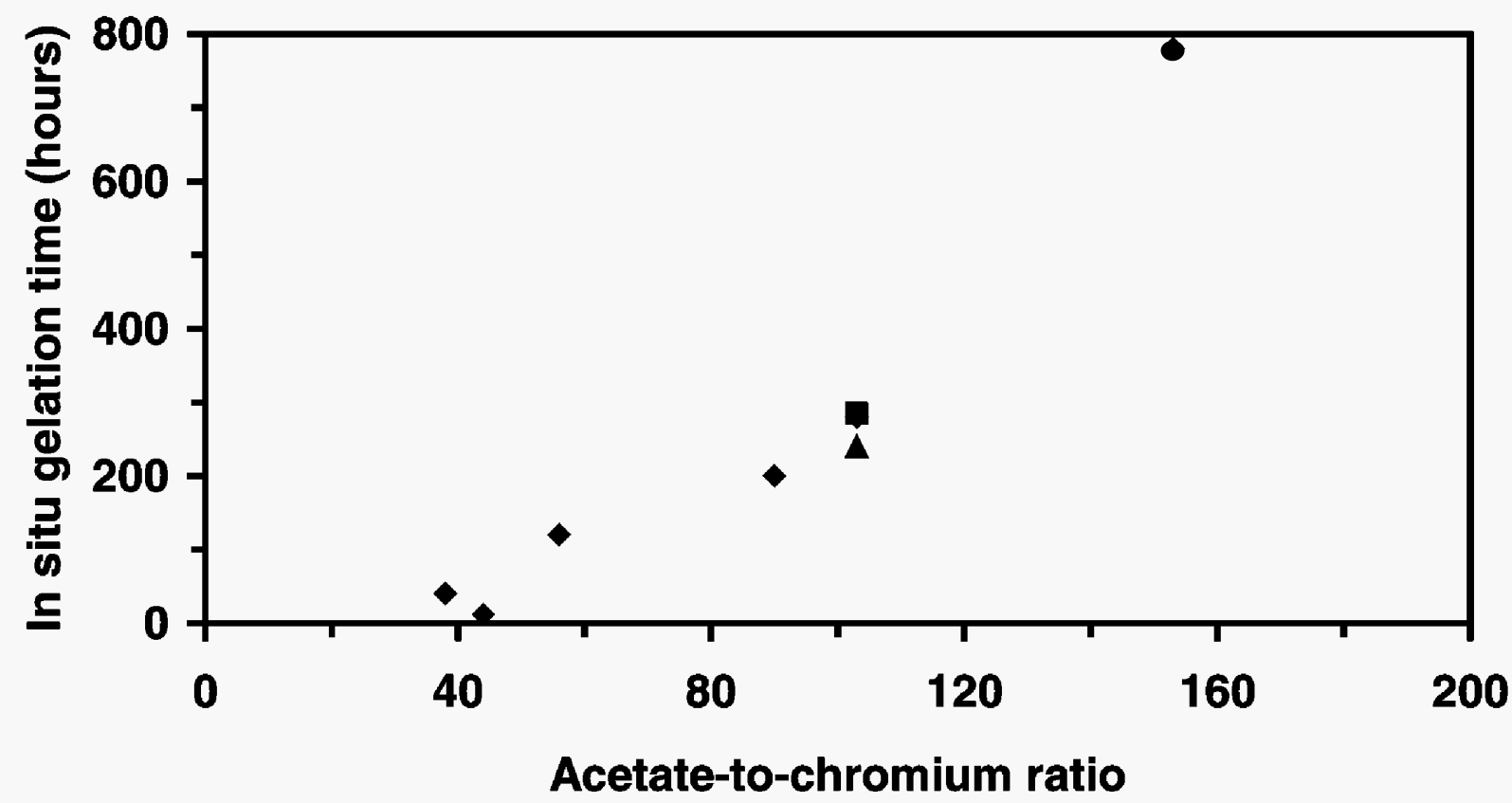

Figure 3.6 - Insitu gel time as a function of the acetate-to-chromium ratio in the gelant.

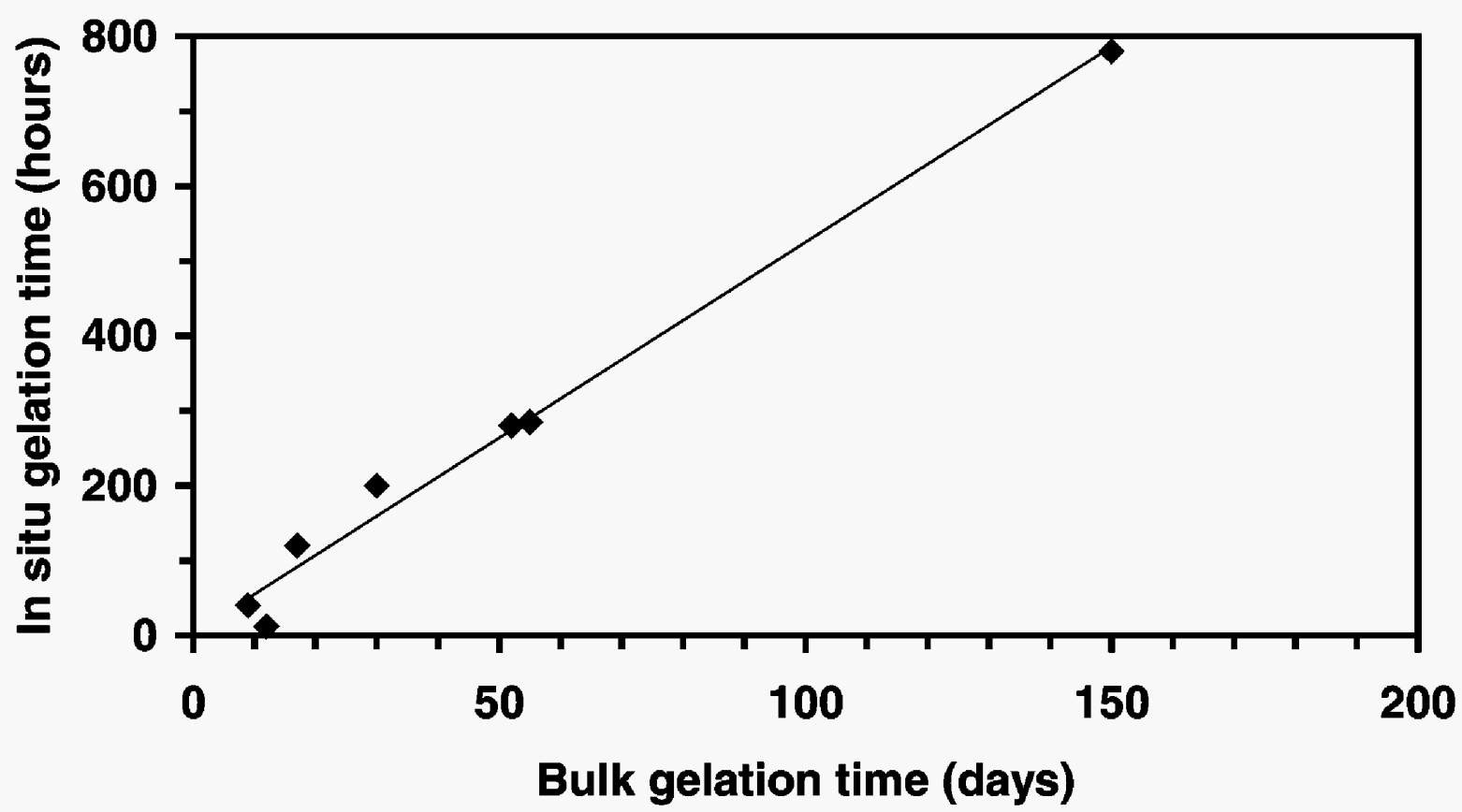

Figure 3.7 - Relationship of the insitu gel time and the bulk gel time. 


\section{References}

1. Burrafato, G. and Lockhart, T.P., "A New, Mild Chemical Method for the Degelation of Cr -Polyacrylamide Gels," Society of Petroleum Engineers paper No. 19354 (submitted May 1989).

2. Burrafato, G. Albonico, P., Bucci, S. and Lockhart, T.P., "Ligand -Exchange Chemistry of Cr+3-Polyacrylamide Gels," Makromolec. Chem.,Macromol, Symposium, 39 (1990) 137-141.

3. Green, D.W., Willhite,G. P., McCool, C. S. and McGuire, M., "Improving Reservior Conformance Using Gelled Polymer Systems," Annual report for the period September 251992 to September 24 1993, DOE contract No. DE-AC22-92BC14881, Report No. DOE/BC/14881-5, Chapter 5, The University of Kansas.

4. Willhite, G.P., Green, D.W. and McCool, "Increased Oil Recovery from Mature Oil Fields using Gelled Polymer Treatments," Annual report fo the period June 16, 1999 to June 15, 200, DOE contract No. DE-AC26-99BC15209, Report No. DOE/BC/15209-2, The University of Kansas.

5. Natarajan, D., McCool, C.S., Green, D.W. and Willhite, G.P., "Control of In-Situ Gelation Time for HPAAM-Chromium Acetate Systems," paper SPE 39696 presented at the 1998 SPE/DOE Improved Oil Recovery Symposium, Tulsa, OK (19-22 April).

6. Sydansk, R.D.and Argabright, P.A., "Conformance Improvement in a Subterranean Hydrocarbon - Bearing Formation using a Polymer Gel,” U.S Patent 4,683,949 (Aug. 4, 1987).

7. Sydansk, R. D., "A Newly Developed Chromium(III) Gel Technology," SPERE, (August 1990) 346-352.

8. Sydansk, R. D., " $\mathrm{pH}$ Dependent Process for Retarding the Gelation rate of a Polymer Gel Utilized to Reduce Permeability in or Near a Subterranean Hydrocarbon-Bearing Formation," U.S. Patent 5,609,208 (March. 11, 1997).

9. Tackett, J.E., "Characterization of Chromium(III) Acetate in Aqueous Solution," Applied Spectroscopy, 43 (1989) 490-499. 



\title{
Chapter 4
}

\section{Study of Water and Oil Flow in Gel-Treated Berea Sandstone}

\author{
Post-Doctoral Researcher: Somenath Ganguly
}

\section{Introduction}

Water produced with oil during waterflooding is a source of perennial problems for the petroleum industry. Each additional barrel of produced water adds to the cost of (a) lifting fluids in a production well, (b) separation of oil and water, (c) protection against corrosion in tubing, and (d) disposal of water. Economic and environmental interests drive development of techniques that can reduce production of water without affecting production of oil significantly.

The treatment of a production well with a gelled polymer system is a remedial measure practiced for reducing the permeability of the formation to water. Several polymers and gels, when injected into porous rock, have demonstrated the ability to lower the permeability to water more than to oil. This phenomenon, termed disproportionate permeability reduction (DPR), is potentially beneficial for water shut-off treatments in production wells when hydrocarbonproductive zones cannot be protected during gel placement.

Permeability to water and oil after gel treatment has been a subject of investigation for almost two decades as indicated by the papers and reports listed in the Reference section at the end of this chapter. Experiments have been conducted in Berea sandstone slabs, sandpacks, micromodels and capillary tubes. The research efforts have been directed primarily at determining the mechanism(s) leading to disproportionate permeability reduction. Mechanisms that have been proposed and investigated include:

- gravity effect [Liang et al., 1995] : density difference between oil and gel particles leading to settling of gel particles in places other than pore throats.

- lubrication effect [Zaitoun and Kohler, 1988]: adsorbed polymer layer acting as a lubricant to the oil that flows through the center.

- gel shrinking and swelling [Liang et al., 1995]: shrinkage of gel in oil creating more open pathways.

- wettability effect / wall effect [Liang et al., 1995; Zaitoun and Bertin, 1998]: gel plugging the pore space near the wall that was otherwise used by water.

- capillary force [Liang et al., 1995]: capillary force acting to open the gel for oil (and not for water).

- segregated pathways [Liang et al., 1995; Nilsson et al., 1998]: water based gel flowing through and plugging pathways for water to a greater degree than for oil.

- dehydration/new pore space [Willhite et al., 2000]: the gel is dehydrated by the injection of oil which creates flow channels through the gel.

No consensus has been established for a single mechanism. There are proponents for the wettability/wall effect and segregated pathways in the literature. 
The objective of this investigation was to study the flow of oil and brine in gel-treated Berea sandstone. A chromium acetate-polyacrylamide (Alcoflood 935) gelant was placed in Berea sandstone slabs at residual oil saturation. After a shut-in period, flows of oil and brine were established in succession from the side of the slab opposite from which the gelant was placed. Gel treatment and post treatment floods were conducted in opposite directions to simulate a production well scenario. Saturation profiles in the slabs at different stages of the experiments were determined using a microwave apparatus. In addition to saturation, tracer responses, pressure gradients and flow rates provided further insight into the flow of brine and oil through gel treated rock. Effective endpoint permeabilities to brine and oil after gel treatment were determined.

\section{Experimental Details}

Two series of flow tests were conducted in two Berea sandstone slabs ( 6 in $\times 6$ in $\times 1$ in). The slabs were coated with epoxy and inlet/outlet endcaps were installed to provide flow to/from the entire face of the end of the slab as shown in Figure 4.1. Two pressure ports divided the slabs into three sections along the direction of flow. Section numbers and the flow direction for gelant and pre- and post-treatment oil/brine floods are shown in Figure 4.1 Both slabs had a porosity of 0.188 (pore volume of $110 \mathrm{~mL}$ ) and an absolute permeability of $560 \mathrm{md}$. The water and oil used in the flow tests were $1.0 \% \mathrm{NaCl}$ brine and normal dodecane.

A microwave scanning system was used to determine water saturation in the slab as shown in Figure 4.2. A 24-GHz microwave beam was directed through the slab. A power meter placed under the slab measured the energy that was transmitted through the slab. The beam is focused on 1.25-inch diameter cylinder through the slab. Water absorbs microwave energy to a significant extent and oil, rock and the epoxy coating are relatively transparent to the microwave beam. Gel is composed mostly of water and absorbs energy to the same extent as water. The local water saturation in the slab was obtained from a calibration of the microwave power that was transmitted through the slab.

The microwave source and detector were mounted on a single frame attached to a trolley. This allowed the device to scan across the face of the slab in two directions providing a planar saturation map. Microwave scanning was performed where the center of the beam covered an area of $3 \times 3.5$ inches in the center of the slab's $6 \times 6$ inch face. Areas along the border of the slab were omitted to avoid edge effects. Measurements were taken at half-inch intervals in both directions. The scanned area covered $55 \%$ of the slab's face.

Scans of the slab when it was dry and when it was $100 \%$ water-saturated were used for calibration. The water saturation at each $\mathrm{x}-\mathrm{y}$ position was determined by the following equation using power measurements in dbm units.

$$
\text { Water Saturation }=\frac{\text { Measured Power }- \text { Power } \cdot \text { from } \cdot \text { dry } \cdot \text { slab }}{\text { Power } \cdot \text { at } \cdot 100 \% \cdot \text { brine } \cdot \text { saturation }- \text { Power } \cdot \text { from } \cdot \text { dry } \cdot \text { slab }}
$$

The average water saturations were also determined by material balance. The volume of the noninjected phase that was produced in the effluent was collected and measured. This volume was 


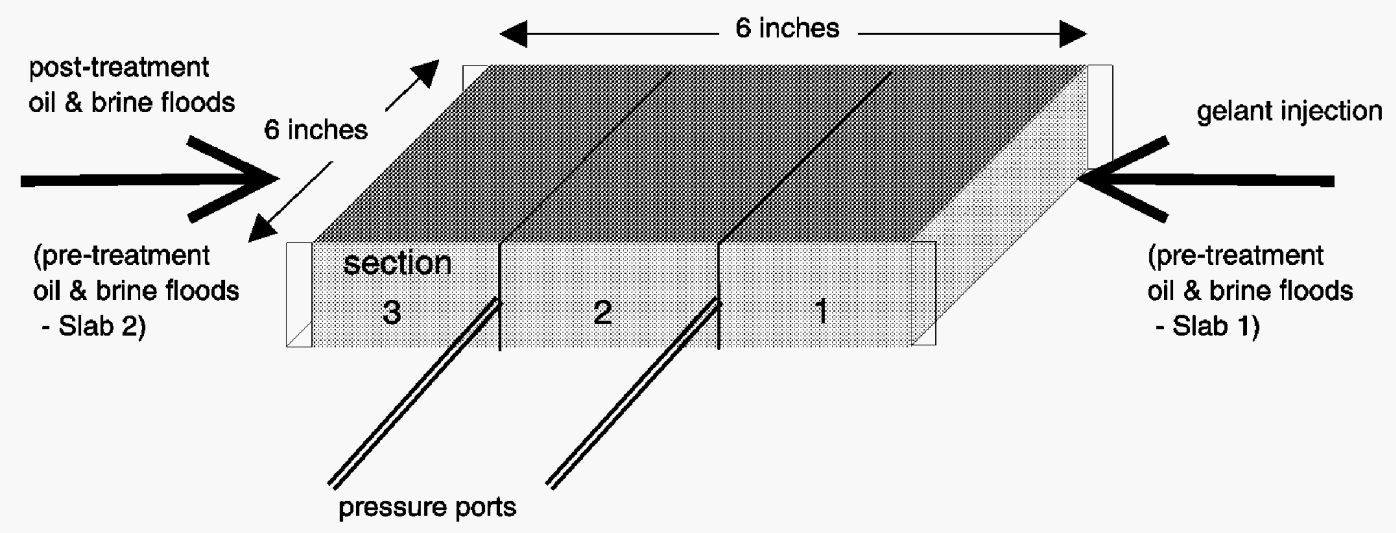

Figure 4.1 - Schematic description of the slabs and flow directions.

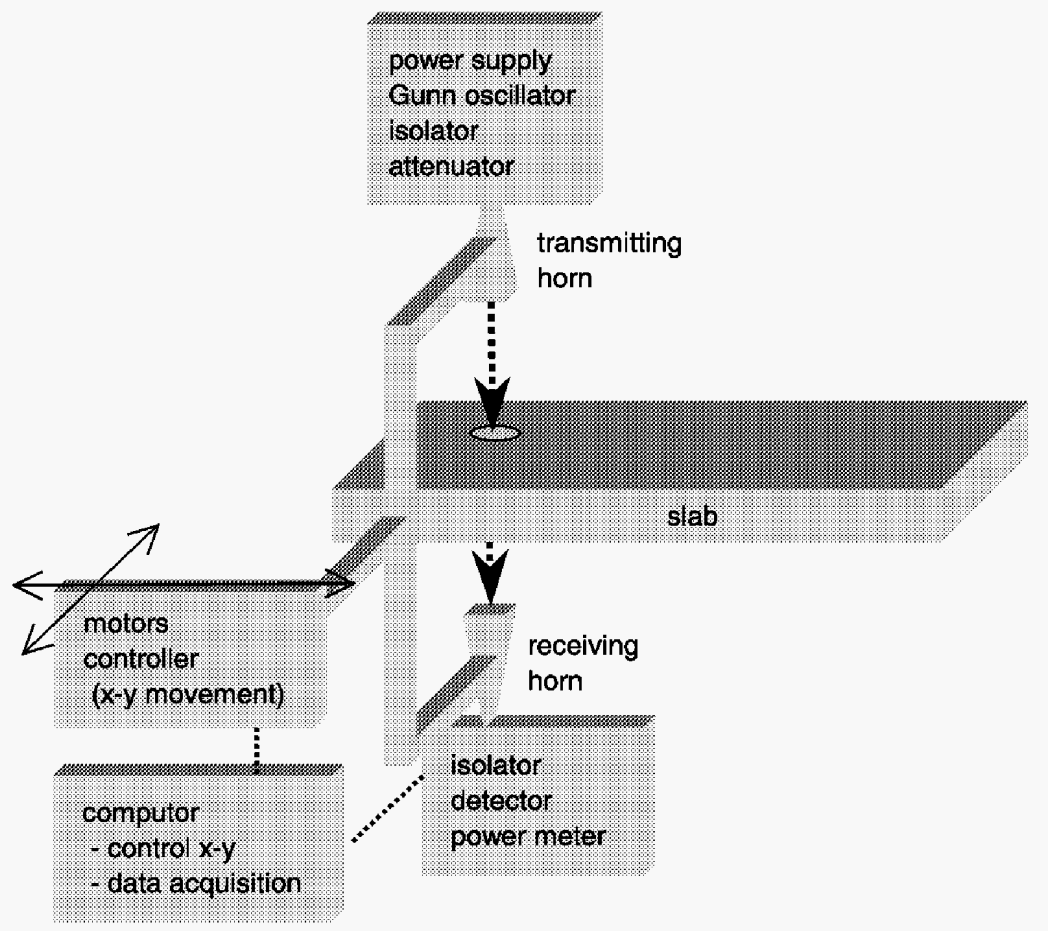

Figure 4.2 - Schematic description of equipment used for microwave scanning of slabs. 
assumed to be equal to the volume decrease of the non-injected phase and equal to the volume increase of the injected phase. For example, the volume of oil that is displaced from the slab during a brine flood is subtracted from the initial oil volume and is added to the aqueous volume. The volumes are then expressed as saturations by dividing by the pore volume.

The sequence of experiments that was conducted on the slabs is given Table 4.1. The slabs were saturated with brine and the pore volume and the absolute permeability to brine were determined. Oil and brine floods were then conducted to determine the end-point relative permeabilities to these phases. Water and oil saturations at the endpoints were determined by the scanning microwave apparatus and by material balance. Prior to the placement of gelant, a buffer solution containing $0.864 \%$ sodium acetate, $0.23 \%$ acetic acid and $1.0 \%, \mathrm{NaCl}$ with a pH of 4.9 was injected through the slabs to adjust the $\mathrm{pH}$ of the resident brine.

\begin{tabular}{|ll|}
\hline Table 4.1 - Sequence of floods. \\
\hline Floods & Purpose or measurements \\
\hline Brine saturation & Pore volume \\
Brine flood & Absolute permeability \\
Oil flood & Relative permeability to oil, saturations \\
Brine flood & Relative permeability to water, saturations \\
Buffer injection & pH adjustment \\
Gelant injection & \\
Shut-in time & Allow for in situ gelation \\
Oil floods & Relative permeability to oil, saturations \\
Brine floods & Relative permeability to water, saturations \\
Oil floods & Relative permeability to oil, saturations \\
\hline
\end{tabular}

A Cr(III)-partially hydrolyzed polyacrylamide (Alcoflood 935) gelant was displaced through the slabs. The composition of the gelant was $0.52 \%$ sodium acetate, $0.5 \%$ Alcoflood 935 , and 450 ppm chromium tri acetate $(112.5 \mathrm{ppm} \mathrm{Cr}(\mathrm{III}))$. The gelant had a $\mathrm{pH}$ of 6.2 , a bottle gel time of $2 \frac{1}{2}$ days and an initial viscosity of $41 \mathrm{cp}$ at a shear rate of $11.25 \mathrm{sec}^{-1}$. The gelant was prepared and placed in a transfer cylinder. Oil was pumped into the cylinder or air pressure was used to displace the gelant through the slabs.

Flow of oil and brine through the slab after the shut-in period was accomplished using a constant pressure air source. Air drove brine or oil from a transfer cylinder into the slab in a direction opposite to the direction at which the gelant had been injected. Pressure gradients across the three sections of the slab were recorded. Effluent fractions were collected with an automated collector. Volumes of oil and aqueous phase in the effluent fractions were measured. The oil and brine floods were conducted at a series of injection pressures.

The sequence of post gelation flow for Slab 1 was as follows. After the shut-in period, flow was first established by injecting oil at constant pressure of $50 \mathrm{psig}$. Once a steady flow rate was established, the injection pressure was increased to 80 psig in steps of 10 psi. Next the injection 
pressure was decreased in 20 psi steps. Again, the pressure was increased to 80 psig in 20 psi steps. Flow was then switched to brine using the same sequence of injection pressures that was used for oil. A second oil flood cycle was then conducted.

A tracer was injected during a couple of the oil floods. Oil tagged with stilbene was injected and the effluent fractions were collected. The stilbene concentration in the effluent was determined by a spectrophotometer at a wavelength of $296 \mathrm{~nm}$.

\section{Results \& Discussion}

The results from runs conducted using Slab 1 are presented in detail. Similar runs were conducted using Slab 2 and similar results were obtained. A summarized version of the results for the runs on Slab 2 is presented including a description of the differences in the experiments and results with respect to Slab 1.

\section{Pre-Treatment Floods.}

The slab was saturated with brine followed by oil and brine floods that left the slabs at residual oil saturation. Average saturations of oil and water and the permeabilities at the end of the floods (endpoint permeabilities) are listed in Table 4.2. Saturations and one set of volumes of displaced fluids that are listed in the table were determined by microwave measurements that were averaged over the scanned area. The volumes of fluid that were expelled from the slab during the pre-treatment oil and brine floods were not measured precisely and deviate from the values calculated from the microwave measurements. Planar water saturations as determined by the microwave apparatus are described later.

\begin{tabular}{|c|c|c|c|c|c|c|c|}
\hline \multirow[b]{3}{*}{$\begin{array}{l}\text { Pre-treatment } \\
\text { Brine flood } 1\end{array}$} & \multicolumn{4}{|c|}{ Determined from $\mu$-wave scan } & \multicolumn{2}{|c|}{ Effluent measurements } & \multirow[b]{2}{*}{$\begin{array}{l}\text { Average } \\
\text { permeability } \\
\text { (md) }\end{array}$} \\
\hline & $\begin{array}{l}\text { Brine (+gel) } \\
\text { saturation }\end{array}$ & $\begin{array}{c}\text { Oil } \\
\text { saturation }\end{array}$ & $\begin{array}{c}\text { Volume of } \\
\text { brine } \\
\text { displaced } \\
\text { (mL) }\end{array}$ & $\begin{array}{c}\text { Volume of } \\
\text { oil } \\
\text { displaced } \\
(\mathrm{mL})\end{array}$ & $\begin{array}{c}\text { Volume of } \\
\text { brine } \\
\text { displaced } \\
\text { (mL) }\end{array}$ & $\begin{array}{c}\text { Volume of } \\
\text { oil } \\
\text { displaced } \\
\text { (mL) }\end{array}$ & \\
\hline & 1.00 & 0.00 & - & - & - & - & 556 \\
\hline $\begin{array}{l}\text { Pre-treatment } \\
\text { Oil flood }\end{array}$ & 0.42 & 0.58 & 64 & - & -66 & - & 265 \\
\hline $\begin{array}{l}\text { Pre-treatment } \\
\text { Brine flood } 2\end{array}$ & 0.72 & 0.28 & - & 33 & - & $\sim 30$ & 51 \\
\hline $\begin{array}{l}\text { Gelant } \\
\text { injection }\end{array}$ & 0.75 & 0.25 & - & 3.3 & - & 2.5 & - \\
\hline $\begin{array}{l}\text { Post-treatment } \\
\text { Oil flood } 1\end{array}$ & 0.61 & 0.39 & 15.4 & - & 16 & - & $10-26$ \\
\hline $\begin{array}{l}\text { Post-treatment } \\
\text { Brine flood }\end{array}$ & 0.81 & 0.19 & - & 22 & - & 19 & $2.6-3.2$ \\
\hline $\begin{array}{l}\text { Post-treatment } \\
\text { Oil flood } 2\end{array}$ & 0.60 & 0.40 & 23.1 & - & 20 & - & $11-22$ \\
\hline
\end{tabular}


Buffer solution was injected into Slab 1 three hours prior to gelant injection to adjust the $\mathrm{pH}$ of the resident brine. Effluent collected during the injection of the buffer solutions turned yellowish after some time indicating the removal of iron from the rock.

\section{Gelant Injection.}

About six pore volumes of bulk-mixed gelant were injected into Slab 1. The flow rate of the gelant was reduced with time to maintain the injection pressure at or below $50 \mathrm{psig}$. The gelant was injected for 36 hours. The effluent $\mathrm{pH}$ remained at 6.5 for most of the displacement (for the first five pore volumes injected) and reached 7.5 at the end of the run when flow rate was low. Two-and-a-half $\mathrm{mL}$ ( 0.023 saturation change) of oil were displaced from the slab during the early part of gelant injection. Effluent samples collected after about one pore volume of gelant was injected gelled at a time equal to the bulk gel time ( $21 / 2$ days) except the last quarter pore volume that required a longer time ( $\sim$ two weeks) to gel. The slab was shut-in for nine days after gel placement.

\section{Post-Treatment Oil and Brine Floods.}

After the gel treatment and a shut-in period, injections of oil and brine were conducted in Slab 1 at selected injection pressures. Injected fluid volumes were determined by measurement of the produced oil and aqueous volumes. The injection pressure of the floods and the average water saturation as a function of the cumulative volume injected are shown in Figure 4.3 for Slab 1. Injection pressures varied between 20 to 80 psig at 10-psi intervals during the flow of oil and brine. Water saturations were determined by the microwave apparatus and by material balance on the collected effluent volumes. The material balance calculations were performed starting with the water saturation that was determined by the microwave measurement at the end of gelant injection. This was done because the effluent volumes for the pre-treatment floods were less reliable. Differences between the saturations determined by the two methods shown in Figure 4.3 were attributed to errors in measuring the small volumes of the displaced phase and summing these volumes for numerous effluent fractions, and to the reduced area of the slab over which the microwave data were collected.

Oil was injected first at an injection pressure of $50 \mathrm{psig}$. The injection of oil was performed over a period of three days (for a few hours each day) in Slab 1. Oil injected in the first post-gelation oil flood created flow pathways through the slab by dehydrating the gel. Brine containing some polymer that was dehydrated from the gel and possibly some residual oil were displaced from the slabs. The average water saturation decreased by 14 percent and was decreasing slowly at the end of the first oil flood when more than 16 pore volumes of oil had been injected. During the post-gelation brine flood and second oil flood, the average water saturation increased by 20 percent and decreased by 19 percent, respectively. These saturation changes are smaller than the 30 percent change in the saturation during the brine flood prior to gel placement. The gel occupies a portion of the pore space and thus reduces the volume of the new pore space for the flow of oil and brine.

The oil saturation after the post-treatment brine flood $\left(\mathrm{S}_{\mathrm{o}}=19 \%\right)$ was smaller than the oil saturation after the pre-treatment brine flood $\left(\mathrm{S}_{\mathrm{or}}=28 \%\right)$ which indicated the mobilization of the pre-treatment residual oil during the post-treatment floods. We suspect that the residual oil 


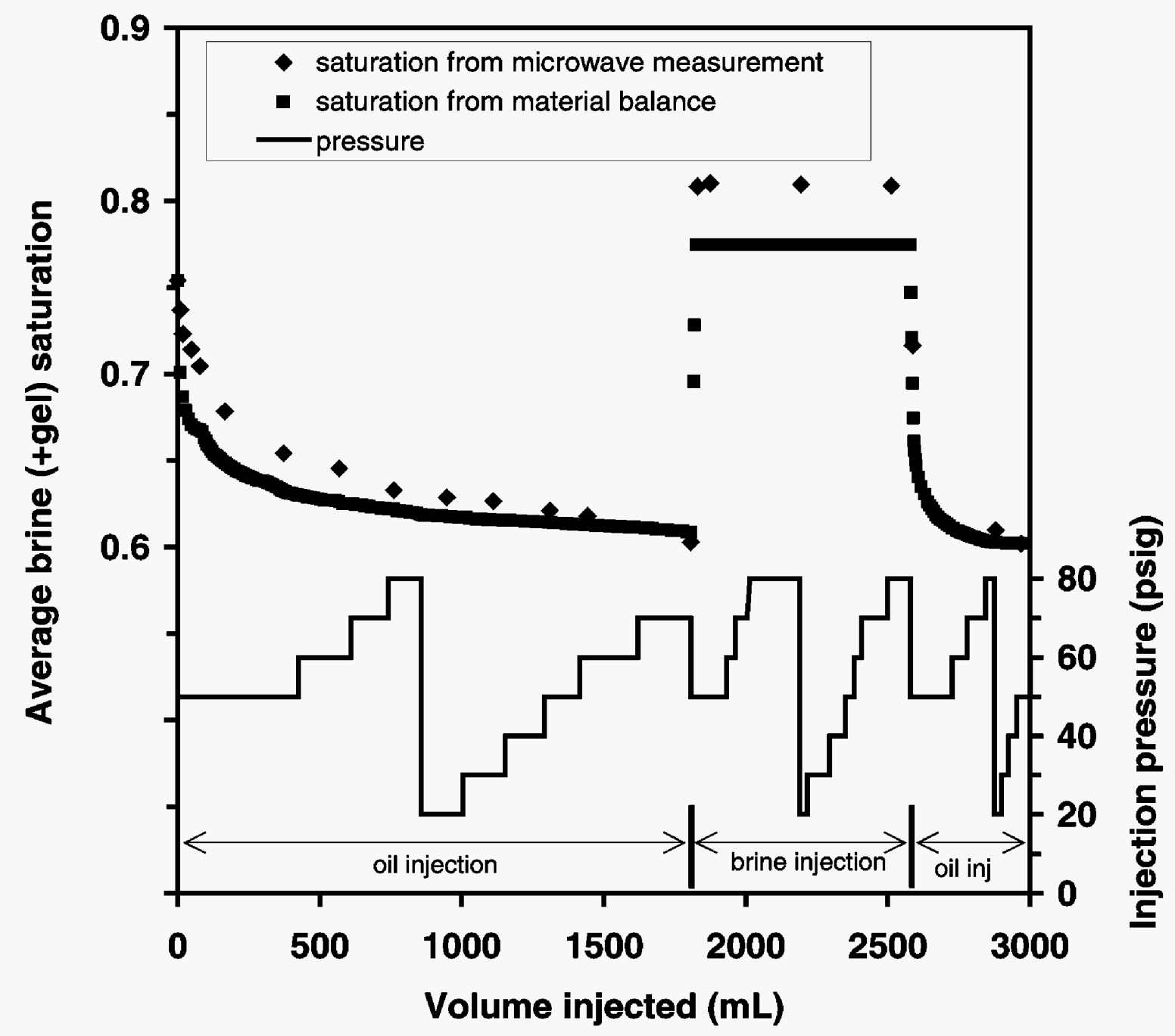

Figure 4.3 - Injection pressures and average saturations during post-treatment oil and brine floods in Slab 1.

saturation after the post-treatment brine flood is composed of the initial residual oil saturation that is encapsulated by gel and possibly some residual oil that remains in the created flow paths. The encapsulated oil is not in contact with the post-treatment flow paths that were created by the dehydration of the gel and the reconnection of the pre-treatment residual oil.

Saturation changes occurred at different rates during the initial portion of the post-treatment oil and brine floods when the injection pressure was 50 psig. This is shown in Figures 4.4 and 4.5 where the cumulative volumes of brine displaced from the core at the start of the two oil floods, 


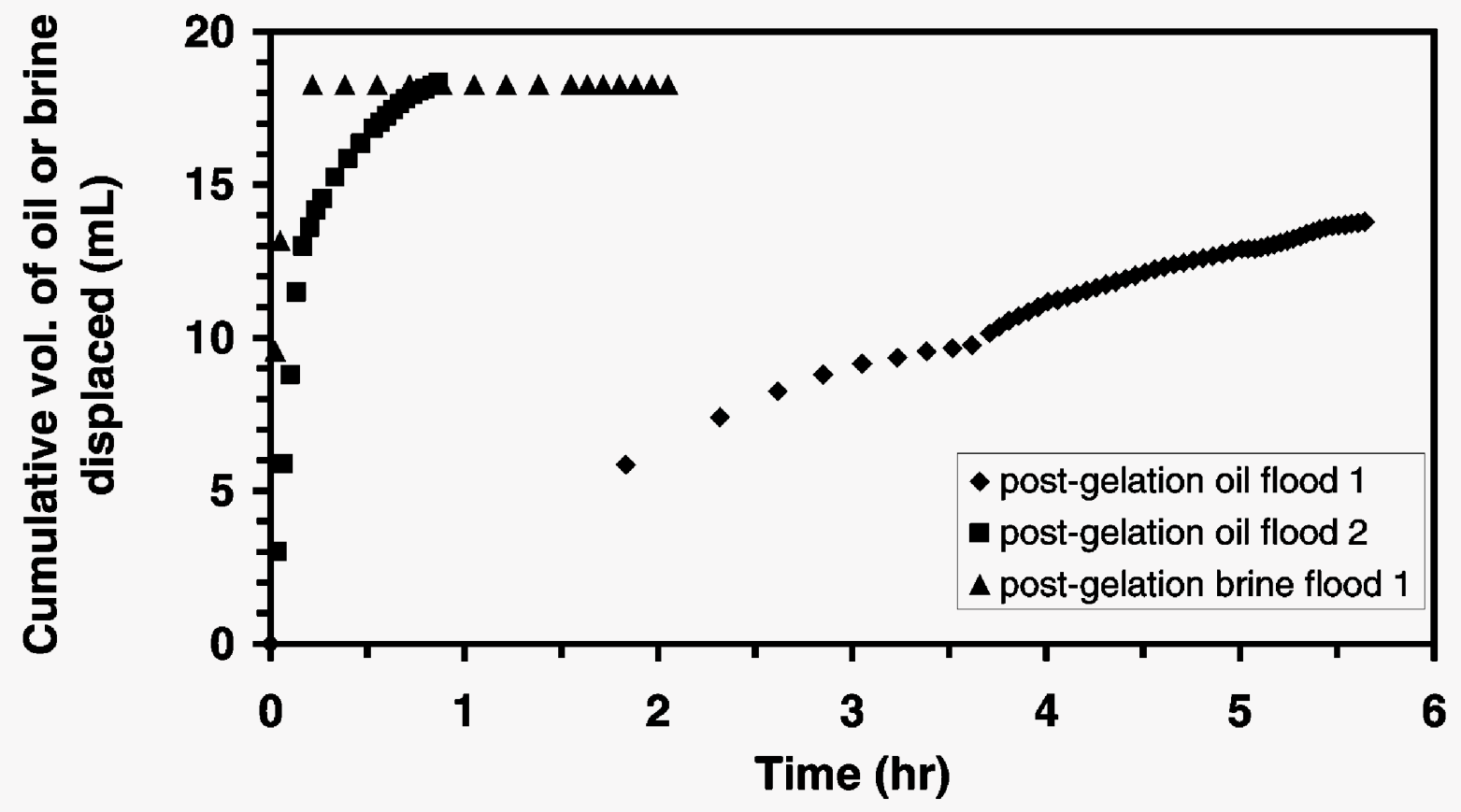

Figure 4.4 - Volumes of oil and brine displaced during post-treatment floods in Slab 1 as a function of time.

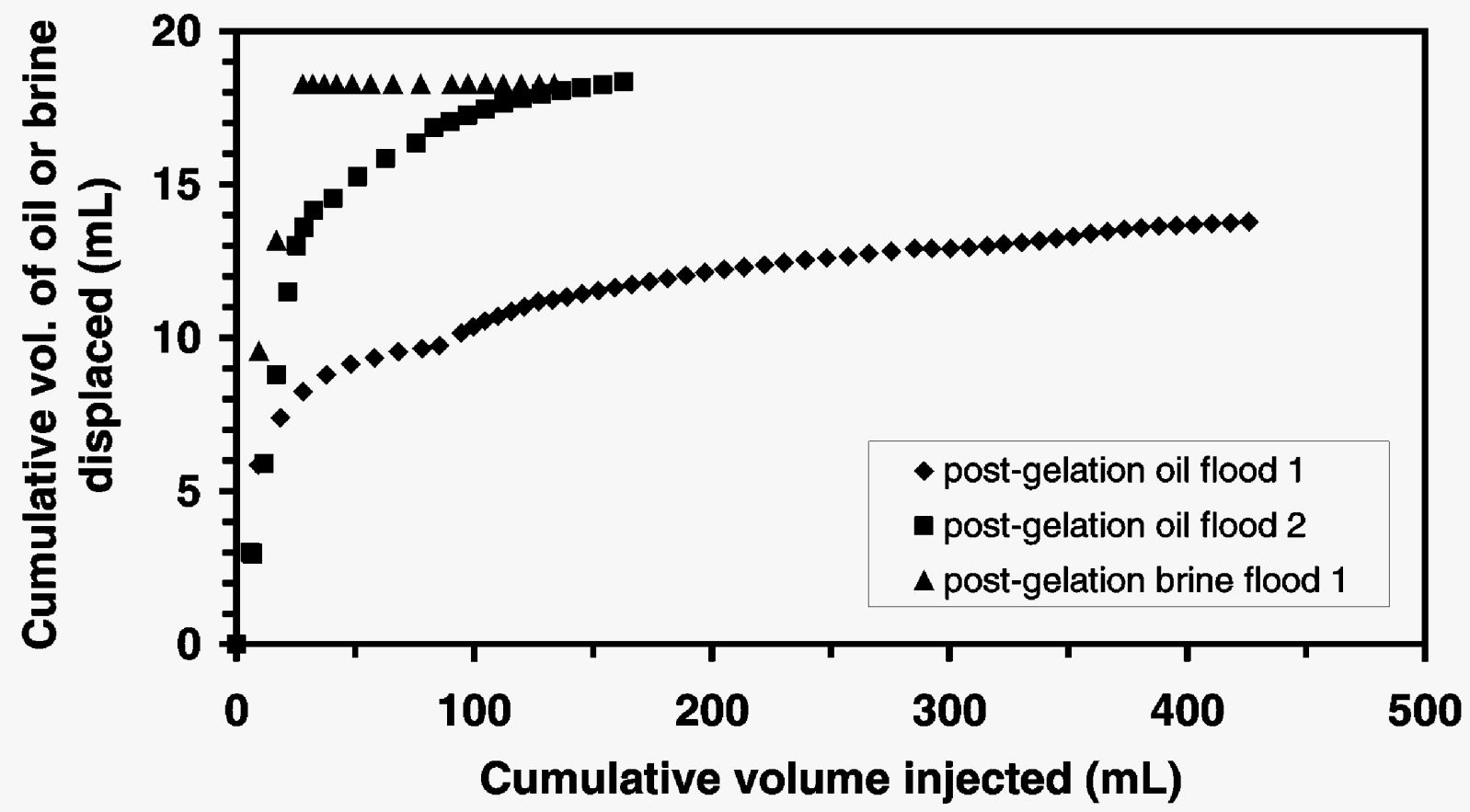

Figure 4.5 - Volumes of oil and brine displaced during post-treatment floods in Slab 1 as a function of volume injected. 
and the cumulative volume of oil displaced at the start of the brine flood, are plotted as a function of time and cumulative volume injected, respectively. Brine was displaced from the slab at a much slower rate during the first oil flood than during the second oil flood since flow channels through the gel were being developed during the first oil flood. Flow channels were all ready developed during the second oil flood as well as during the brine flood.

The viscosity of the first aqueous phase effluent sample collected during the first oil flood was $24 \mathrm{cp} @$ a shear rate of $11.25 / \mathrm{sec}$, indicating that some polymer was displaced from the slab. For comparison, the viscosity of freshly mixed gelant was $36 \mathrm{cp} @$ a shear rate of $11.25 / \mathrm{sec}$. Subsequent effluent fractions were not analyzed.

The saturation change during the brine flood occurred with much less injection volume than the saturation change during the second oil flood as shown in Figure 4.5. This type of displacement is indicative of a strongly water-wet system and is what would be expected in flow channels that are developed through a gel that is composed mostly of water and/or next to the Berea sandstone surface.

The overall (or average) permeabilities to oil and brine (based on the total length of the slab) were determined at each injection pressure and are shown in Figure 4.6. Arrows on the curves indicate the order the injection pressures that were applied. The permeabilites generally increase with injection pressure (or flow rate). A portion of this increase for the oil permeabilities might be caused by a small increase in the oil saturation with volume injected during the sequence of injection pressures (see Figure 4.3). However, the overall permeabilities decreased appreciably when the injection pressure was reduced from 80 psig to 20 psig with negligible saturation changes. The small change in the permeability to oil between the first and second oil floods indicated minor additional development of the flow channels after the initial segment of the first oil flood.

Permeabilities for the three sections of the slab during the oil and brine floods are shown in Figures 4.7, 4.8 and 4.9 as a function of the injection pressure. The data for the sections were similar to the data for the overall permeability (Figure 4.6) in that the permeablities generally increase with injection pressure and that the permeability values for the first and second oil floods were similar. However, the data do show that the permeabilities were lowest in Section 1 where the gelant was injected and that the permeabilities increased downstream from that section.

The listing of the residual resistance factors (RRFs) in Table 4.3 shows a comparison of the preand post-treatment permeability values. RRF is the factor by which the treatment reduced the permeability and is the ratio of the pre-treatment permeability to the post-treatment permeability. A range of values is given since the post-treatment permeability was a function of the injection pressure. Permeabilities to oil and brine in each section were reduced by similar factors (RRFs) and these factors decreased downstream from the end at which gelant was injected. No disproportionate permeability reduction was realized. (It is noted, and discussed later, that the pre-treatment oil permeability is probably low since the oil flood was conducted at conditions that did not drive the water saturation down to a steady value. A higher pre-treatment value for the oil permeability would result in larger RRFs for the oil.) 


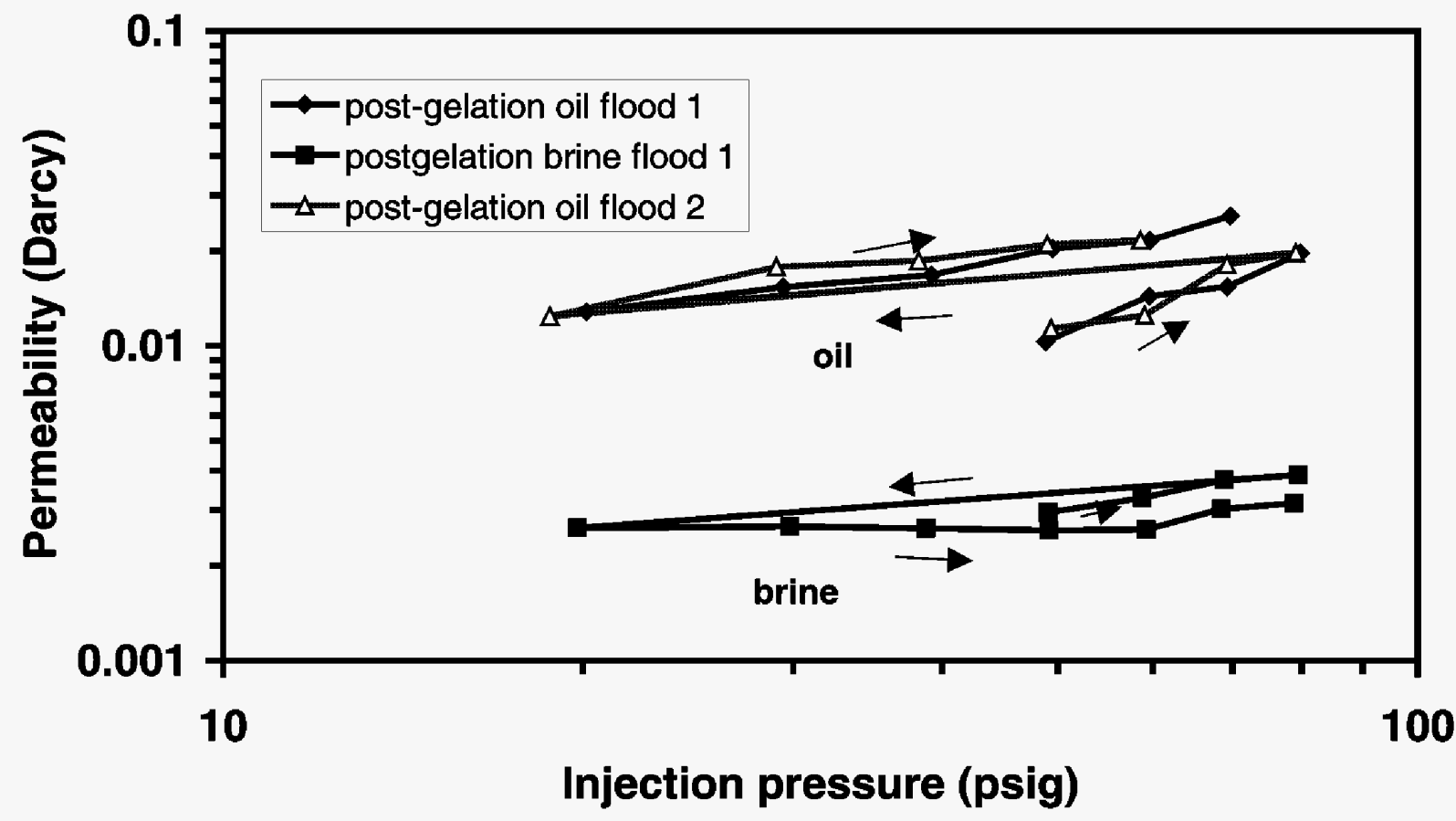

Figure 4.6 - Permeability of oil and brine at the end of the post-treatment floods in Slab 1.

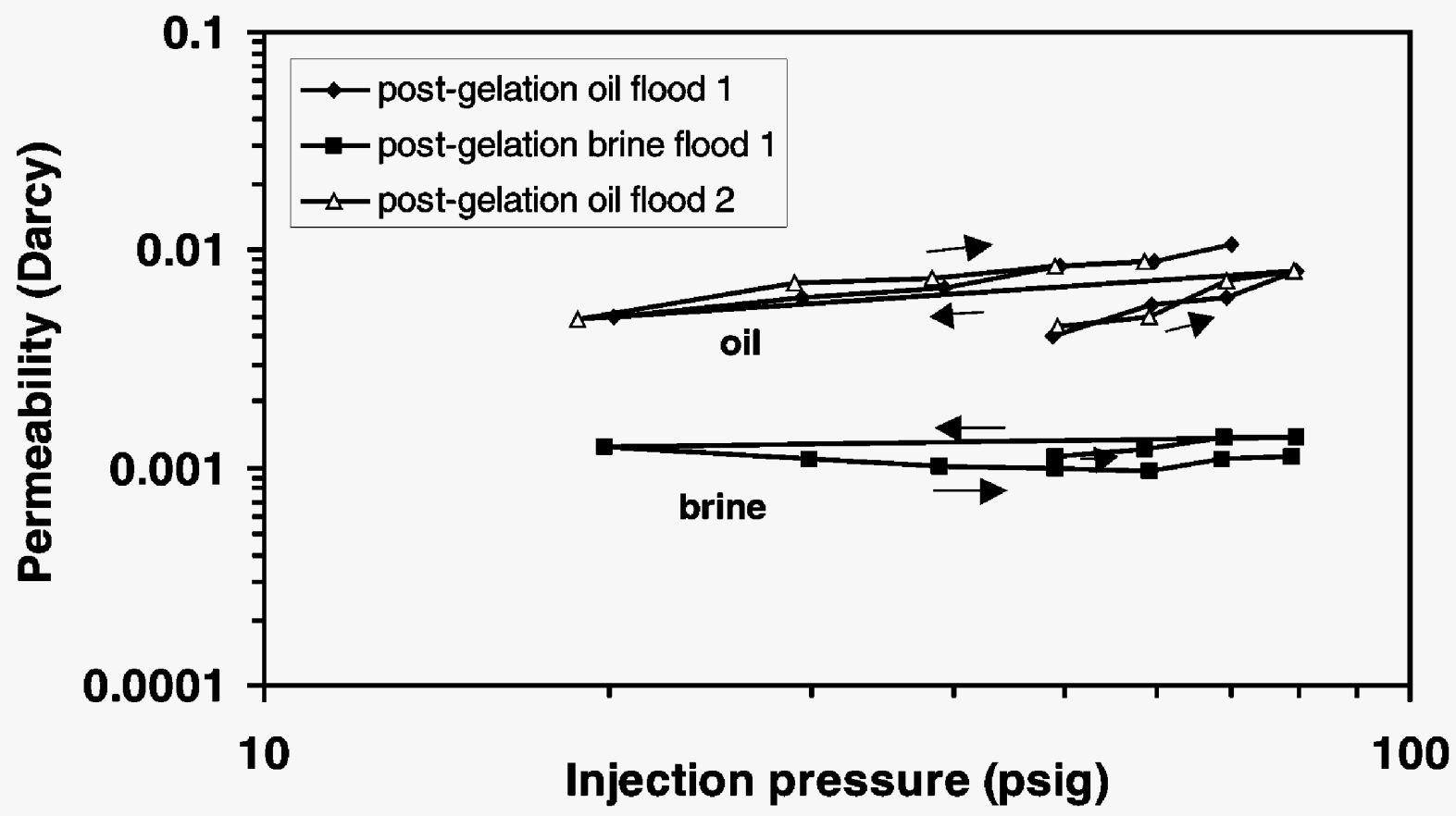

Figure 4.7 - Permeability of oil and brine at the end of the post-treatment floods in Section 1 of Slab 1. 


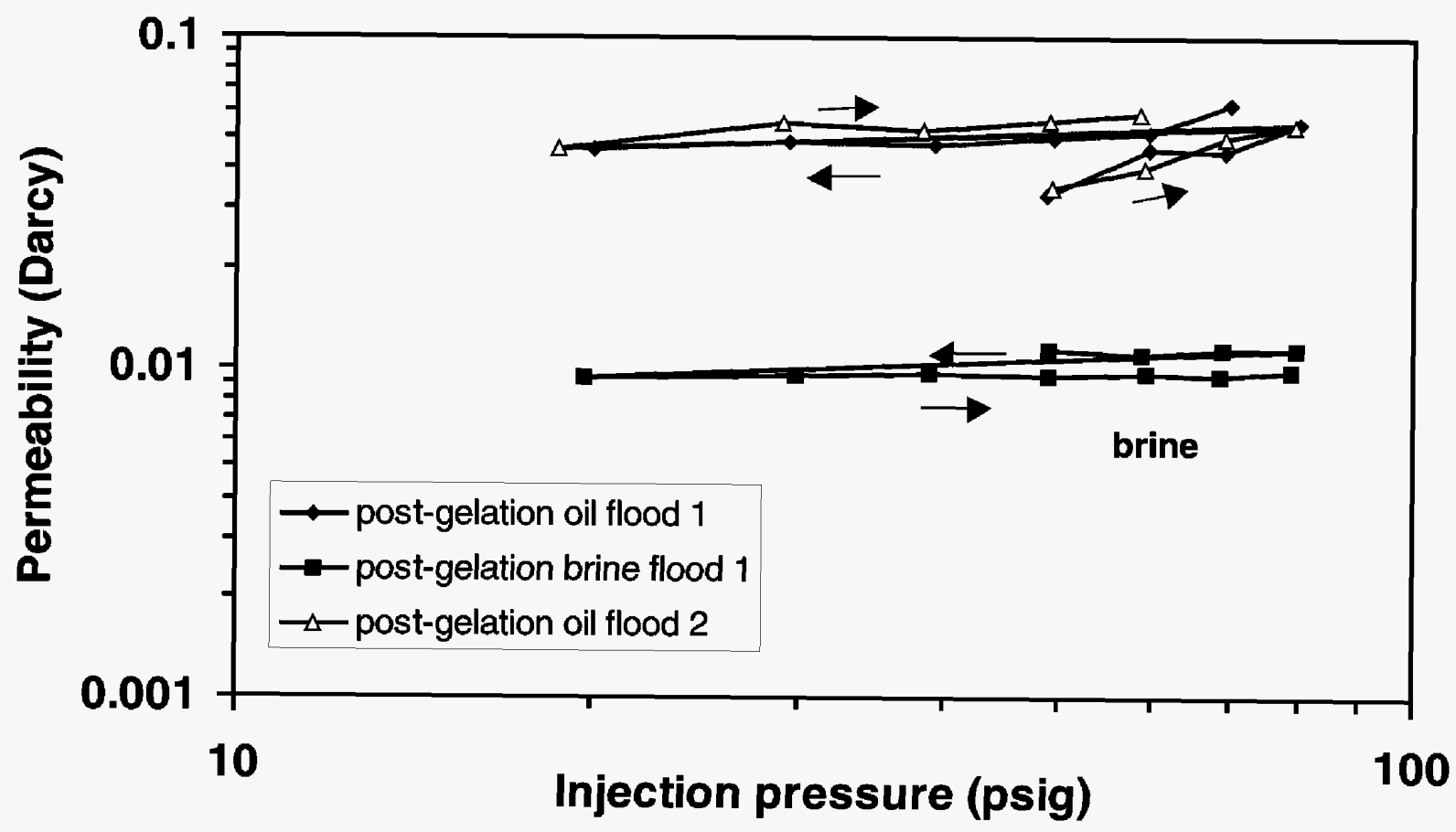

Figure 4.8 - Permeability of oil and brine at the end of the post-treatment floods in Section 2 of Slab 1.

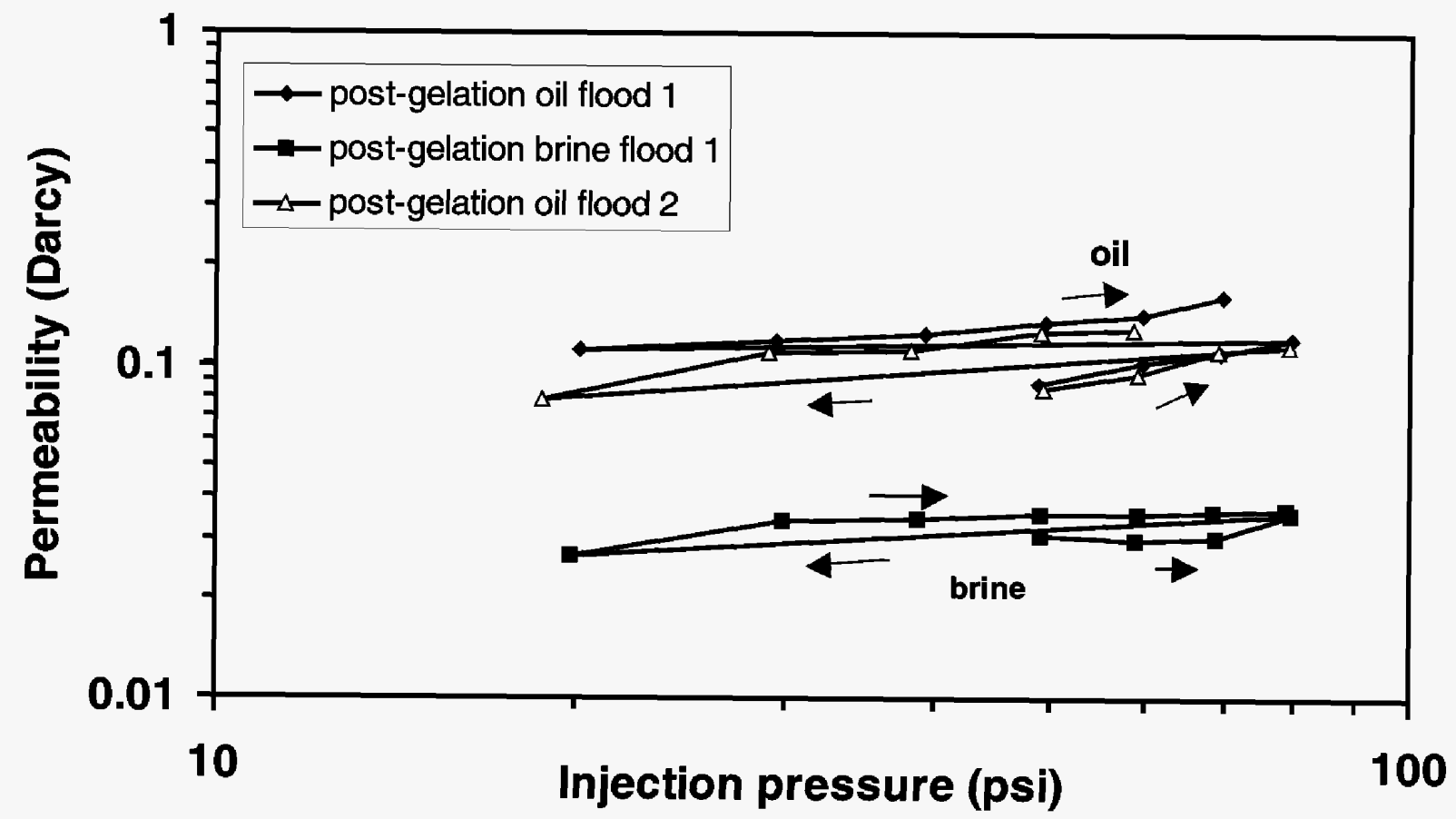

Figure 4.9 - Permeability of oil and brine at the end of the post-treatment floods in Section 3 of Slab 1. 
Table 4.3 - Residual resistance factors (RRFs) for sections and for the total length of Slab 1.

\begin{tabular}{|c|c|c|c|c|c|c|}
\hline & $\begin{array}{c}\text { Oil / Brine } \\
\rightarrow\end{array}$ & Section 3 & Section 2 & Section 1 & $\underset{\leftarrow}{\text { Gelant }}$ & Overall \\
\hline $\begin{array}{l}\text { Post-treatment } \\
\text { Oil flood } 1\end{array}$ & & $1.1-1.9$ & $5.1-11$ & $35-94$ & & $10-26$ \\
\hline $\begin{array}{l}\text { Post-treatment } \\
\text { Brine flood }\end{array}$ & & $1.5-2.1$ & $4.4-5.3$ & $34-53$ & & $13-20$ \\
\hline $\begin{array}{l}\text { Post-treatment } \\
\text { Oil flood } 2\end{array}$ & & $1.3-2.2$ & $5.5-9.2$ & $43-85$ & & $12-24$ \\
\hline
\end{tabular}

\section{Planar Water Saturation Maps}

Planar water saturation maps that were determined by the microwave apparatus at the end of the different floods in Slab 1 are presented in figures in the Appendix. Water saturations that were averaged over the scanned area at the end of each flood are listed in Table 4.2. It is useful to examine the saturation change that occurs during a flood. This is accomplished by subtracting the saturation at the start of a flood from the saturation at the end of a flood as shown in Figures 4.10 through 4.16. In these figures (and the figures in the Appendix), a 3-D surface plot is presented above a contour plot. The $x-y$ axes in both plots define the scanned area over the $6 \times 6-$ inch surface of the slab. The directions in which fluids were injected are indicated on the figures.

The change in water saturation that occurred during the pre-treatment brine flood 2 is shown in Figure 4.10. These data represent the fraction of the pore volume in which both oil and water occupy and/or flow. The lower values across the slab at the $y$ value of 3 inches indicates a heterogeneity in the slab and is observed in most of the microwave scans. The saturation surface drops down at the downstream end of the slab due to a high water saturation that occurred at that position at the end of the pre-treatment oil flood (See Figure 4.A1 in the Appendix) We suspect that the duration of the pre-treatment oil flood was not sufficient to drive the water saturation down at that position. At the end of the pre-treatment brine flood and prior to gelant injection, the water saturation was relatively uniform across the scanned area (see Figure 4.A2).

The average oil saturation decreased by $3 \%$ during the injection of gelant. Most of this oil was displaced from the end of the slab where gelant was injected as shown in Figure 4.11 which presents the saturation change as a result of gelant injection. The displaced oil traveled through the slab with the front of the gelant bank.

Saturation changes that occurred during each of the post-treatment oil and brine floods are shown in Figures 4.12 through 4.14. Larger saturation changes during the post-treatment floods occurred at the end of the slab where the oil and brine were injected and the smallest saturation changes occurred at the end of the slab where gelant was injected. This type of saturation change is also revealed in Figures 4.15 and 4.16. The difference between the saturations measured after 

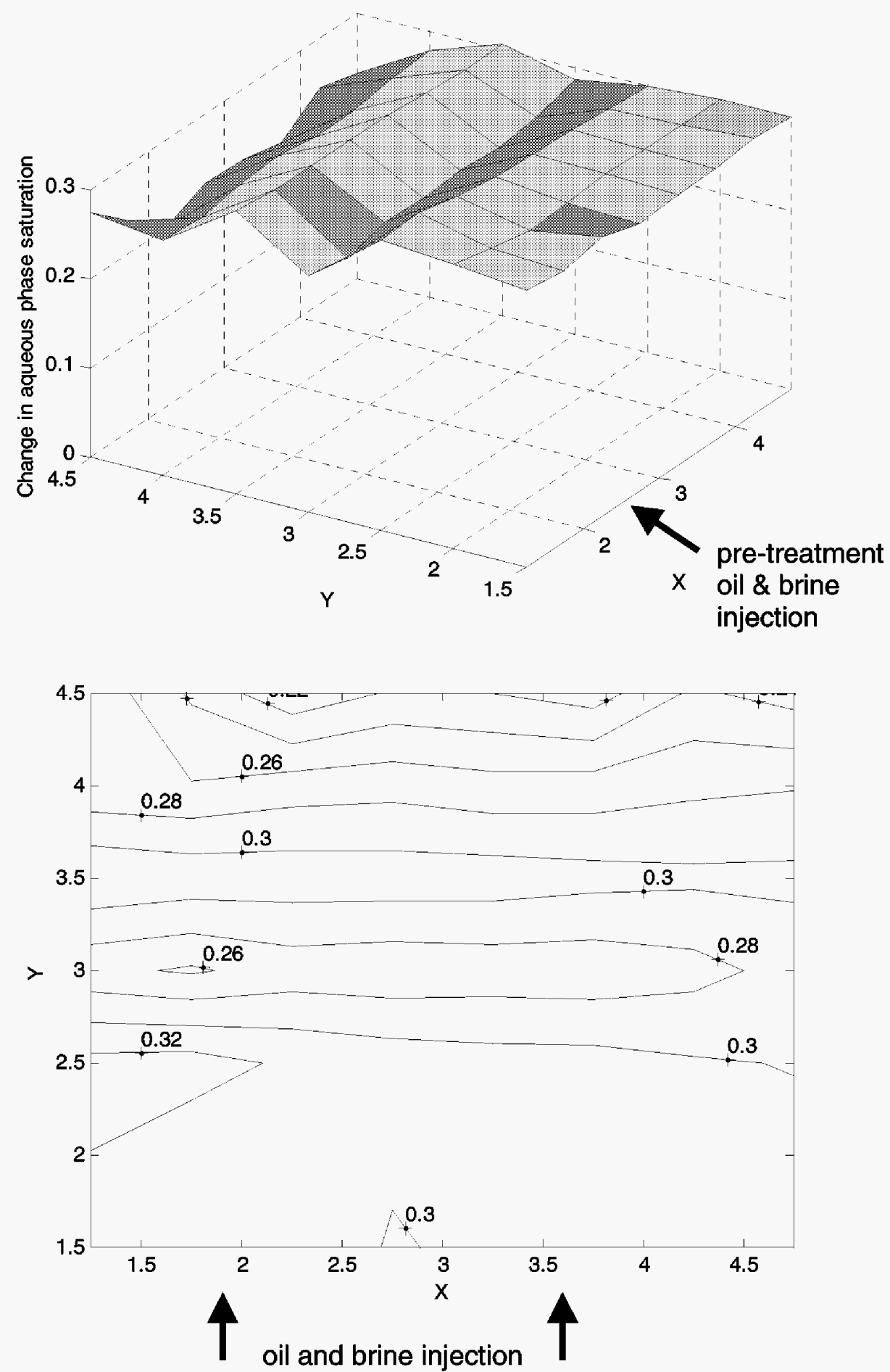

Figure 4.10 - Change in brine saturation during pre-treatment brine flood 2 in Slab 1. 

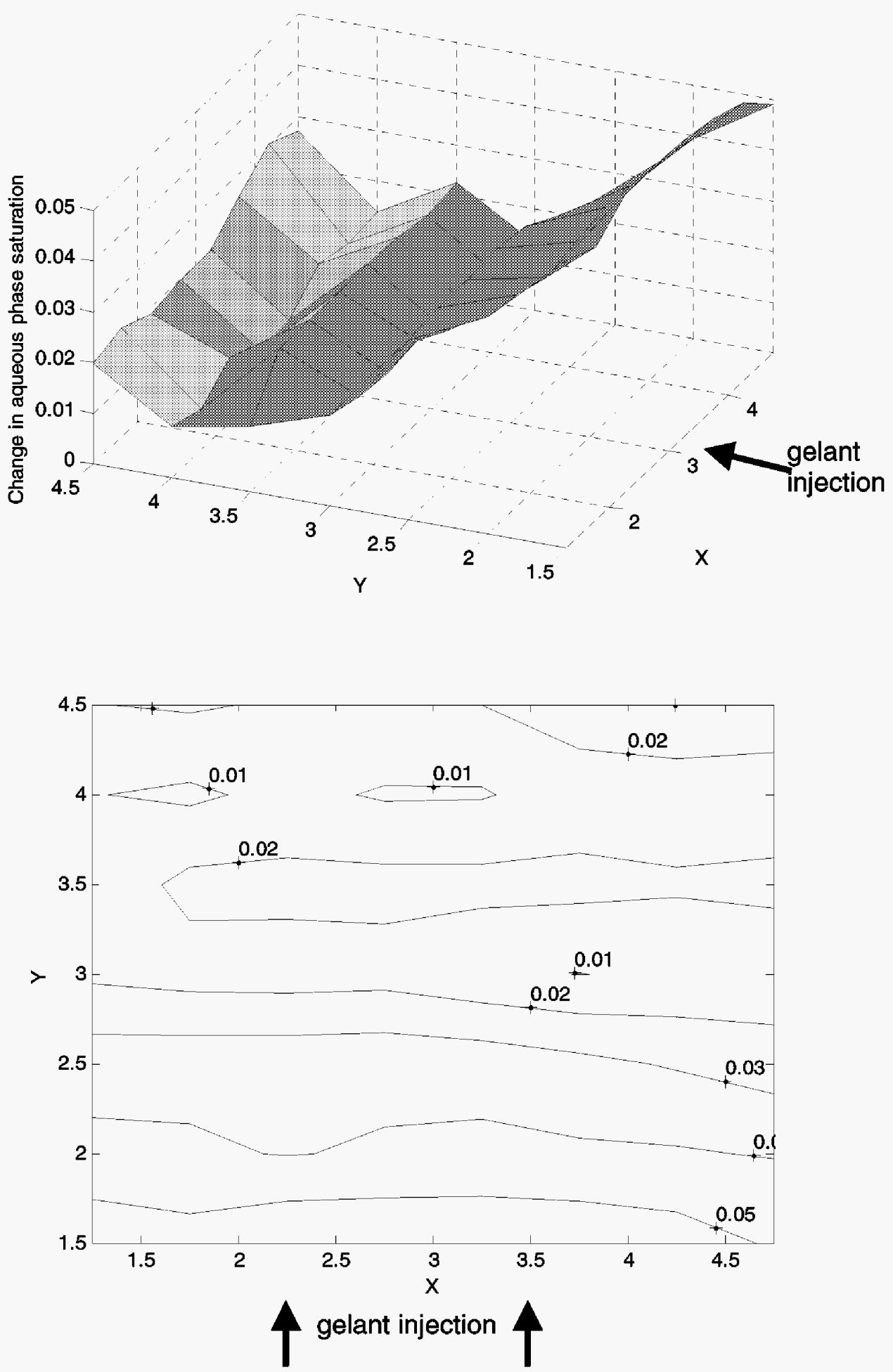

Figure 4.11 - Change in brine saturation during injection of gelant in Slab 1. 

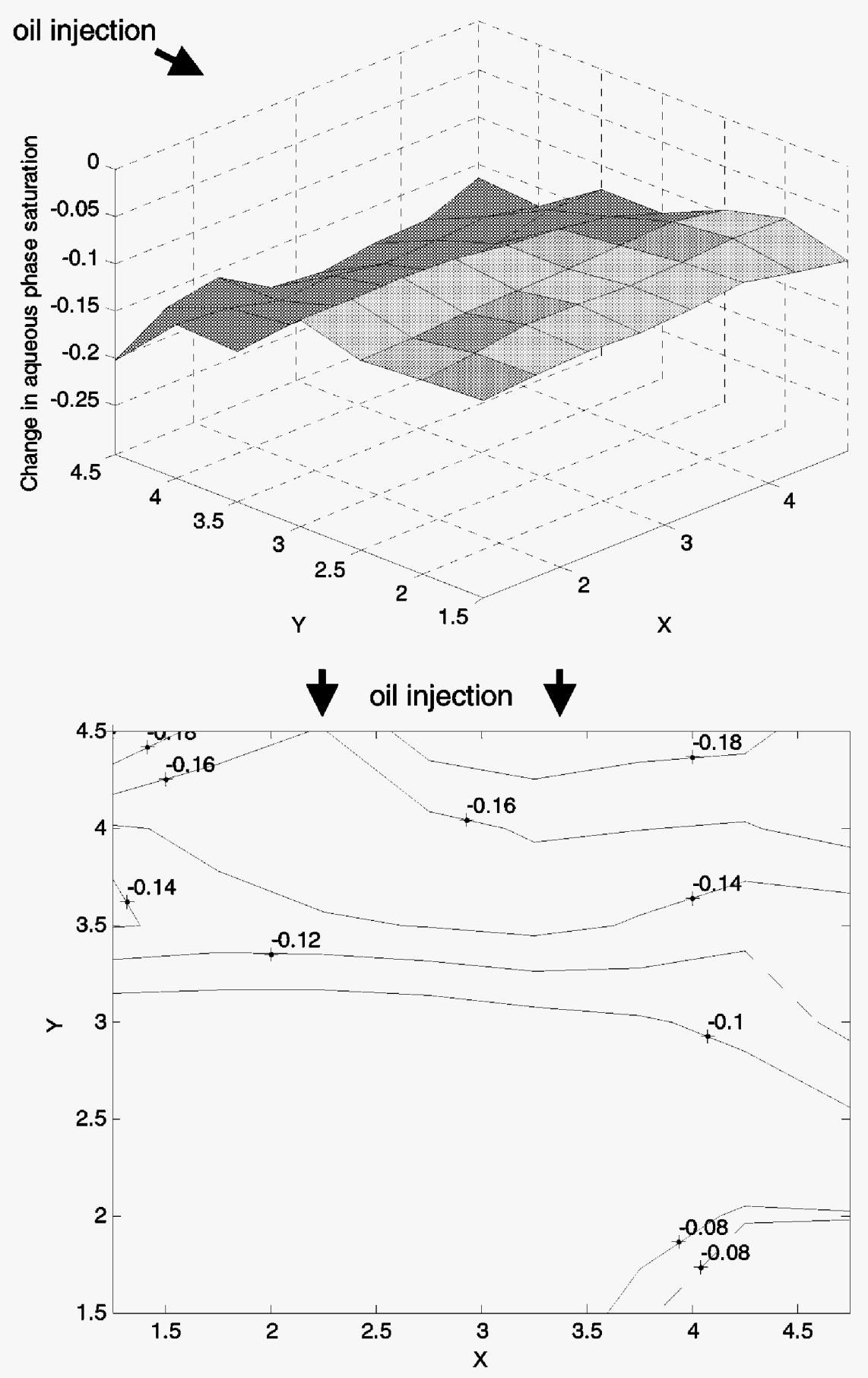

Figure 4.12 - Change in brine saturation during the first post-treatment oil flood in Slab 1. 

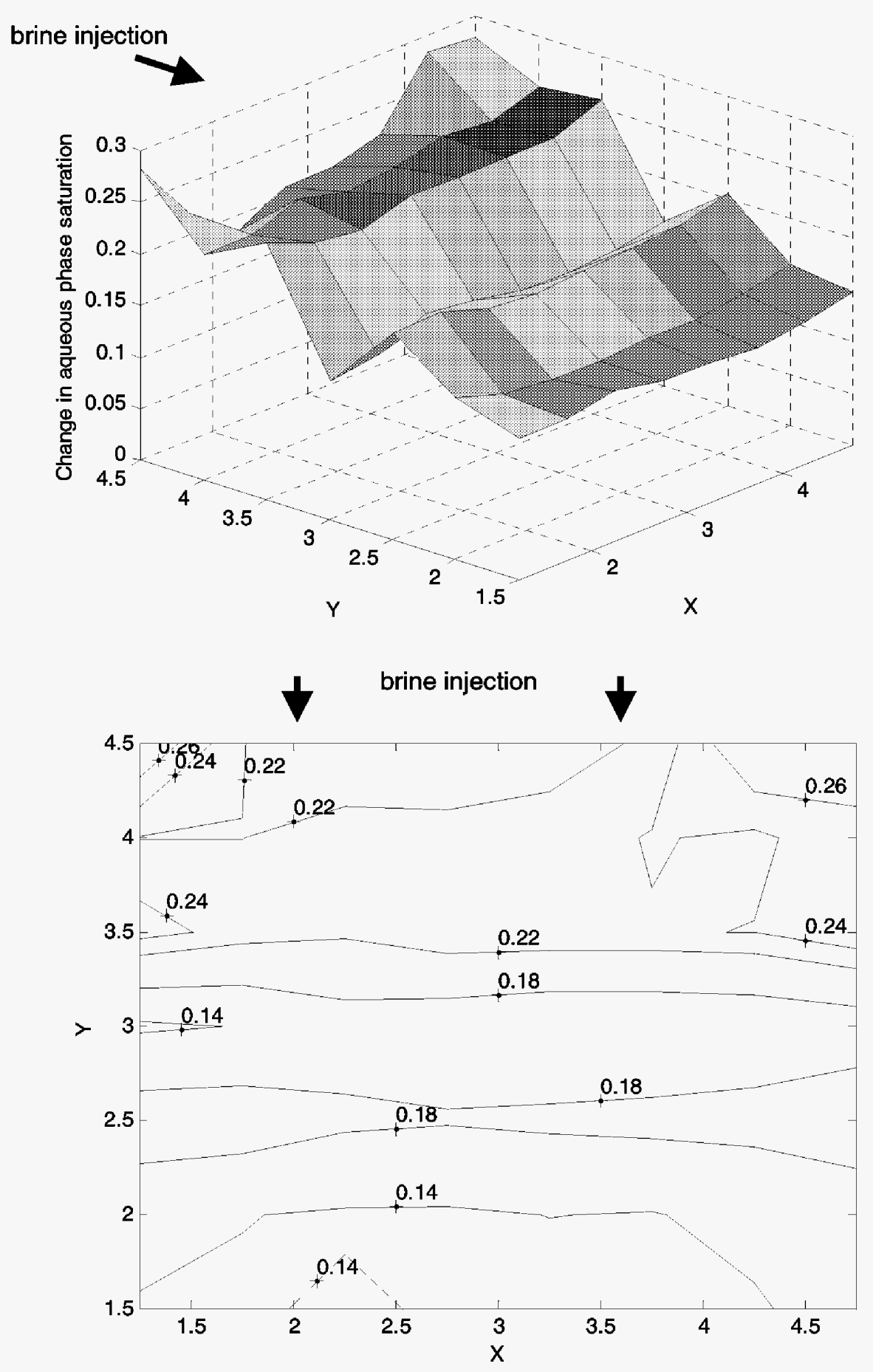

Figure 4.13 - Change in brine saturation during post-treatment brine flood in Slab 1. 

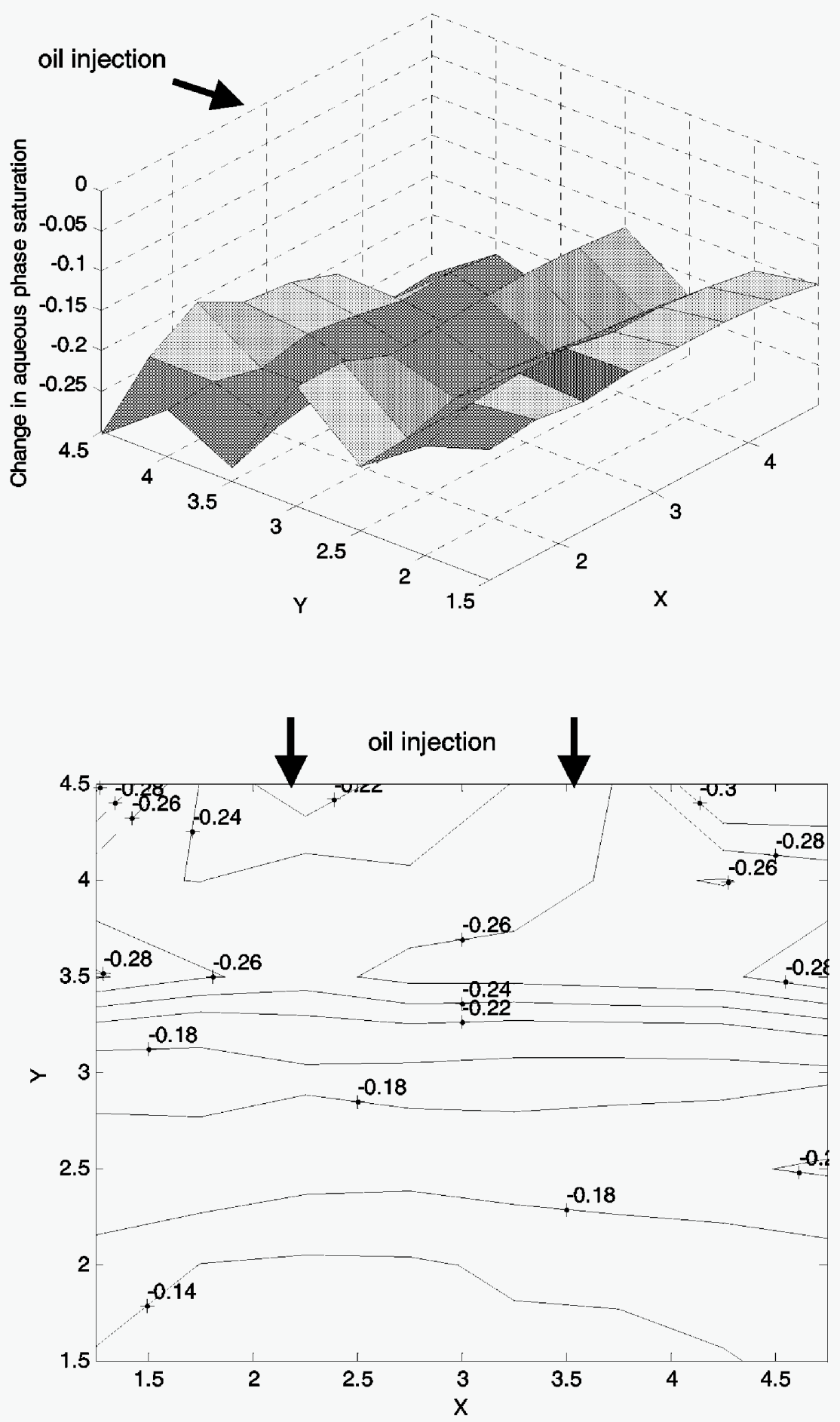

Figure 4.14 - Change in brine saturation during the second post-treatment oil flood in Slab 1. 

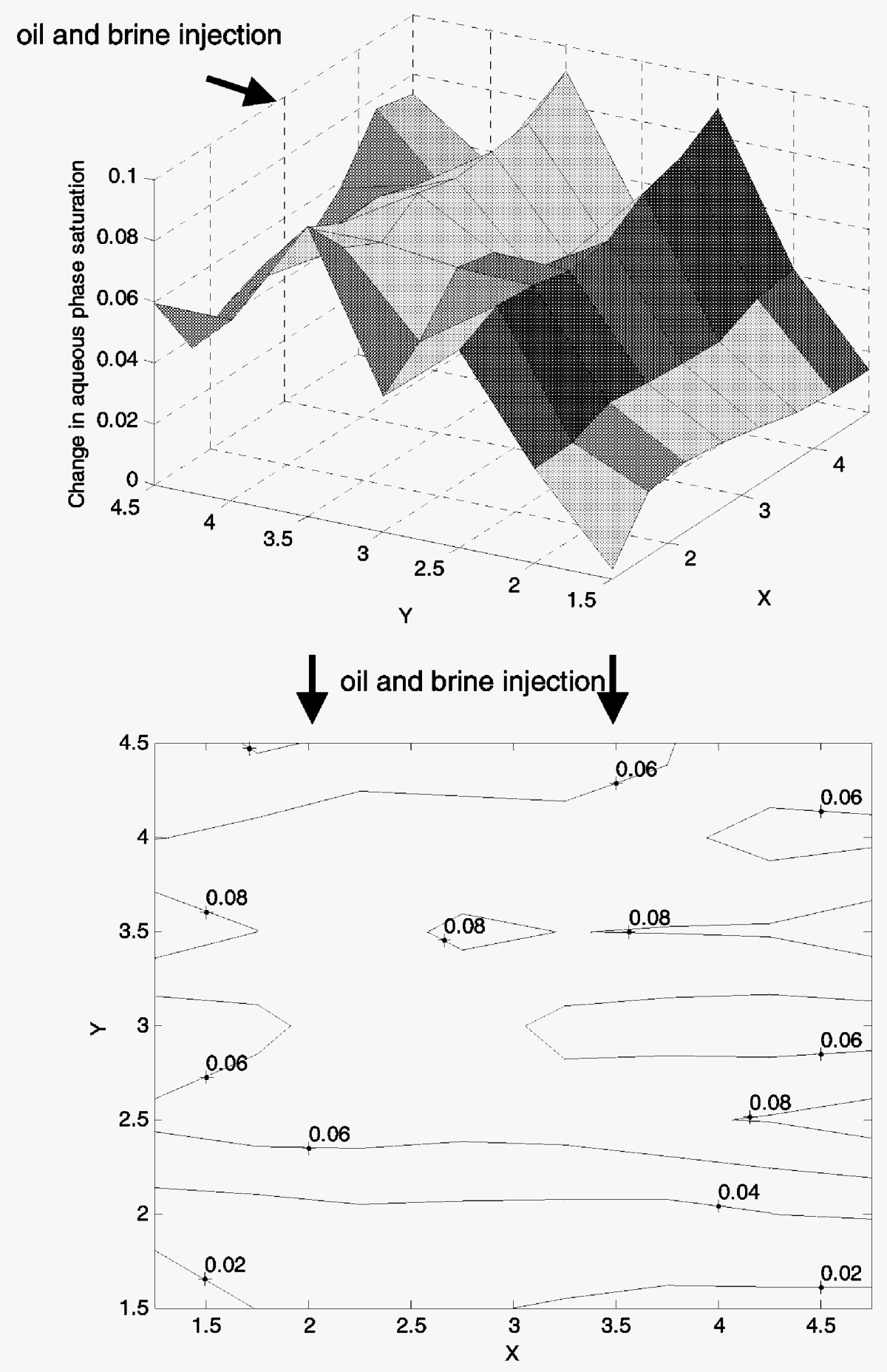

Figure 4.15 - Change in brine saturation during the first post-treatment oil flood and the posttreatment brine flood in Slab 1. 

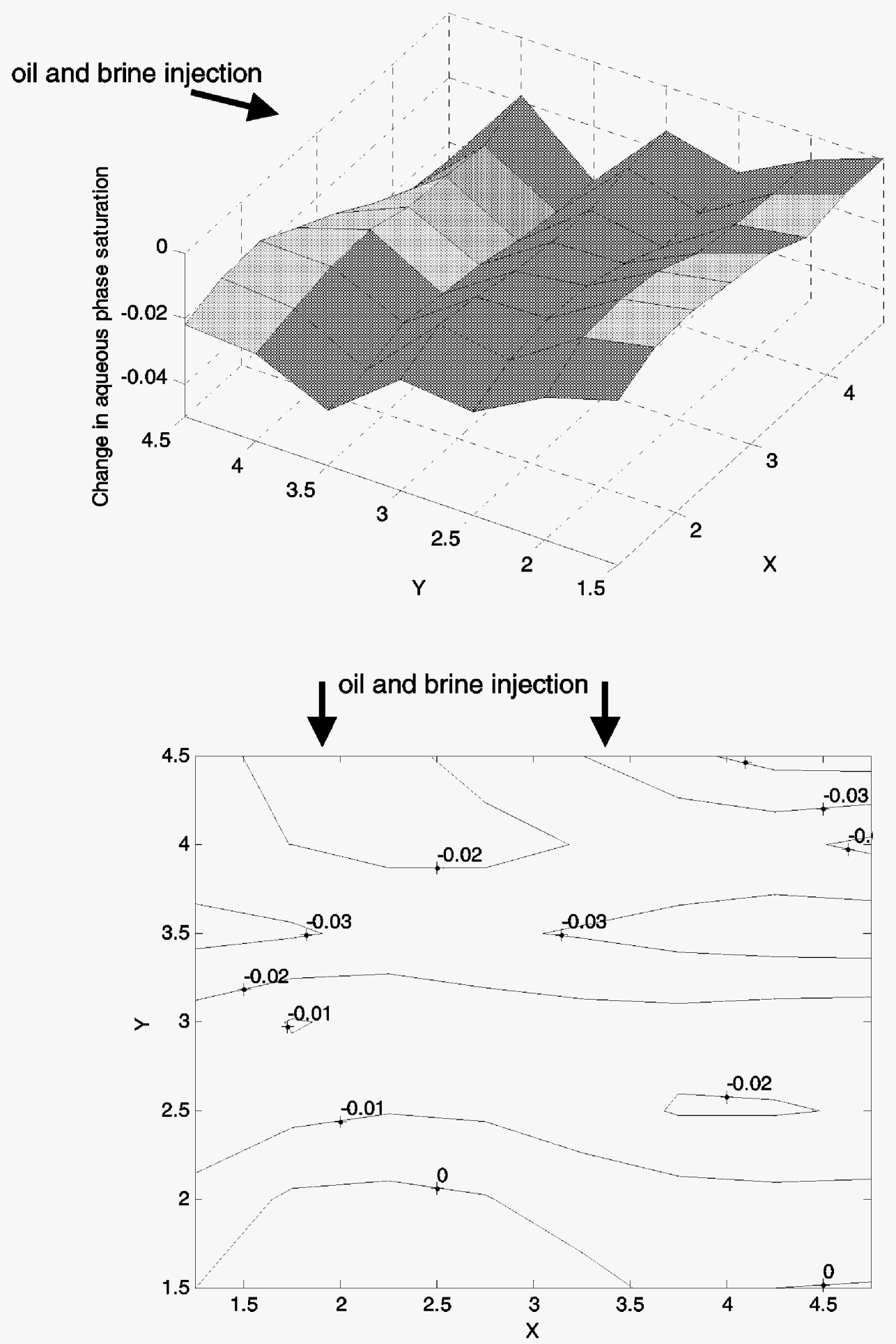

Figure 4.16 - Change in brine saturation during the post-treatment brine flood and the second post-treatment oil flood in Slab 1. 
gelant injection and after the post-treatment brine flood is shown in Figure 4.15. These values represent the minimum amount of residual oil trapped before the treatment that was displaced from the slab during the first post treatment oil flood and the subsequent brine flood. More of the pre-treatment residual oil was actually displaced from the slab because the oil saturation represented by the scan after the post-treatment brine flood includes both the pre-treatment residual oil and residual oil that is contained in the new flow channels. The relative amounts of these two residual oil volumes were estimated using an oil phase tracer and the results are described below.

The brine saturation at the end of the post-treatment oil flood 1 was subtracted from the brine saturation at the end of the post-treatment oil flood 2 and the result is shown in Figure 4.16. This figure shows the small decrease in the brine saturation, or increase in the oil saturation, that occurred during the post-treatment brine and second oil flood. Most of the saturation change occurred at the end of the slab where brine and oil were injected.

\section{Results for Slab 2.}

Experiments conducted with Slab 2 were similar to those for Slab 1 except for the following. Oil and brine floods in Slab 2 were injected into Section 3 before and after the gel treatment as shown in Figure 4.1. Buffer solution was injected into Section 1 in Slab 2 twenty hours prior to the injection of gelant. A smaller volume of gelant was injected into Slab 2. Two and one-half pore volumes of bulk-mixed gelant were injected into Section 1 of Slab 2 at a constant injection pressure of 50 psig. Twenty hours were required to inject the gelant. No oil was displaced from the Slab 2 during gelant injection. All effluent samples, collected after the first pore volume of gelant was injected, gelled at a time equal to the bulk gel time ( $21 / 2$ days). The $\mathrm{pH}$ of the gelant that flowed through the slab was initially about 6.8 and slowly increased to 7.5 at the end of injection when the flow rate had slowed. The shut-in time between gelant injection and the posttreatment oil flood was seven days, less than the nine-day shut-in time for Slab 1. Post-treatment oil and brine floods were conducted at fewer different injection pressures.

The water saturation during the pre-treatment oil flood in Slab 2 was driven to a lower value than in Slab 1. In Slab 2, the oil flood was conducted at a higher injection pressure and for a longer time period. The oil flood was conducted for several days at an injection pressure of $80 \mathrm{psig}$ in Slab 2 and was conducted for a couple of hours at an injection pressure of 10 psig in Slab 1. This difference was not considered significant since similar water saturations for the slabs were obtained after the subsequent pre-treatment brine floods. However, the value of the pre-treatment permeability to oil for Slab 1 was probably low and this affected the evaluation of disproportionate permeability reduction caused by the gel treatment. The pre-treatment oil permeabilities for Slab 2 were more representative of endpoint values.

Apparent viscosities calculated from the flow rate and pressure drops across the three sections of Slab 2 during the injection of gelant are presented in Figure 4.17. The flow resistance increased with throughput and higher flow resistance was observed closer to the inlet of the slab. This indicated that gelant material (aggregates) was being filtered from the flowing gelant and that the filtration was more pronounced near the injection end. Similar flow data during gelant injection were not collected for Slab 1. 


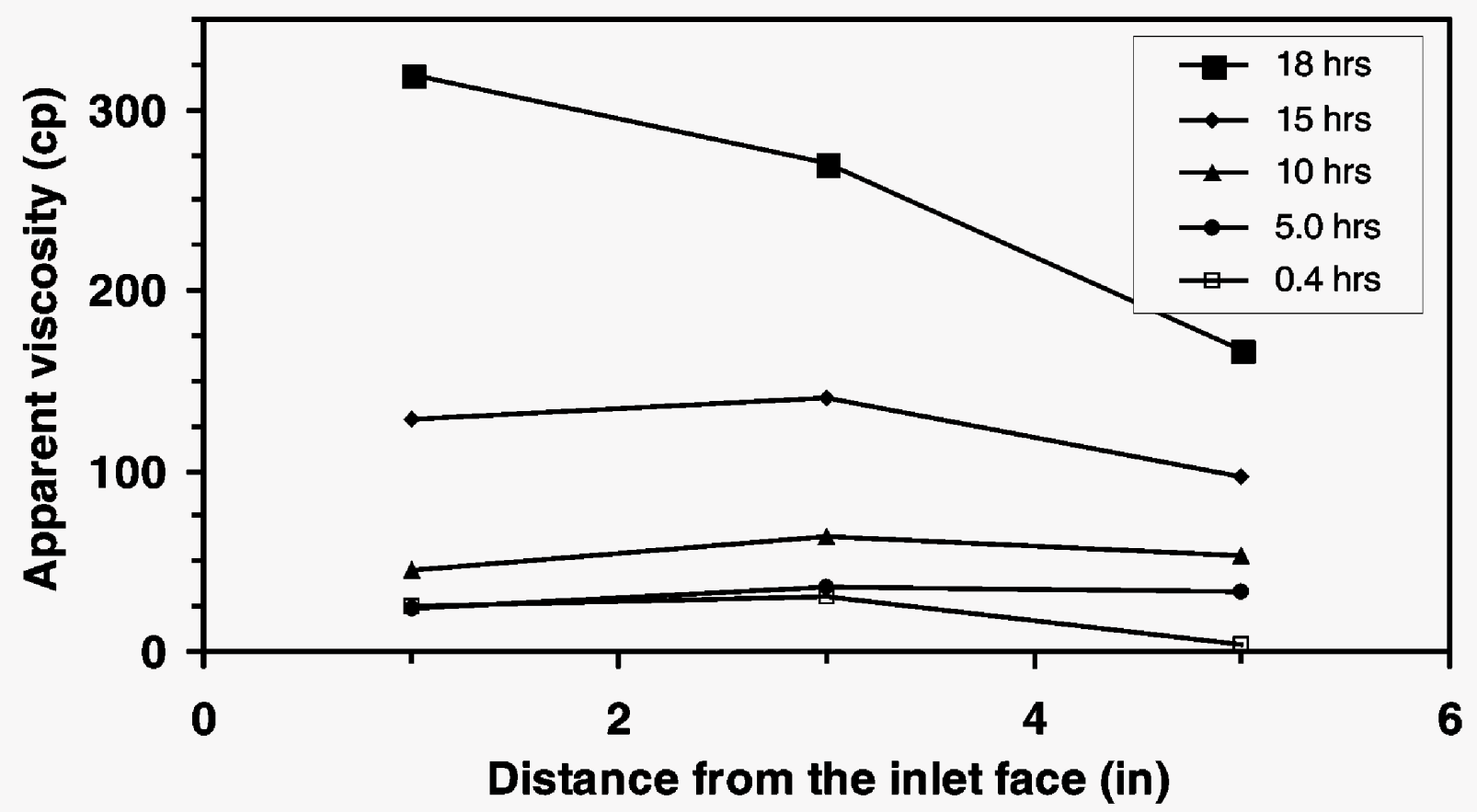

Figure 4.17 - Flow resistance in Slab 2 during injection of gelant.

RRFs for the post-treatment oil and brine floods in Slab 2 are given in Table 4.4. Post-treatment permeabilities were a function of the injection pressure and a range of RRF values is given in the table. Combined values for Sections 1 and 2 are given due to an error in measuring the individual pressure drops. The gel treatment reduced the permeability to oil by a greater factor than the permeability to brine. That is, disproportionate reduction of the permeability of water relative to that of oil was not observed. As in Slab 1, the permeability reduction was greater in the section of Slab 2 where gelant was injected (Sections 1 and 2). The same trends were observed in Slab 2 and in Slab1 but the magnitude of permeability reduction was less in Slab 2. This is attributed to less volume of gelant injected into Slab 2. The brine permeability in Section 3 was even greater following the gel treatment.

Average water saturations and permeabilities after each of the floods conducted on Slab 2 are given in Table 4.5 Water saturations and injection pressures as a function of fluid volume injected for the post-treatment oil and brine floods are shown in Figure 4.18. These results are comparable to those for Slab 1. Saturation scans by the microwave apparatus were measured in Slab 2 and the trends were the same as those described for Slab 1 above. The saturation scans, the development of flow resistance during gelant injection (Figure 4.17) and the RRFs (Table 4.4) are all consistent with the observation that the gel treatment primarily affected the permeability at the end of the slab at which gelant was injected. 
Table 4.4 - Residual resistance factors (RRFs) for sections and for the total length of Slab 2.

\begin{tabular}{|l|c|cc|c|c|}
\hline & $\begin{array}{c}\text { Oil / Brine } \\
\rightarrow\end{array}$ & Section 3 & Sections 1 and 2 & $\begin{array}{c}\text { Gelant } \\
\leftarrow\end{array}$ & Overall \\
\hline $\begin{array}{l}\text { Post-treatment } \\
\text { Oil flood 1 }\end{array}$ & $3.8-7.6$ & $13-25$ & $7.1-14$ \\
$\begin{array}{l}\text { Post-treatment } \\
\text { Brine flood }\end{array}$ & $0.7-0.8$ & $1.8-2.5$ & $1.5-1.9$ \\
$\begin{array}{l}\text { Post-treatment } \\
\text { Oil flood 2 }\end{array}$ & $3.7-4.8$ & $12-18$ & $6.5-9.5$ \\
\hline
\end{tabular}

Table 4.5 - Average water saturations and permeabilities of Slab 2.

\begin{tabular}{|c|c|c|c|c|c|c|c|}
\hline \multirow[b]{3}{*}{$\begin{array}{l}\text { Pre-treatment } \\
\text { Brine flood } 1\end{array}$} & \multicolumn{4}{|c|}{ Determined from $\mu$-wave scan } & \multicolumn{2}{|c|}{ Effluent measurements } & \multirow[b]{2}{*}{$\begin{array}{l}\text { Average } \\
\text { permeability } \\
\text { (md) }\end{array}$} \\
\hline & $\begin{array}{c}\text { Brine }(+ \text { gel) } \\
\text { saturation }\end{array}$ & $\begin{array}{c}\text { Oil } \\
\text { saturation }\end{array}$ & $\begin{array}{c}\text { Volume of } \\
\text { brine } \\
\text { displaced } \\
\text { (mL) }\end{array}$ & $\begin{array}{c}\text { Volume of } \\
\text { oil } \\
\text { displaced } \\
(\mathrm{mL})\end{array}$ & $\begin{array}{c}\text { Volume of } \\
\text { brine } \\
\text { displaced } \\
\text { (mL) }\end{array}$ & $\begin{array}{c}\text { Volume of } \\
\text { oil } \\
\text { displaced } \\
(\mathrm{mL})\end{array}$ & \\
\hline & 1.00 & 0.00 & - & - & - & - & 556 \\
\hline $\begin{array}{l}\text { Pre-treatment } \\
\text { Oil flood }\end{array}$ & 0.30 & 0.70 & 77 & - & 75 & - & 360 \\
\hline $\begin{array}{l}\text { Pre-treatment } \\
\text { Brine flood } 2\end{array}$ & 0.70 & 0.30 & - & 44 & - & 46 & 21 \\
\hline $\begin{array}{l}\text { Gelant } \\
\text { injection }\end{array}$ & 0.70 & 0.30 & - & 0 & - & 0 & - \\
\hline $\begin{array}{l}\text { Post-treatment } \\
\text { Oil flood } 1\end{array}$ & 0.56 & 0.44 & 15 & - & 16 & - & $26-51$ \\
\hline $\begin{array}{l}\text { Post-treatment } \\
\text { Brine flood }\end{array}$ & 0.80 & 0.20 & - & 25 & - & 25 & $11-14$ \\
\hline $\begin{array}{l}\text { Post-treatment } \\
\text { Oil flood } 2\end{array}$ & 0.55 & 0.45 & 26 & - & 25 & - & $38-55$ \\
\hline
\end{tabular}




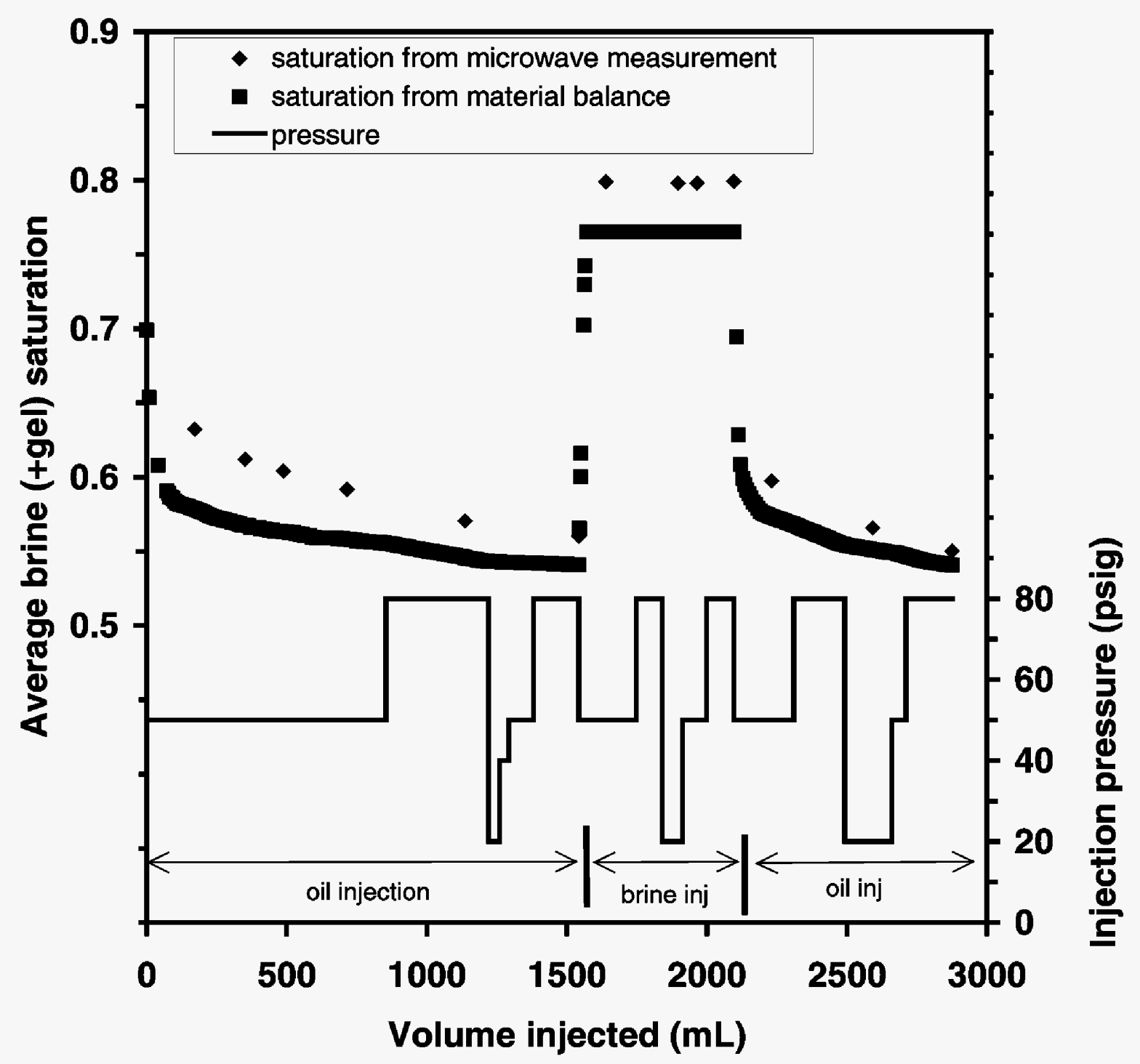

Figure 4.18 - Injection pressures and average saturations during post-treatment oil and brine floods in Slab 2.

\section{Oil-Phase Tracers.}

Oil containing stilbene tracer was injected into the slabs to determine the volume of the pore space through which the oil flowed. A step input of tracer was injected into Slab 2 at the end of the pre-treatment oil flood. The normalized concentration of tracer in the effluent is shown in Figure 4.19. The tracer curve was integrated to determine the area to the left of the tracer curve which represents the volume of oil through which oil flowed in the slab. This volume was $74 \mathrm{~mL}$ and is in close agreement with the volumes determined by the material balance (on the displaced brine) and by the microwave scan that are listed in Table 4.5 . 


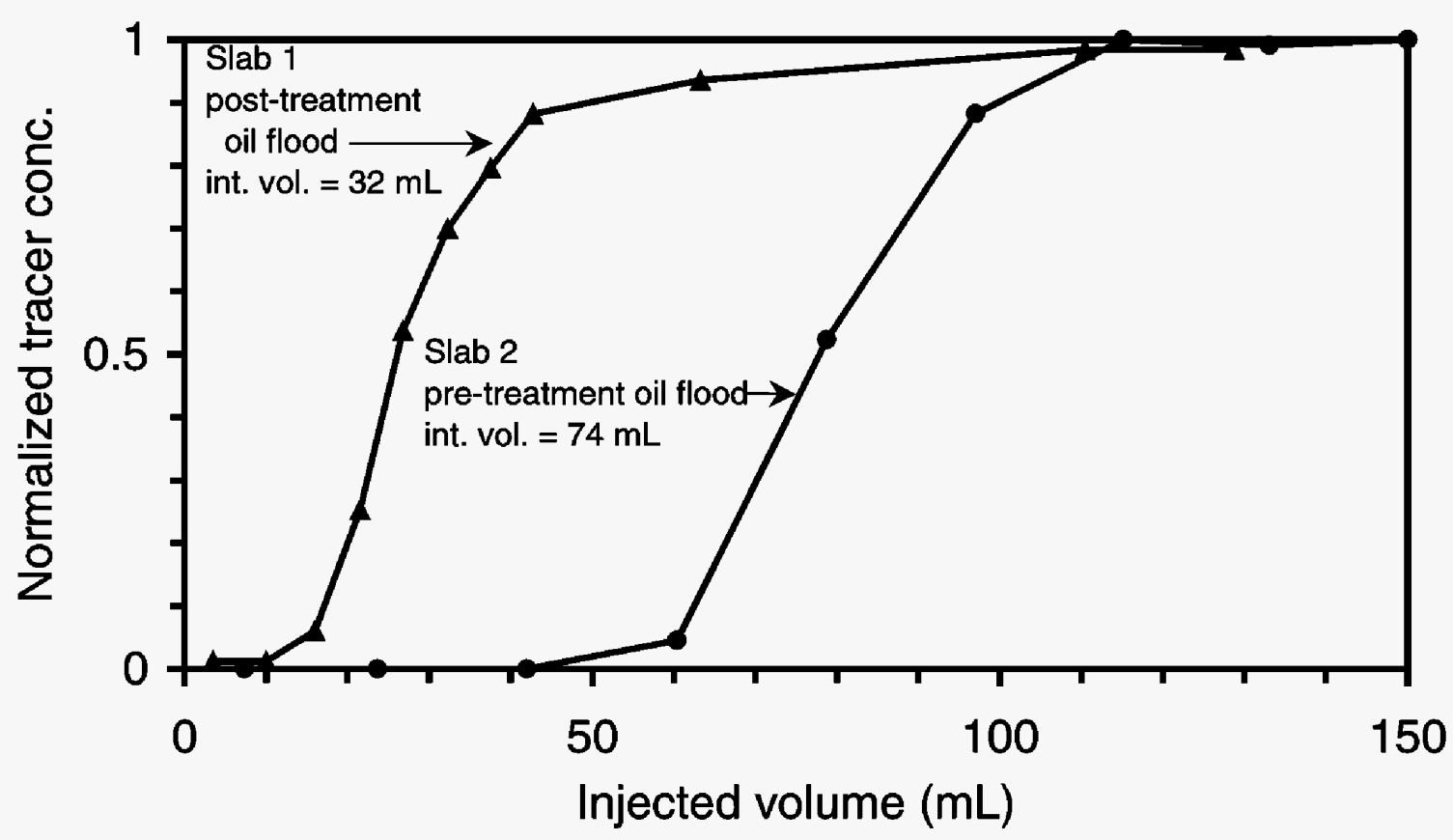

Figure 4.19 - Response of oil-phase tracers conducted at end of oil floods.

The oil-phase tracer was injected into Slab 1 at the end of the second post-treatment oil flood. The normalized concentration of tracer in the effluent is shown in Figure 4.19. The tracer concentration tailed off after the tracer bank reached the end of the slab. Integration of the curve showed that tracer-tagged oil displaced $32 \mathrm{~mL}$ of non-tagged oil from the slab. This volume of displaceable oil is greater than the amount of brine that was displaced from the Slab 1 during the second post-treatment oil flood $(23.1 \mathrm{~mL}, \mu$-wave data) as listed in Table 4.2 . The difference between these volumes $(8.9 \mathrm{~mL})$ is the amount of oil trapped during the brine flood as a residual saturation in the flow channels that were created by dehydration of the gel. Material balances indicate that the amount of encapsulated oil (the pre-treatment residual oil) in Slab 1 decreased following the post treatment brine-flood and possibly during the second post-treatment oil flood. Some of the residual oil trapped by the post-treatment waterflood is presumably located in pore space that was previously occupied by encapsulated residual oil.

\section{Summary}

Treatment of the Berea sandstone slabs with the chromium acetate-polyacrylamide gel system reduced the permeability to brine and oil by about the same factors in Slab 1 and reduced the oil permeability more than the water permeability in Slab 2. RRFs decreased along the length of the slabs as measured from the end of the slab where gelant was injected. Many pore volumes of gelant were injected and we assume that the gelant saturated the slab except for the volume occupied by the residual oil. Apparently, the gelant did not mature into a gel throughout the slab, possibly because of a high-pH environment that is characteristic of Berea rock due to carbonate 
dissolution. Chromium precipitates at high $\mathrm{pH}$ values which delays or inhibits gelation. Rather, it is thought that permeability reduction originated during gelant injection when gelant material (gel aggregates) was retained or filtered from the solution. Retention/filtration was largest in the first section and decreased down the slab as evidenced by the flow resistance measured during gelant injection (Figure 4.17) and by the RRFs (Tables 4.3 and 4.5). Retention/filtration might have been augmented since the gelant was batch mixed and then injected which allowed time for reactions to proceed prior to injection.

The gel treatment altered the flow characteristics of oil and brine and the flow characteristics are further altered during the first post-treatment oil flood. We view the first post-treatment oil flood as a process that develops flow channels through the gel-treated slab. In zones of the slab where gel occupies most of the pore space (except for the pre-treatment residual oil), the oil imparts a pressure gradient on the gel which causes the gel to dehydrate. The gel volume decreases by expelling brine and the brine is displaced from the slab by flowing through narrow channels between the gel and the rock surface and/or through the gel itself. This process is initially slow due to the low permeability of brine through the gel occupied pore space. Flow channels are developed through the entire slab length defining a new pore space. Both oil and brine can flow through the new pore space. A residual saturation of the opposite phase becomes trapped during flow of only oil or water through the channels. Relative permeabilities of oil and brine in the new pore space can be significantly different than those in the untreated slabs due to changes in morphology, wettability and elastic properties of the gel. Further dehydration of the gel can occur during flow of oil and water through the new pore space, further changing the flow characteristics.

\section{References}

1. Barreau, P., Lasseux, D., Bertin, H., and Zaitoun, A.: "Polymer adsorption effect on relative permeability and capillary pressure: investigation of a pore scale scenario", paper SPE 37303 presented at the 1997 SPE International Symposium on Oilfield Chemistry, Houston, TX (18-21 February 1997).

2. Hamed H. Al-Sharji, Carlos A. Grattoni, Dawe, R., and Zimmerman, R.W.: "Pore-Scale study of the flow of oil and water through polymer gels", paper SPE 56738 presented at the 1999 SPE Annual Technical Conference and Exhibition, Houston, TX (3-6 October 1999).

3. Liang, J., and Seright, R.S.: "Further investigations of why gels reduce $\mathrm{k}_{\mathrm{w}}$ more than $\mathrm{k}_{\mathrm{o}}$ " paper SPE 37249 presented at the 1997 SPE International Symposium on Oilfield Chemistry, Houston, TX (18-21 February 1997).

4. Liang, J., and Seright, R.S.: "Wall-effect/gel-droplet model of disproportionate permeability reduction", paper SPE 59344 presented at the 2000 SPE/DOE Improved Oil Recovery Symposium, Tulsa OK (3-5 April 2000).

5. Liang, J., Sun, H., and Seright, R.S.: "Why do gels reduce water permeability more than oil permeability", SPE Reservoir Engineering, (1995), 282-286.

6. Nilsson, S., and Jonsbraten, H.C.: "Mechanistic study of disproportionate permeability reduction", paper SPE 39635 presented at the 1998 SPE/DOE Improved Oil Recovery Symposium, Tulsa OK (19-22 April 1998). 
7. Seright, R.S., et al.: "Improved methods for water shut-off", Annual Report for the Period October 1996 to September 1997, Contract No. AC22-94PC91008, Report No. DOE/PC/91008-4, U.S.DOE, Washington, DC.

8. Seright, R.S., et al.: "Improved methods for water shut-off", Annual Report for the Period October 1997 to September 1998, Contract No. AC 22-94PC91008, Report No. DOE/PC/91008-4, U.S.DOE, Washington, DC.

9. Seright, R.S., et al.: "Using chemicals to optimize conformance control in fractured reservoirs", Annual Report for the Period October 1998 to September 1999, Contract No. AC26-98BC15110, Report No. DOE/BC/15110-2, U.S. DOE, Washington, DC.

10. Stavland, A., Steinar, E., Hettervik, K.O., Jakobsen, S.R., Schmidt, T., and Schilling, B.: "Disproportionate permeability reduction is not a panacea", SPE Reservoir Engineering, (1998), 359-366.

11. Thompson, K.E., and Fogler, H.S.: "Pore level mechanisms for altering multiphase permeability with gel", SPE Journal (1997) 2, 350-362.

12. Willhite, G.P., Zhu, H., Natarajan, D., McCool, C.S., Green, D.W.: "Mechanisms causing disproportionate permeability in porous media treated with chromium acetate / HPAAM gels", paper SPE 59345 presented at the 2000 SPE/DOE Improved Oil Recovery Symposium, Tulsa, OK (3-5 April 2000).

13. Yan, Z., McCool, C.S., Green, D.W., and Willhite, G.P.: " Modification of oil and water permeabilities in Berea sandstone by a gel treatment", paper SPE 50753 presented at the 1999 SPE International Symposium on Oilfield Chemistry, Houston, TX (16-19 February 1999).

14. Zaitoun, A., and Bertin, H.:“ Two-phase flow property modifications by polymer adsorption", paper SPE 39631 presented at the 1998 SPE/DOE Improved Oil Recovery Symposium, Tulsa, OK (19-22 April, 1998).

15. Zaitoun, A., and Kohler, N.: "Thin polyacrylamide gels for water control in high permeability production wells" paper SPE 22785 presented at the 1991 SPE Annual Technical Conference and Exhibition, Dallas, TX (6-9 Oct., 1991).

16. Zaitoun, A., and Kohler, N.: "Two phase flow through porous media: effect of an adsorbed polymer layer" paper SPE 18085 presented at the $63^{\text {rd }}$ Annual Technical Conference and Exhibition of the Society of Petroleum Engineers, Houston, TX (2-5 Oct., 1988).

\section{Appendix}

Brine saturations in Slab 1 that were determined by the microwave scanning apparatus at the end of each flow experiment are presented in Figures 4.A1 through 4.A6. A listing of the flow experiments is given in Table 4.2. The measured brine saturation includes the fractional volume occupied by gel since gel is composed mostly of brine. Brine/gel saturations are presented in a 3D surface plot and a 2-D contour plot. The direction fluids were injected is indicated on the figures. 

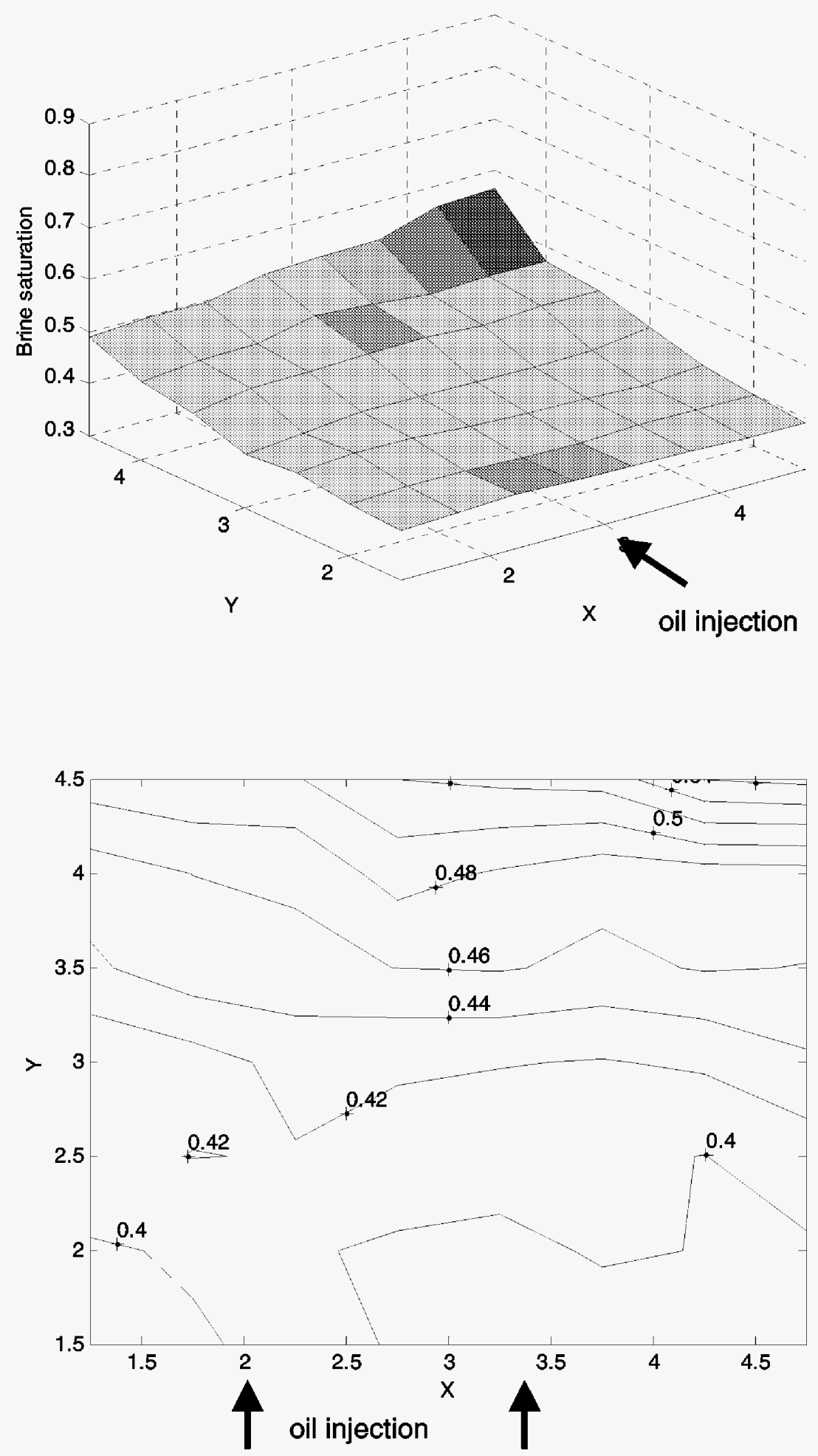

Figure 4.A1 - Brine saturation after pre-treatment oil flood in Slab1. 

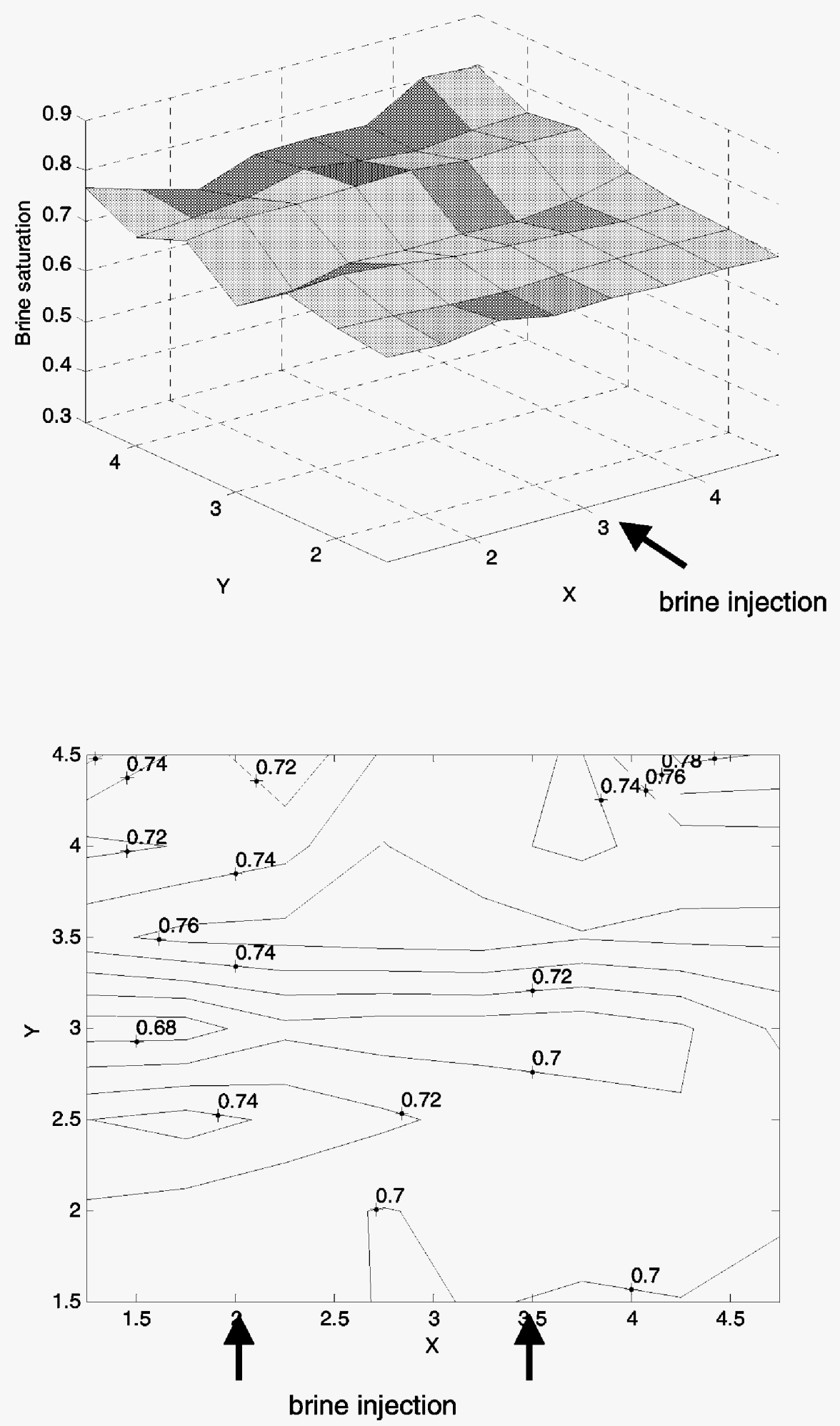

Figure 4.A2 - Brine saturation after pre-treatment brine flood in Slab1. 

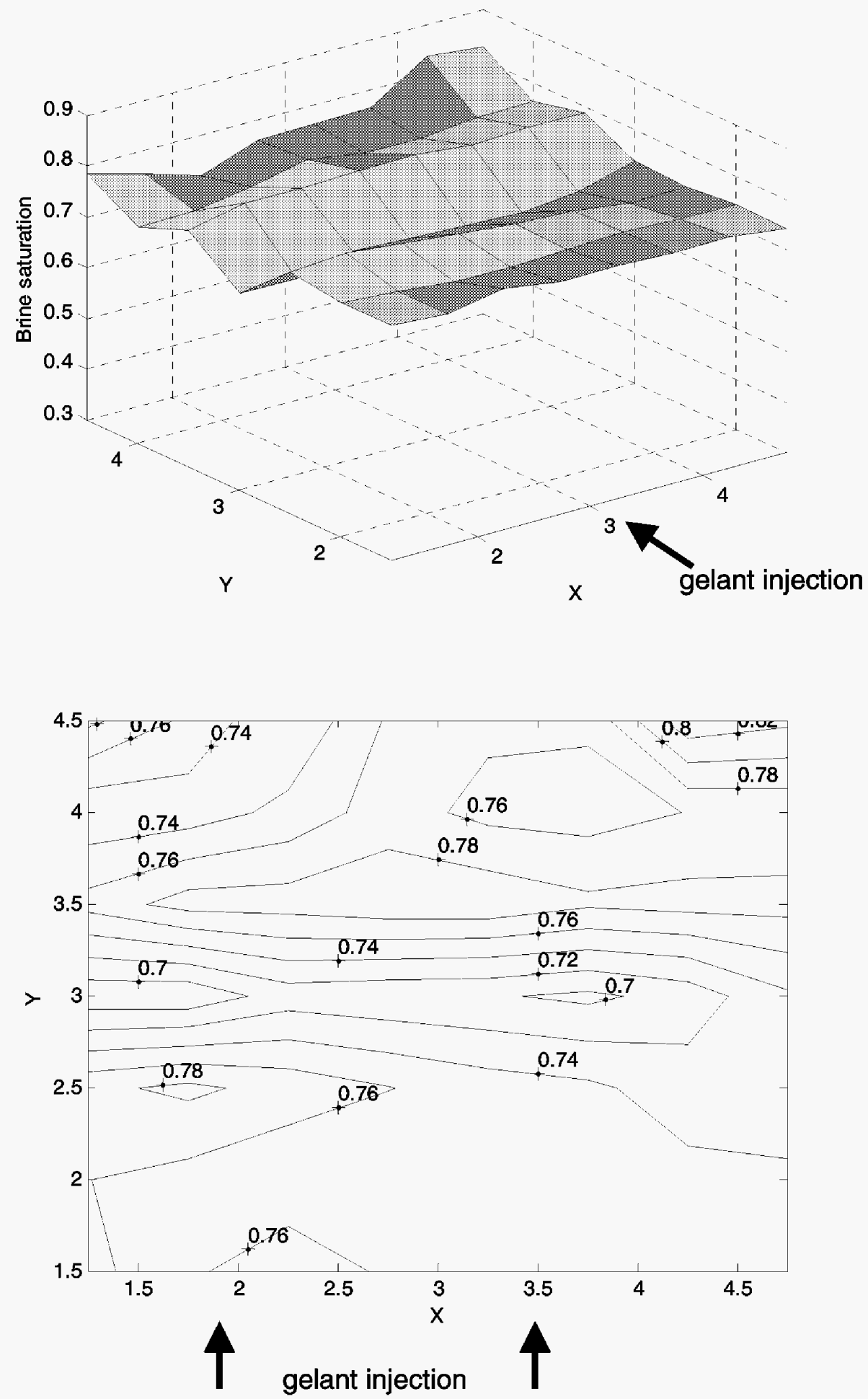

Figure 4.A3 - Brine saturation after gelant injection in Slab1. 

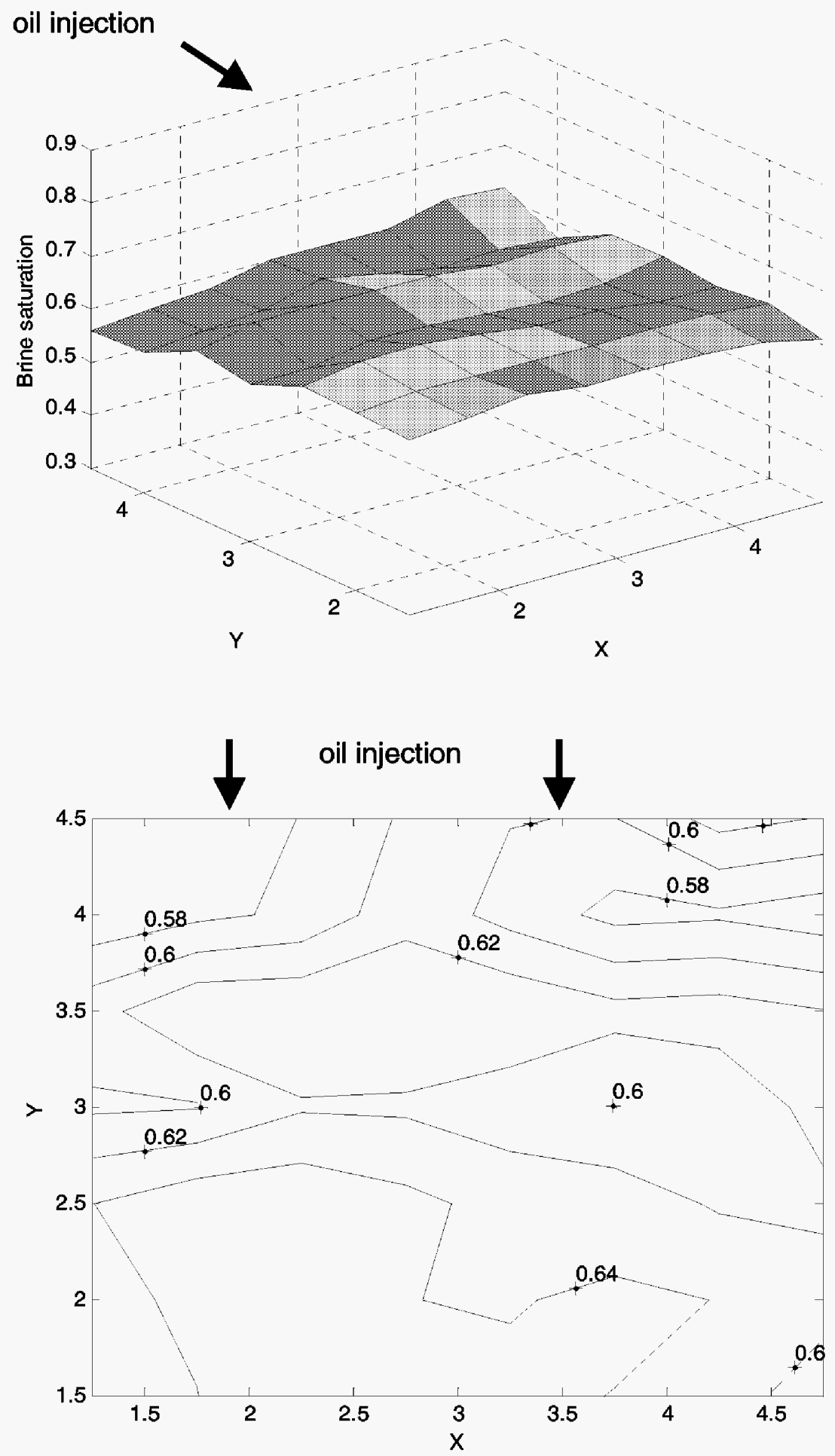

Figure 4.A4 - Brine saturation after first post-treatment oil flood in Slab1. 

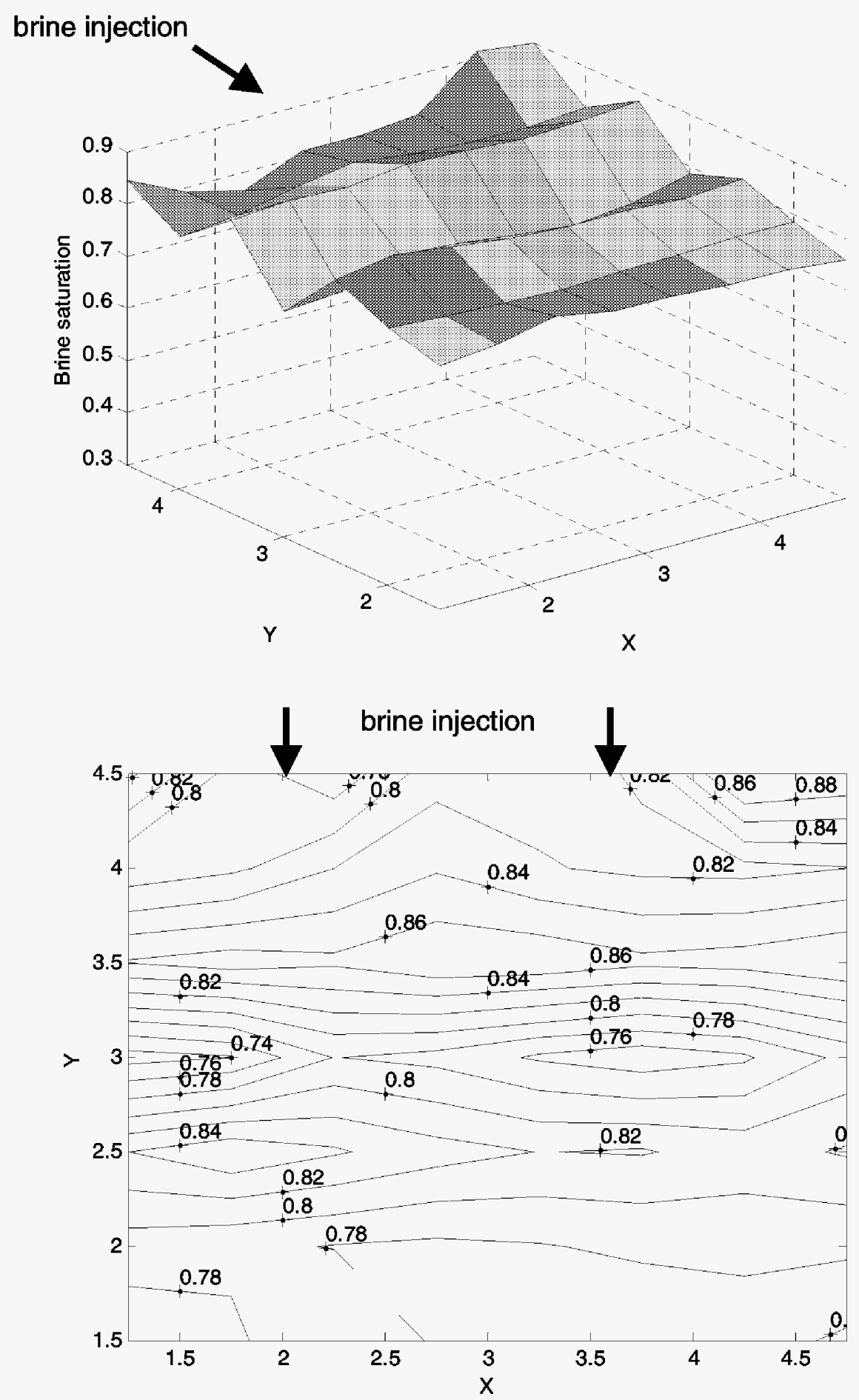

Figure 4.A5 - Brine saturation after post-treatment brine flood in Slab1. 

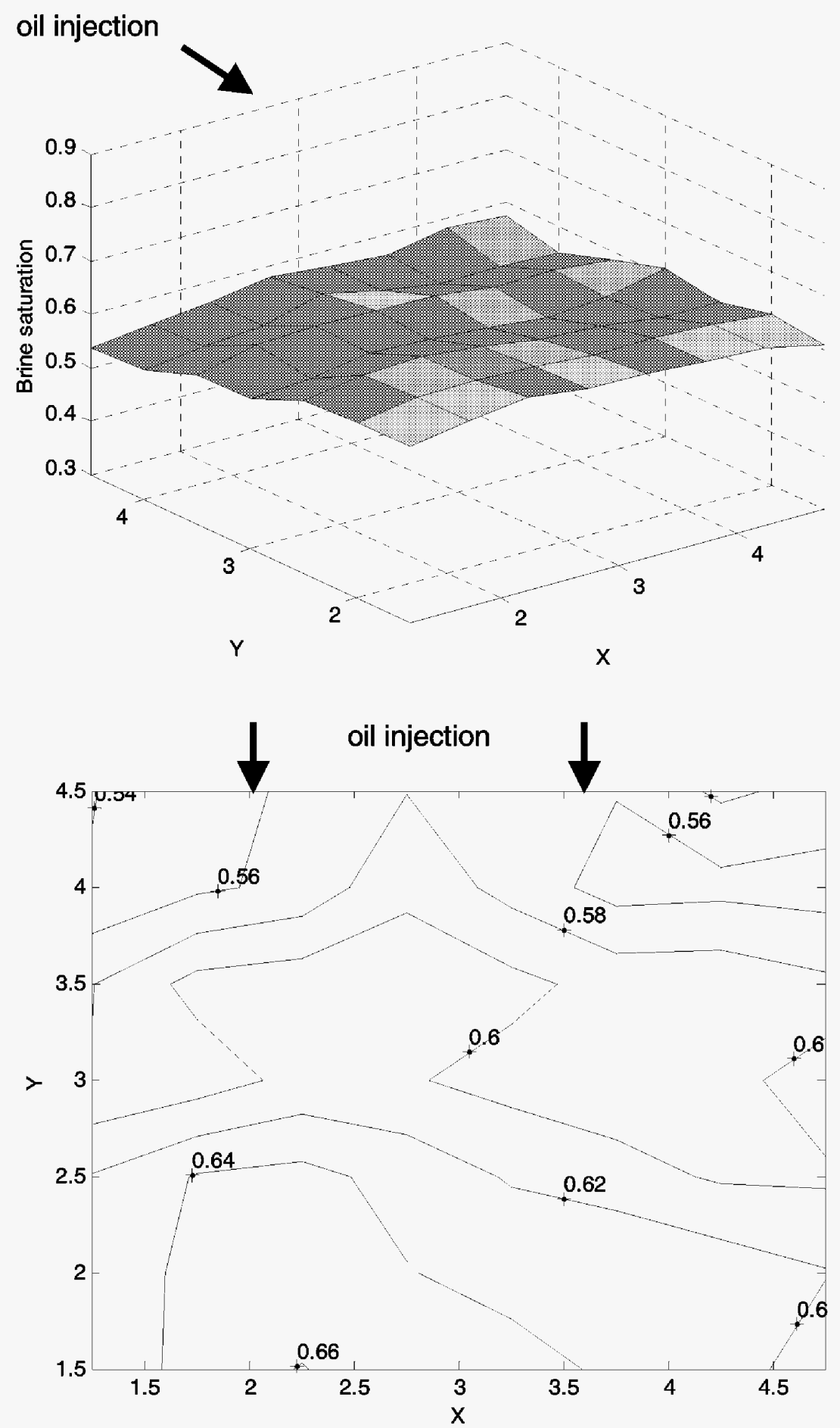

Figure 4.A6 - Brine saturation after second post-treatment oil flood in Slab1. 


\section{Chapter 5}

\section{Technology Transfer}

\section{Publications during Year 2}

McCool, C.S., Green, D.W., and Willhite, G.P., "Fluid/Rock Interaction Between XanthanChromium(III) Gel Systems and Dolomite Core Material," 15, SPE Prod. \& Facilitites (August 2000) 159.

Zou, B., McCool, C.S., Green, D.W., and Willhite, G.P., "Precipitation of Chromium Acetate Solutions", SPE Journal, 5 (September 2000) 324.

Zhuang, Y., Pandey, S.N., McCool, C.S. and Willhite, G.P., "Permeability Modification with Sulfomethylated Resorcinol-Formaldehyde Gel System," 3, SPE Reservoir Eval. \& Eng. (October 2000) 386.

McCool, C.S., Shaw, A.K., Singh, A., Bhattacharya, S., Green, D.W., and Willhite, G.P "Permeability Reduction by Treatment with KUSP1 Biopolylmer," SPE Journal, 5 (December 2000) 371.

Ganguly S., Willhite, G.P., Green, D.W. and McCool, C.S., "The Effect of Fluid Leakoff on Gel Placement and Gel Stability in Fractures," paper SPE 64987, presented at the 2001 SPE International Symposium on Oilfield Chemistry held in Houston, TX (13-16 February 2001).

McCool, C.S., Green, D.W., and Willhite, G.P., "Fluid/Rock Interaction Between XanthanChromium(III) Gel Systems and Dolomite Core Material," 15, SPE Prod. \& Facilitites (August 2000) 159.

\section{Presentations during Year 2}

"A Different Perspective of Disproportionate Permeability Reduction," C.S. McCool, Petroleum Recovery Research Center, New Mexico Tech, Socorro, New Mexico, 2 November 2000.

"Development and Application of Polymer Gels for Water Control," G.P.Willhite, presented at a workshop titled Gelled Polymers and Their Applications, Petroleum Technology Transfer Council, Wichita, KS, 6 December 2000.

"Basics of Polymers and Gelled Polymers," C.S. McCool, presented at a workshop titled Gelled Polymers and Their Applications, Petroleum Technology Transfer Council, Wichita, KS, 6 December 2000. 
“The Effect of Fluid Leakoff on Gel Placement and Gel Stability in Fractures," S. Ganguly (post-doctoral person) presented paper SPE 64987 at the 2001 SPE International Symposium on Oilfield Chemistry held in Houston, TX (13-16 February 2001). 
